\title{
Reward contingency gates selective cholinergic suppression of amygdala neurons
}

Eyal Y. Kimchi ${ }^{1,2,3 *}$, Anthony Burgos-Robles ${ }^{1,4}$, Gillian A. Matthews ${ }^{1,5}$, Tatenda Chakoma ${ }^{1,3}$, Makenzie Patarino ${ }^{1,5}$, Javier Weddington ${ }^{1}$, Cody A. Siciliano ${ }^{1,6}$, Wannan Yang ${ }^{1}$, Shaun Foutch ${ }^{1}$, Renee Simons ${ }^{1}$, Ming-fai Fong ${ }^{1}$, Miao Jing ${ }^{7}$, Yulong Li ${ }^{8}$, Daniel B. Polley ${ }^{3,9}$, Kay M. Tye ${ }^{1,5,10,11 *}$

${ }^{1}$ The Picower Institute for Learning and Memory, Department of Brain and Cognitive Sciences, Massachusetts Institute of Technology, Cambridge, MA 02139, USA

${ }^{2}$ Department of Neurology, Massachusetts General Hospital, Boston, MA 02114, USA

${ }^{3}$ Eaton-Peabody Laboratories, Massachusetts Eye and Ear Infirmary, Boston, MA 02114, USA

${ }^{4}$ UTSA Neurosciences Institute, Department of Biology, The University of Texas at San Antonio, San Antonio, TX 78249, USA

${ }^{5}$ The Salk Institute for Biological Studies, La Jolla, CA 92037, USA

${ }^{6}$ Vanderbilt Center for Addiction Research, Department of Pharmacology, Vanderbilt University, Nashville, TN 37232 USA

${ }^{7}$ Chinese Institute for Brain Research, Beijing 102206, China.

${ }^{8}$ State Key Laboratory of Membrane Biology, Peking University School of Life Sciences; PKUIDG/McGovern Institute for Brain Research; Peking-Tsinghua Center for Life Sciences, Beijing 100871, China

${ }^{9}$ Department of Otolaryngology - Head and Neck Surgery, Harvard Medical School, Boston, MA 02114, USA

${ }^{10}$ Howard Hughes Medical Institute Investigator

${ }^{11}$ Lead Contact

*Correspondence: ekimchi@partners.org, @ekimchi (E.Y.K.) and tye@salk.edu, @kaymtye (K.M.T.) 


\section{Summary}

Basal forebrain cholinergic neurons are thought to modulate how organisms process and respond to environmental stimuli through impacts on arousal, attention, memory, and motivated behavior. We questioned whether basal forebrain cholinergic neurons are directly involved in conditioned behavior, independent of ancillary roles in stimulus processing. We found that cholinergic neurons are active during behavioral responding for a reward - even in the absence of reward or discrete stimuli. Photostimulation of cholinergic neurons in the basal forebrain or their terminals in the basolateral amygdala (BLA) selectively drove conditioned responding (licking), but not unconditioned licking nor innate motor outputs. In vivo electrophysiological recordings revealed reward-contingency-dependent-gating of cholinergic suppression of BLA neural activity during cholinergic photostimulation, but not dorsomedial prefrontal cortex (dmPFC). Finally, cholinergic terminals suppressed BLA projection neuron activity via monosynaptic muscarinic receptor signaling and facilitation of firing in GABAergic interneurons. Taken together, we show that cholinergic effects are modulated by reward contingency in a target-specific manner to promote conditioned responding. Given that the effects cholinergic photostimulation were modulated by rewards, our results constrain clinical goals of augmenting cholinergic function to improve neuropsychiatric symptoms.

\section{Keywords}

Acetylcholine, Basal Forebrain, Basolateral amygdala, Prefrontal cortex, Limbic networks, Motivated behavior, Conditioning, Reward 


\section{Introduction}

Multiple mental health disorders involve cholinergic deficiency, including delirium, schizophrenia, and attention deficit hyperactivity disorder (Higley and Picciotto, 2014; Hshieh et al., 2008; Potter et al., 2014). Each of these disorders is associated with severe cognitive and functional impairments (American Psychiatric Association, 2013), symptoms that impact not only patients (Morandi et al., 2015a), but also their families and caregivers (Morandi et al., 2015b; O'Malley et al., 2008).

Acetylcholine (ACh) is a powerful neuromodulator thought to influence how the brain processes and learns about external stimuli (Ballinger et al., 2016; Higley and Picciotto, 2014; Likhtik and Johansen, 2019; Newman et al., 2012). The basal forebrain is a prominent source of cholinergic innervation of the entire cortical mantle, as well as related telencephalic structures such as the amygdala (Gielow and Zaborszky, 2017; Li et al., 2018). Most work on basal forebrain cholinergic circuits to date has focused on how ACh modifies the processing of other stimuli, either by increasing attention to conditioned stimuli (Bakin and Weinberger, 1996; Baxter and Chiba, 1999; Gritton et al., 2016; Pinto et al., 2013), or by enhancing associations between conditioned stimuli and unconditioned stimuli or reinforcers in learning and memory (Ballinger et al., 2016; Guo et al., 2019; Jiang et al., 2016; Letzkus et al., 2011). Basal forebrain cholinergic circuits may also have slower influences on learning through their effects on arousal and sleep (Irmak and de Lecea, 2014; Mu and Huang, 2019).

There is continued interest in understanding how ACh influences other motivated and affective behaviors (Aitta-Aho et al., 2018; Mineur et al., 2016), as well as how it modulates neural activity in limbic structures such as the amygdala, especially ex vivo (McDonald and Mascagni, 2010, 2011; Unal et al., 2015). Previous work has suggested that neurons within the basolateral amygdala (BLA) can respond in different ways to cholinergic input, perhaps to amplify signal to noise ratios (Unal et al., 2015). Ex vivo optogenetic activation of the cholinergic projection to the BLA suppresses neural activity at low firing rates selectively (Unal et al., 2015). In contrast, in vivo cholinergic activation may increase spontaneous BLA neural firing and facilitate LTP (Jiang et al., 2016).

It therefore remains unclear what effects ACh may have on downstream neural circuit targets in vivo, as well as on motivated behavior in the absence of other discrete external cues. Here, we sought a mechanistic explanation for how cholinergic signaling can alter neural dynamics in a context-dependent manner. 


\section{Results}

\section{Establishing conditioned behavior in the absence of discrete cues}

To study whether basal forebrain cholinergic neurons can drive conditioned responding in more general contexts, for example even in the absence of discrete cues, we developed a novel head-fixed behavioral paradigm. Our goal was to promote a baseline level of behavioral engagement, as measured by licking, onto which photostimulation of basal forebrain cholinergic neurons could later be performed at precise times, even without discrete cues. The underlying task structure was an operant, variable-interval reinforcement schedule with limited hold (Ferster and Skinner, 1957). In this schedule, unsignaled reward opportunities become available after a variable interval, but only for a limited time. A subject could only trigger reward delivery if they responded during this limited window of opportunity after each variable interval.

We refer to our behavioral paradigm as the Window of Opportunity Task (WoOT) (Figure 1C). During WOOT, mice were head-fixed in front of a spout. WoOT sessions were divided into trials of 3-second windows of opportunity, with intervening variable intertrial intervals (ITIs). Rewards were only delivered if mice licked the spout during an unsignaled Reward Window. Because rewards were only delivered after the first lick in a Reward window, and because windows occurred after variable ITIs and were not discretely cued, mice did not know when they initiated a lick whether it would be rewarded. We also included a set of Unrewarded Windows, on which, even if the mouse licked, reward would not be delivered, similar to the intervening ITIs (Figure 1D). These Unrewarded windows practically functioned as an extended ITI, but were pragmatically necessary in order to analyze behavior in the absence of reward opportunities, in a way that matched the temporal structure of the Reward windows.

Prior to training, mice had undergone surgery to prepare them for head-fixation and subsequent photostimulation of basal forebrain cholinergic neurons, using Cre-dependent targeting of either optogenetic Channelrhodopsin-2 (ChR2) or a control fluorophore (enhanced yellow fluorescent protein, eYFP) (Figure 1A-B). Fibers were implanted to target the sublenticular substantia innominata/extended amygdala, the posterior portion of the basal forebrain whose cholinergic neurons project to the BLA and entire cortical mantle (Rye et al., 1984; Zaborszky et al., 2012). Nearly $90 \%$ of neurons expressing ChR2 were cholinergic, as confirmed by immunostaining for choline acetyltransferase (ChAT), an obligate enzyme in the synthesis of ACh (Prado et al., 2002) (Figure S 1A-B). During WoOT training, which did not involve photostimulation, ChR2 and eYFP groups had similar rates of licking over entire sessions (Figure S 1D), and collected similar numbers of rewards (Figure S 1E). ChR2 and eYFP mice were also both similarly likely to lick on Reward windows as on Unrewarded windows, confirming that mice could not predict reward delivery prior to licking (Figure S 1F).

\section{Transient photostimulation of basal forebrain cholinergic neurons increases conditioned responding when paired with reinforcement}

Using this novel task (WoOT), we then investigated whether transient photostimulation of basal forebrain cholinergic neurons affected conditioned responding under two different conditions (Figure 1E-G). We first tested whether photostimulation of basal forebrain cholinergic neurons inherently affected licking, by delivering $2 \mathrm{sec}$ of photostimulation exclusively during Unrewarded windows, i.e. when licking would not be reinforced (Photostim-Unreinforced session, Figure 1F). In these Photostim-Unreinforced sessions, licking did not increase during 
photostimulated windows compared to windows with no photostimulation, in either ChR2 or eYFP mice (Figure $1 \mathrm{H}$ ).

In separate sessions, we tested whether transient photostimulation of basal forebrain cholinergic neurons affected licking when photostimulation was delivered exclusively during a subset of Reward windows, i.e. when licking would be reinforced (Figure 1G, PhotostimReinforced session, right panel). In these Photostim-Reinforced sessions, photostimulation increased licking in mice expressing ChR2 (Figure 1l, right panel). Licking during windows with no photostimulation, however, remained similar between ChR2 and eYFP mice. Hence, transient photostimulation of basal forebrain cholinergic neurons became capable of driving conditioned responding in a temporally precise way when paired with the opportunity to collect rewards.

While we initially used photostimulation parameters similar to prior work (Herman et al., 2016; Jiang et al., 2016), we also examined whether even briefer photostimulation of cholinergic basal forebrain neurons was sufficient to drive conditioned responding. In a separate session, we randomly delivered photostimulation on reward windows using either $0,1,2$, or 10 pulses at 20 $\mathrm{Hz}$, corresponding to 5-500 ms of photostimulation (Figure 1J-K). Even a single $5 \mathrm{~ms}$ laser pulse was sufficient both to increase the likelihood of licking (Figure $1 \mathrm{~J}$ ) and to decrease the latency of the first lick following photostimulation onset (Figure 1K). In summary, brief photostimulation of cholinergic basal forebrain neurons, even in the absence of other discrete stimuli, can drive conditioned responding, but only when paired with potential reinforcement.

\section{Photostimulation of basal forebrain cholinergic neurons does not increase unconditioned movement and is not inherently reinforcing}

Given the striking finding that photostimulation of basal forebrain cholinergic neurons drove conditioned behavior when paired with potential reinforcement, we performed a series of experiments to determine whether the effects of photostimulation were specific to conditioned responding. We first examined whether photostimulation of cholinergic neurons increased other types of movement, for example locomotion in an unreinforced context. Basal forebrain cholinergic photostimulation did not increase locomotion in an open field test (OFT, Figure $S$ $2 A B$ ), as measured by mouse velocity (Figure S 2C). Additionally, photostimulation did not modify innate location preference, as measured by the amount of time spent in the center of the open field, which was avoided similarly by ChR2 and eYFP mice (Figure S 2D).

We next assessed whether photostimulation of cholinergic basal forebrain neurons inherently reinforced other types of locomotor behavior (Figure S 2E). Mice were freely allowed to explore a chamber in which one half was paired with photostimulation, in a Real-Time Place Preference assay (RTPP). Neither ChR2 nor eYFP mice demonstrated a preference for the side paired with photostimulation, suggesting that photostimulation of cholinergic basal forebrain neurons was not inherently reinforcing (Figure S $2 F$ ).

Since cholinergic photostimulation did not increase movement in unreinforced contexts, we also tested whether cholinergic photostimulation affected unconditioned movements within our reinforced, behavioral context. A subset of mice were trained on the simple, uncued head-fixed licking task while on a treadmill, in order to measure spontaneous locomotion. There was no difference in locomotion around the time of photostimulation between ChR2 and eYFP mice, during either Photostim-Unreinforced or Photostim-Reinforced sessions (Figure S 2G). 
Locomotion also did not differ significantly between Photostim-Unreinforced and PhotostimReinforced sessions, for either ChR2 or eYFP mice (Figure $\mathrm{S} 2 \mathrm{H}$ ).

Lastly, we examined whether photostimulation of cholinergic basal forebrain neurons increased arousal during our simple head-fixed task, as measured by pupil diameter, using machine learning based pupillometry (DeepLabCut, Figure S 2I-L). During Photostim-Unreinforced sessions, photostimulation of cholinergic neurons caused a modest increase in pupil dilation in ChR2 mice compared to eYFP mice (Figure S 2l, left; rank-sum between groups, $p<0.05$ ). The first significant difference in pupil size between ChR2 and eYFP mice began 1.2 sec after laser onset. During Photostim-Reinforced sessions, photostimulation also caused an increase in pupil dilation in ChR2 mice compared to eYFP mice, now beginning $0.7 \mathrm{sec}$ after laser onset (Figure $\mathrm{S} 2 \mathrm{I}$, right; rank-sum between groups, $\mathrm{p}<0.05)$. Pupil changes were larger during PhotostimReinforced than Photostim-Unreinforced sessions for ChR2 mice (Figure S 2J). There was no clear change in pupil size after photostimulation for eYFP mice (Figure S 2J).

Some of the differences in photostimulation-evoked pupil dilation during the PhotostimReinforced session for ChR2 mice may relate to reward collection behavior. We examined pupillary diameter at the time of reward delivery in both Photostim-Unreinforced and PhotostimReinforced sessions (Figure S 2K). During both sessions, pupils dilated similarly in ChR2 and eYFP mice following reward delivery (Figure S $2 \mathrm{~L}$ ). Therefore, cholinergic photostimulation increases arousal modestly and this effect becomes evident more slowly for pupillary dilation than for licking behavior ( $0.5 \mathrm{sec}$ latency for licking as in Figure 1).

\section{Muscarinic receptors are necessary for conditioned licking}

ACh can affect post-synaptic neurons in target regions through two classes of receptors: fast, ionotropic nicotinic receptors and relatively slower, G-protein coupled, metabotropic muscarinic receptors (Brown, 2019). In order to test which receptors mediate the effects of photostimulation of cholinergic basal forebrain neurons on conditioned responding, we observed the effects of blocking each receptor class using intraperitoneal injections of either a muscarinic antagonist (scopolamine) (Kruk et al., 2011; Kruk-Słomka et al., 2014) or a nicotinic antagonist (mecamylamine) (Adermark et al., 2014; Zachariou et al., 2001) (Figure 2A).

Prior to injections, in order to increase within-subject control, mice were also trained to respond to tones (i.e. where a tone indicated a reward window) (Figure 2B). On separate trials, mice received either a tone or transient photostimulation ( $2 \mathrm{sec}$ duration each). If mice licked after the onset of the tone or after the onset of photostimulation (within $3 \mathrm{sec}$ ), they received a fluid reward. Licking after tones or photostimulation was compared to licking on matched unrewarded ITI windows to assess baseline licking likelihoods. On a control day in which mice were injected with saline, both ChR2 and eYFP mice responded more during tones than during ITIs (Figure 2C). However, only optogenetic ChR2 mice responded more during Photostimulation than during ITIs, and they responded at similar rates during photostimulation as tones.

When mice received an injection of the muscarinic receptor antagonist scopolamine $(0.3 \mathrm{mg} / \mathrm{kg})$, however, ChR2 mice began to lick less during photostimulation than tones. With a higher dose of scopolamine $(1 \mathrm{mg} / \mathrm{kg})$, ChR2 mice licked similarly on photostimulation trials as during ITIs, despite still licking more during tone trials than ITIs. This suggested that blocking muscarinic receptors decreased conditioned responding, and that conditioned responding to basal forebrain cholinergic neuron photostimulation was more sensitive than conditioned responding to tones. 
In contrast, conditioned responding after injection of the nicotinic receptor antagonist mecamylamine was similar to saline control for both ChR2 and eYFP mice. Therefore muscarinic receptors, rather than nicotinic receptors, were necessary for conditioned responding to basal forebrain cholinergic neuron photostimulation.

\section{Basal forebrain cholinergic neurons are active during conditioned responding}

Having determined that photostimulation of basal forebrain cholinergic neurons can drive conditioned responding even in the absence of discrete external cues, we next examined whether basal forebrain cholinergic neurons are active during conditioned responding. Basal forebrain cholinergic neurons have been described to be active during reinforcer delivery (Hangya et al., 2015), reward consumption (Harrison et al., 2016), movements including locomotion (Harrison et al., 2016; Nelson and Mooney, 2016), and conditioned stimuli (Guo et al., 2019; Parikh et al., 2007). However, we observed that photostimulation of basal forebrain cholinergic neurons increased conditioned responding independent of these factors: in the absence of conditioned cues, prior to reinforcer delivery or consumption, and without affecting unconditioned movements such as locomotion. We therefore studied whether basal forebrain cholinergic neuron activity also changes at the time of conditioned responding, using a genetically-encoded fluorescent calcium indicator, GCaMP6s (Chen et al., 2013), as a proxy for neural activity.

We targeted expression of GCaMP6s to basal forebrain cholinergic neurons using virallymediated, Cre-dependent expression (AAVdj-EF1a-DIO-GCaMP6s) (Figure 3A). An optic fiber implanted over the basal forebrain enabled real-time recording of fluctuations in neural activity using fiber photometry (Adelsberger et al., 2005; Cui et al., 2013; Gunaydin et al., 2014; Lütcke et al., 2010). We recorded GCaMP6s fluorescence while mice performed a more traditional operant task to detect tones. Licking after the onset of tones (within $3 \mathrm{sec}$ ) was rewarded (Figure 3B). Recordings during this task demonstrated fluorescent transients in the $470 \mathrm{~nm}$ signal channel that appeared linked to behavioral events (Figure 3C). Peri-event analyses suggested that fluorescence levels increased following behavioral events, most clearly after licking in the presence of a tone, prior to reward delivery $(0.5 \mathrm{sec})$, but also during spontaneous licking (i.e. in the absence of tone cues and reward delivery) (Figure 3D-G). There were no apparently meaningful changes in the $405 \mathrm{~nm}$ reference channel, suggesting that changes in fluorescence were not related to simple movement artifacts.

It is possible that licking and basal forebrain cholinergic neuron activity even in the absence of tone cues and reward delivery was in some way influenced by the broader cue-reinforcer association context of this task. To account for this, we also recorded fluorescent activity from basal forebrain cholinergic neurons prior to any experience with tone cues, during our uncued reward task (Figure $3 \mathrm{H}$ ). Even in this context, without discrete tones or cues, changes in fluorescent activity were observed both for licking that triggered reward delivery, as well as for licking in the absence of reward delivery (Figure 3I-K). This suggests that cholinergic neurons are physiologically active at the time of conditioned responding, even in the absence of cues and reward consumption. 
bioRxiv preprint doi: https://doi.org/10.1101/2022.02.04.479188; this version posted February 5, 2022. The copyright holder for this preprint (which was not certified by peer review) is the author/funder. All rights reserved. No reuse allowed without permission.

\section{Local ACh levels in the BLA, measured using a genetically-encoded sensor, increase during conditioned stimuli and responses}

Although we had determined that basal forebrain cholinergic neuron activity increases with conditioned responding (Figure 3), we wanted to confirm whether ACh is released into target regions. We measured $A C h$ release within the BLA using a novel version of a geneticallyencoded ACh sensor (GRABACh3.0, abbreviated as GACh3.0 hereafter) (Jing et al., 2018), whose fluorescence reports the dynamics of extracellular ACh (Figure 4A-B).

We drove expression of the genetically-encoded ACh sensor in BLA neurons by injecting an adeno-associated virus carrying the ACh sensor (AAV9-hSyn-GACh3.0) into the BLA (Figure 4A). An optic fiber implanted over the BLA enabled real-time recording of ACh dynamics in the BLA by fiber photometry. We recorded local ACh while mice performed a more traditional operant task to detect tones, during which licking after tone onset was rewarded (Figure 4C). Sample recordings during this task revealed fluorescent transients that appeared linked to behavioral events (Figure 4D). Similar to somatic GCaMP photometry, GACh3.0 fluorescence signals increased following behavioral events, significantly for licking leading to reward delivery (Figure 4E-F). We also recorded BLA ACh dynamics prior to any experience with tone cues, during our uncued reward task (Figure 4I). Even in this context, without discrete tones or other discrete cues, changes in fluorescent signals were observed both for licking that triggered reward delivery, as well as for licking without subsequent reward delivery (Figure 4J-L). This suggests that BLA ACh levels increased at the time of conditioned responding, even in the absence of discrete cues and reward consumption.

\section{Photostimulation of basal forebrain cholinergic terminals in the BLA increases conditioned behavior when paired with reinforcement}

Having confirmed that ACh levels in the BLA increase at the time of conditioned responding, we next studied whether photostimulation of basal forebrain cholinergic terminals directly within the BLA was sufficient to drive conditioned responding. Using Cre-dependent targeting, we again expressed either ChR2 or a control fluorophore (eYFP) in basal forebrain cholinergic neurons (Figure 5A). To stimulate cholinergic terminals in the BLA, we placed an optic fiber over the BLA.

Following initial uncued head-fixed training, we tested whether transient photostimulation of basal forebrain cholinergic terminals in the BLA affected conditioned licking under two different conditions. When photostimulation was performed during unrewarded windows (PhotostimUnreinforced sessions), licking did not increase compared to statistically matched baseline windows, in either ChR2 or eYFP mice (Figure 5B). When photostimulation was delivered exclusively during a subset of Reward windows (Photostim-Reinforced sessions), photostimulation increased licking only in mice expressing ChR2 (Figure 5C). Baseline licking rates, however, remained similar between ChR2 and eYFP mice. Hence, transient photostimulation of basal forebrain cholinergic terminals in the BLA drove conditioned responding in a temporally precise way, only when photostimulation was associated with the opportunity to collect rewards, similar to results with somatic basal forebrain cholinergic neuron photostimulation (Figure 1). 
bioRxiv preprint doi: https://doi.org/10.1101/2022.02.04.479188; this version posted February 5, 2022. The copyright holder for this preprint (which was not certified by peer review) is the author/funder. All rights reserved. No reuse allowed without permission.

\section{Concurrent photostimulation of cholinergic terminals and local ACh measurement in the $B L A$ reveals that levels of $A C h$ do not change when associated with reward}

We next measured local ACh in the BLA while concurrently photostimulating basal forebrain cholinergic terminals (Figure 5D). We placed an optic fiber over the BLA in order to use orange light $(589 \mathrm{~nm})$ to transiently photostimulate basal forebrain cholinergic terminals using a Credependent, red-shifted optogenetic protein (ChrimsonR) expressed in the basal forebrain of ChAT::Cre mice. We concurrently shined blue light $(470 \mathrm{~nm})$ through the same optic fiber to measure local ACh levels using a genetically-encoded ACh sensor in BLA neurons. Sample recordings demonstrated that $\mathrm{ACh}$ sensor fluorescence increased during photostimulation only in mice expressing ChrimsonR (Figure 5E), but not in those expressing a control fluorophore (Figure 5F).

We compared, in the same mice, BLA levels of ACh fluorescence during photostimulation of basal forebrain cholinergic terminals in Photostim-Unreinforced and Photostim-Reinforced sessions (Figure 5G-I). Photostimulation elicited robust responses in mice expressing ChrimsonR, but not in mice expressing a control fluorophore (Figure 5G). The amount of measured fluorescence did not depend upon whether photostimulation was provided in Photostim-Unreinforced or Photostim-Reinforced sessions. Taken together with our previous finding that photostimulation of cholinergic terminals in the BLA selectively elevated licking during Photostim-Reinforced sessions (Figure 5C), our observation that BLA ACh levels did not change with reward suggests that reward associations may gate responses to photostimulation in post-synaptic neurons.

Lastly, given that even briefer photostimulation was capable of driving conditioned responding, we additionally performed recordings during a Photostim-Reinforced session, in which photostimulation was provided at various numbers of laser pulses at the same duty cycle. The amount of ACh sensor fluorescence evoked by 1-2 laser pulses, which had been sufficient to drive behavior when photostimulation was targeted to the soma (Figure 1), was similar to levels of ACh at the time of reward delivery in the absence of any photostimulation (Figure S 3 ). Therefore a level of optogenetically induced ACh release similar to physiologic release can drive conditioned responding, specifically when paired with the opportunity to collect rewards (Photostim-Reinforced sessions).

\section{Cholinergic effects in vivo differ between target regions and depend upon reinforcer context in the amygdala}

Having identified that basal forebrain cholinergic neurons are active during conditioned responding even in the absence of discrete external cues, we next evaluated whether effects on target regions involved in conditioned responding might depend on reinforcer context. The BLA and dorsomedial prefrontal cortex (dmPFC) are both involved in conditioned behavior (Cardinal et al., 2002), receive projections from basal forebrain cholinergic neurons (Kitt et al., 1994; Woolf et al., 1984), and are functionally interrelated (Burgos-Robles et al., 2017; Likhtik et al., $2005,2014)$. We therefore studied how photostimulation of basal forebrain cholinergic neurons affects in vivo neural activity in these target regions (Figure 6). We again performed surgery on mice to express either ChR2 or a control fluorophore (eYFP) in basal forebrain cholinergic neurons, using Cre-dependent targeting (Figure 6A, Figure S 4A). In addition to implanting optic fibers over the basal forebrain to photostimulate basal forebrain cholinergic neurons, we also 
implanted microwire bundles in the dmPFC and BLA to record single unit activity in vivo during photostimulation.

During photostimulation of basal forebrain cholinergic neurons, dmPFC neural activity increased across the population (Figure 6B, left). The increase in dmPFC population neural activity during photostimulation was similar for both Photostim-Unreinforced sessions (purple), and PhotostimReinforced sessions (green), consisting primarily of facilitation. In contrast to the dmPFC, the effects of photostimulation of basal forebrain cholinergic neurons on BLA neural activity differed depending on the session (Figure 6B, right). In Photostim-Unreinforced sessions (purple), the BLA population response consisted of facilitation, particularly at onset, whereas in the Photostim-Reinforced sessions (green), the BLA population response had a more striking and sustained suppression. The difference in the BLA population response between the two sessions was evident as early as $135 \mathrm{~ms}$ after photostimulation onset. There were minimal changes related to photostimulation itself in control mice expressing eYFP, for both PhotostimUnreinforced and Paired sessions types (Figure S 4).

The population neural responses in the dmPFC and BLA reflected a mix of individual neurons that were facilitated or suppressed by photostimulation of cholinergic basal forebrain neurons (Figure 6CD). In the dmPFC, the proportion of neurons facilitated and suppressed by photostimulation did not change depending on session type (Figure 6E, left). In the BLA, however, the proportion of individual neurons that were facilitated tended to have decreased during Photostim-Reinforced sessions, and the proportion of neurons that were suppressed increased in Photostim-Reinforced sessions (Figure 6E, right). Comparing between these regions, a higher proportion of BLA neurons were suppressed than dmPFC neurons during both session types (Figure 6F), but a lower proportion of BLA neurons than dmPFC neurons were facilitated during the Photostim-Reinforced sessions. These findings suggested cholinergic effects in vivo differ between target regions and depend upon reinforcer context in the amygdala.

There was a striking heterogeneity of neural responses in the target regions, with some neurons in each region facilitated by photostimulation of cholinergic basal forebrain neurons, while other neurons were suppressed. We therefore explored how neurons that were facilitated or suppressed might differ. Neurons in the dmPFC that were facilitated by photostimulation of cholinergic basal forebrain neurons during the Photostim-Reinforced sessions had higher baseline firing rates than neurons that were suppressed (Figure $S 5$ ). There was a possible similar trend in the BLA ( $p=0.057$ after correction for multiple comparisons) - neurons that were facilitated during the Photostim-Reinforced sessions had higher baseline firing rates, while neurons that were suppressed had lower baseline firing rates. The possible differences in firing rates suggested that different neurons might be facilitated or suppressed. In order to identify specific neural subpopulations of BLA neurons that might differentially respond to photostimulation of cholinergic basal forebrain neurons, we transitioned to an ex vivo preparation.

\section{Cholinergic afferents suppress basolateral amygdala output through multiple, molecularly specific pathways ex vivo}

We used an ex vivo preparation in order to determine unambiguously which types of BLA neurons are facilitated or suppressed by photostimulation of cholinergic basal forebrain neurons. We performed surgeries to fluorescently label two populations of BLA neurons in order 
to record their post-synaptic responses to photostimulation of basal forebrain cholinergic terminals (Figure 7A). Specifically, we investigated GABAergic that are putative local interneurons, and neurons that project to $\mathrm{MPFC}$, which are putative glutamatergic neurons. We used double-transgenic mice (ChAT::Cre x VGAT::flpo) to photostimulate basal forebrain cholinergic axonal terminals in the BLA, through Cre-dependent expression of ChR2. We additionally fluorescently labeled BLA GABAergic neurons by flpo-dependent expression of eYFP. After at least 6 weeks, we performed a second surgery to fluorescently label BLA neurons projecting to the medial prefrontal cortex (mPFC) through injection of a retrograde tracer (cholera toxin b subunit fused to Alexa-647, CTB-647) in the mPFC. One week after the second surgery, mice were euthanized and coronal slices of the BLA were prepared in order to perform whole-cell recordings from either fluorescently identified mPFC projecting BLA neurons (BLA-mPFC) or GABAergic VGAT::flpo BLA neurons (BLAGABA), while photostimulating basal forebrain cholinergic axonal terminals (Figure 7B-C).

These two BLA neural populations were non-overlapping and had strikingly different responses to photostimulation of cholinergic axonal terminals. BLA-mPFC responded to cholinergic terminal photostimulation with a prolonged suppression (Figure 7E-F). In contrast, BLAGABA neurons responded to cholinergic photostimulation with a rapid and more transient facilitation. The amplitude of the fast excitatory postsynaptic potential (EPSP) was greater in BLAGABA neurons compared with BLA-mPFC neurons, while the inhibitory postsynaptic current (IPSP) amplitude was greater in BLA-mPFC neurons relative to BLAGABA (Figure 7G). These represented independent, direct monosynaptic responses to photostimulation of cholinergic afferents, as each persisted in the absence of spike-driven synaptic release (to eliminate indirect/polysynaptic transmission), blocked by tetrodotoxin (TTX) (Figure $7 \mathrm{H}-\mathrm{I}$ ).

To understand how these neural populations could have such divergent responses to basal forebrain cholinergic inputs, we tested whether suppression in BLA-mPFC neurons and facilitation in BLAGABA neurons were regulated by different cholinergic receptor classes. The optically-evoked IPSP in BLA-mPFC neurons was blocked by muscarinic antagonists, but not nicotinic antagonists (Figure 7J, top row). In contrast, the facilitation in BLAGABA neurons was blocked by nicotinic antagonists, but not muscarinic antagonists (Figure $7 \mathrm{~J}$, bottom row). These results suggest a circuit model in which cholinergic afferents suppress BLA output through multiple, molecularly-specific pathways, both through direct muscarinic suppression of projection neurons, as well as through nicotinic facilitation of GABAergic neurons, which can locally inhibit BLA projection neurons (Figure 7K). In total, the effects of cholinergic input to the BLA appear to be a suppression of BLA projector neuron output, and strikingly this effect is most prominent when the system is primed to respond to cholinergic input by behavioral reinforcement. 


\section{Discussion}

\section{Basal forebrain cholinergic neurons can drive conditioned responding in the absence of discrete cues}

Here we demonstrate that photostimulation of basal forebrain cholinergic neurons can drive conditioned responding. ACh has long been posited to play an important role in directing attention to extrinsic stimuli, as measured by facilitating conditioned responses to such stimuli (Parikh et al., 2007; Pinto et al., 2013). Surprisingly, we observed that photostimulation of cholinergic basal forebrain neurons was sufficient to drive conditioned responding, even in the absence of other discrete stimuli (Figure 1). We observed direct behavioral (Figure 1) and neural responses (Figure 6), often used as readouts of attention, to photostimulation of basal forebrain cholinergic neurons.

\section{Reward availability modulates the impact of basal forebrain cholinergic neurons}

Remarkably, photostimulation of basal forebrain cholinergic neurons only drove conditioned responding when paired with the opportunity to collect rewards (Figure 1). Basal forebrain cholinergic neurons are active at the time of both positively and negatively valenced reinforcers (Hangya et al., 2015; Harrison et al., 2016), and previous work has suggested ACh may amplify the effects of reinforcers during learning and strengthen plasticity (Jiang et al., 2016). In the current study, however, reward availability actually modified the behavioral and neural effects of basal forebrain cholinergic neurons themselves. BLA neurons became more suppressed as a population (Figure 6), consistent with our findings in an ex vivo preparation from behaviorally naïve animals (Figure 7). Taken together, these data are consistent with a model wherein effects of ACh are unmasked or amplified by reward availability.

\section{The effects of basal forebrain cholinergic neurons may be dynamically gated post- synaptically}

Given the modulation of ACh effects by reward availability, we investigated whether this difference was due to a difference in the amount of ACh elicited by photostimulation. Cholinergic terminals can express presynaptic receptors, including cholinergic receptors, which may modulate ACh release (Muller et al., 2016; Thany and Tricoire-Leignel, 2011). If photostimulation induced a different amount of ACh release during Photostim-Reinforced sessions, this may have explained the change in conditioned behavior. However, photostimulation of cholinergic terminals in the BLA evoked similar levels of ACh in PhotostimUnreinforced and Photostim-Reinforced sessions (Figure 5). This suggests that similar levels of ACh may be gated or differentially interpreted by downstream neurons depending on reward availability. Such gating may be mediated by coincident signals of reinforcement to the BLA, such as dopaminergic inputs (Lutas et al., 2019; Tye et al., 2010), given that dopaminergic receptors are expressed by BLA neurons that also express cholinergic receptors (Równiak et al., 2017). We did not observe similar cholinergic gating in the dmPFC, despite the robust gating effect of dopamine seen in this region (Vander Weele et al., 2018).

\section{Basal forebrain cholinergic neurons reflect a transition from conditioned stimulus to response}

Rather than changing how other stimuli are processed from neutral into conditioned stimuli, our results suggest that cholinergic activity can itself become conditioned. The lack of response to 
photostimulation during Photostim-Unreinforced Sessions provides important constraints on possible interpretations (Figure 1). Mice were in a familiar context wherein the only meaningful behavioral response was to lick for unpredictable rewards. However, photostimulation of basal forebrain cholinergic neurons during Photostim-Unreinforced sessions did not drive conditioned licking in these sessions, as might be predicted by a number of alternative interpretations, such as nonspecific increases in movement, arousal, or contextual awareness.

Our findings suggest that photostimulated release of ACh can have a similar function as conditioned stimuli or cues, able to trigger conditioned responses. Recent work has shown that basal forebrain cholinergic neurons are active following presentation of conditioned stimuli (Crouse et al., 2020; Guo et al., 2019; Sturgill et al., 2020). Additionally, work in visual cortex has suggested that ACh may help link stimuli with the time of expected rewards (Chubykin et al., 2013; Liu et al., 2015). We also demonstrated, however, that cholinergic neurons were consistently active at the times of conditioned responding, even in the absence of cues and rewards. This suggests that cholinergic transients are poised to play a role in conditioned responding and serve to signal more than just a salient event driving a response. Indeed, blocking cholinergic muscarinic receptors impaired the ability of mice to respond even to conditioned tones (Figure 2). This is consistent with other studies in which inhibition of cholinergic terminals in the BLA prevented mice from expressing freezing behavior at the time of fear conditioning (Jiang et al., 2016).

Our observation on the impact of ACh on conditioned behavior also provides new context for interpreting several prior results that have examined the role of basal forebrain cholinergic neurons in attention to external stimuli. Interestingly, even when photostimulation of cholinergic basal forebrain neurons has previously been noted to increase discriminability between stimuli, it appears to do this primarily by increasing conditioned responses to conditioned stimuli, rather than suppressing false alarms (Pinto et al., 2013). Additionally, in sustained attention tasks to report the presence of stimuli to collect rewards, photostimulation of basal forebrain cholinergic neurons drive conditioned responding as if cues are present, even in their absence (Gritton et al., 2016), and immunotoxic lesions of basal forebrain cholinergic neurons lead to omissions of any response at all (McGaughy et al., 2002).

The responses of cholinergic basal forebrain neurons (Figure 3) and acetylcholine release within the BLA (Figures 4 and 5) indicate that conditioned responses of licking are represented by cholinergic signaling even in the absence of conditioned stimuli or reward delivery, reminiscent of signals seen in lateral hypothalamic $(\mathrm{LH})$ neurons projecting to the ventral tegmental area (VTA) (Nieh et al., 2015). While LH-VTA neurons were capable of driving compulsive sucrose seeking behavior, we do not observe the same stereotyped motor sequences in cholinergic neurons as when disinhibiting VTA dopamine neurons via the LH-VTA pathway (Nieh et al., 2016), and the ability of cholinergic signaling to drive compulsivity begs further exploration.

\section{Comparisons to other studies of photostimulation of cholinergic basal forebrain neurons}

Cholinergic neurons from the basal forebrain have different projections depend on their location in the basal forebrain (Zaborszky et al., 2012), and even within regions may be physiologically heterogeneous (Laszlovszky et al., 2020). While photostimulation of anterior basal forebrain cholinergic neurons projecting to the lateral hypothalamus suppresses appetite (Herman et al., 2016), here, photostimulation of the more posterior cholinergic population in the sublenticular 
substantia innominata/extended amygdala that project to the BLA increased consummatory behavior (Figure 1). While other work has suggested that photostimulation of basal forebrain cholinergic axonal terminals in the BLA can be rewarding (Aitta-Aho et al., 2018), we did not observe a reinforcing effect of somatic basal forebrain cholinergic photostimulation (Figure $S 2$ ). Similarly, we did not observe an effect on locomotion, in both an unrewarded and a rewarded context, despite the association of cholinergic activity with locomotion (Harrison et al., 2016).

\section{Cell type specific responses to ACh}

We noted heterogeneous responses among BLA neurons in vivo to photostimulation of basal forebrain cholinergic neurons (Figure 6). Heterogeneous responses have also been previously noted ex vivo (Unal et al., 2015; Washburn and Moises, 1992). Through a double transgenic approach we determined that these heterogeneous responses could be explained on a cellular level, with dmPFC-projecting neurons suppressed and GABAergic neurons facilitated by cholinergic inputs (Figure 7). The BLA GABAergic neuron population is thought to represent local interneurons that inhibit projection neurons (Washburn and Moises, 1992). Although both excitation of GABAergic neurons and inhibition of mPFC projection neurons were monosynaptic, these cholinergic effects could in concert function to suppress BLA output (Lee and Kim, 2019; Pidoplichko et al., 2013; Zhu et al., 2005), which may decouple regions downstream from the $\mathrm{BLA}$ and allow them to function independently.

This cellular specificity was mediated by different receptors, with short-latency facilitation in GABAergic neurons mediated by nicotinic receptors and longer-latency suppression in projection neurons mediated by muscarinic receptors (Figure 7). Prior histological work had suggested that M1 muscarinic receptors are predominantly expressed by pyramidal neurons in the BLA (McDonald and Mascagni, 2010), and interneurons express nicotinic receptors (Pidoplichko et al., 2013). Functional differences similar to those we have observed between excitatory and inhibitory neurons have been seen in somatosensory cortex (Dasgupta et al., 2018). Strikingly, the behavioral response to even brief photostimulation of basal forebrain cholinergic neurons occurred by approximately $0.5 \mathrm{sec}$ (Figure 1). Surprisingly, this sub-second response appeared primarily mediated by slower muscarinic receptors rather than faster nicotinic receptors (Figure 2). Our pharmacology experiments suggest that the effects of basal forebrain cholinergic neurons on nicotinic receptors are insufficient to trigger conditioned responding, although it is possible that we did not block all types of nicotinic receptors. Projection neurons, which receive a preponderance of cholinergic input (McDonald et al., 2011), may serve as a critical point of convergence for ACh influence over BLA networks.

\section{The effects of augmenting ACh levels may depend on context}

Disappointingly, current strategies to augment cholinergic function, such as cholinesterase inhibitors, have not had a strong clinical impact on several neuropsychiatric illnesses such as dementia, delirium, schizophrenia, and ADHD, because of both insufficient benefit and significant side effects (Biederman et al., 2006; Cubo et al., 2008; Siddiqi et al., 2016; Singh et al., 2012). While there are many reasons that cholinergic augmentation is unlikely to treat any of these complex diseases completely, our translationally motivated concern is that augmenting cholinergic levels, even with temporal and spatial specificity here through optogenetics, may have unpredictable effects depending upon the reward context surrounding this augmentation. Additionally, it is possible that extrinsic augmentation of cholinergic tone may be processed differently than intrinsic fluctuations in cholinergic tone. It is possible that coupling cholinergic 
bioRxiv preprint doi: https://doi.org/10.1101/2022.02.04.479188; this version posted February 5, 2022. The copyright holder for this preprint (which was not certified by peer review) is the author/funder. All rights reserved. No reuse allowed without permission.

augmentation with other therapies, such as cognitive or behavioral therapies, that can explicitly incorporate rewards or proxies for reinforcers, may provide a new opportunity for more sustained and predictable benefits to patients. 


\section{Acknowledgments}

We thank C. Wildes, R. Wichmann, J. Wang, A. Heynen for technical assistance. We thank V. Breton-Provencher, J. Shih, M. Sur, and the members of the Bear lab for additional support. We thank A. Sutton, M. Picciotto, R. Crouse, A. Kepecs, F. Sturgill, and E. Calipari for helpful discussions.

The authors declare no competing interests.

Funding: E.Y.K. was supported by NIH grant K08-MH116135 (NIMH). C.A.S. was supported by an NIH grant R00 DA04510 (NIDA), a NARSAD Young Investigator Award (Brain and Behavior Research Foundation), and by an Alkermes Pathways Research Award grant, an independent competitive grants program supported by Alkermes. M.F. was supported by NIH grant K99EY029326 (National Eye Institute). D.B.P. was supported by R01-DC017078 and funding from the Nancy Lurie Marks Family Foundation. K.M.T. is a New York Stem Cell FoundationRobertson Investigator and McKnight Scholar and was supported by funding from the JPB Foundation, New York Stem Cell Foundation, R01-MH102441 (NIMH), the NIH Director's New Innovator Award DP2-DK102256 (NIDDK), and Pioneer Award DP1-AT009925 (NCCIH).

\section{Author Contributions}

Conceptualization, E.Y.K. and K.M.T.;

Methodology, E.Y.K., A.B-R., G.A.M., C.A.S., M.J., Y.L., and K.M.T.;

Software, E.Y.K.;

Validation, E.Y.K., T.C., and M.P.;

Formal Analysis, E.Y.K.;

Investigation, E.Y.K., A.B-R., G.A.M., T.C., M.P., J.W., W.Y., S.F., R.S., and M.F.;

Resources, Y.K., D.B.P., and K.M.T.;

Writing - Original Draft, E.Y.K., A.B-R., G.A.M., T.C., M.P., C.A.S., and K.M.T.;

Writing - Review \& Editing, D.B.P.;

Funding Acquisition, E.Y.K, D.B.P., and K.M.T.; 


\section{Figure Legends}

\section{Figure 1 | Photostimulation of basal forebrain cholinergic neurons drives conditioned responding when associated with reward}

(A) Optogenetic strategy to photostimulate cholinergic basal forebrain neurons, by driving Cre-dependent expression of Channelrhodopsin-2 (ChR2) or a control fluorophore (eYFP) in mice expressing Cre-recombinase under control of the choline acetyltransferase promoter (ChAT::Cre). The photostimulation parameters displayed were used in later behavioral sessions.

(B) Sample histology of fiber placement over cholinergic neurons in the basal forebrain. Blue=DAPI nucleic acid staining, Green=cre-dependent expression of ChR2 fused to eYFP, Red=anti-ChAT immunohistochemical staining. See also Figure $S 1 A B$.

(C) Window of Opportunity Task (WoOT) to study conditioned responding in the absence of discrete cues. Mice were trained prior to any photostimulation, using an operant, variableinterval reinforcement schedule with limited hold (Ferster and Skinner, 1957). Sessions were divided into trials of 3-second windows of opportunity, with variable intertrial intervals (ITIs). Rewards were only delivered if mice licked during an unsignaled Reward window (green; $90 \%$ of trial windows). We also included a subset of Unrewarded windows, on which, even if the mouse licked, reward would not be delivered (purple; $10 \%$ of trial windows), similar to the intervening ITIs (white). Because windows were not discretely cued and occurred after variable ITIs, mice did not know when they initiated a lick whether it would be rewarded. (See also Figure S 1).

(D) Sample WoOT behavior. Reward deliveries were only triggered by licking during uncued Reward windows (green). Licking during uncued Unrewarded windows (purple) or the ITIs (white) did not trigger reward delivery.

(E) Behavioral training and testing sessions. After early WoOT training without any photostimulation, mice received a Photostim-Unreinforced Session (F), or Photostim-Reinforced sessions $(G)$, with fixed or varied durations of photostimulation as noted below.

(F) Photostim-Unreinforced Session. In addition to Reward windows (green, 80\%) and Unrewarded windows (purple, 8\%) with no photostimulation, mice received 2 sec of photostimulation (blue lines) during additional Unrewarded windows (purple, 12\%) to study innate responses.

(G) Photostim-Reinforced Session. Conversely to Photostim-Unreinforced sessions, during Photostim-Reinforced sessions, photostimulation (blue lines) was delivered during a subset of reward windows (green, $12 \%$ ), during which, if mice licked, they would receive a reward. Mice still had more numerous reward windows with no photostimulation (68\%).

( $\mathrm{H} \& \mathrm{I})$ The likelihood of licking depended on an interaction of Virus, Photostimulation Window type, and Photostim-Reinforcement Session type (linear mixed effects model, $F_{1,78}=5.26$, $p=0.025)$. Thin lines represent data from all individual mice, pooled data are represented as mean \pm SEM. During the Photostim-Unreinforced Session $(H)$, there was no significant difference between ChR2 (blue) and eYFP (gray) groups, regardless of photostimulation window type. However, during the Photostim-Reinforced Session (I), ChR2 mice licked 
significantly more during Photostim windows than No Photostim windows (post-hoc tests with Sidak correction for multiple comparisons: $\left.{ }^{* * *} p<0.0001\right)$. ChR2 mice also licked significantly more than eYFP mice during Photostim windows $\left({ }^{* *} p=0.001\right)$. There were no detectable effects of photostimulation on licking in eYFP mice, and no detectable differences in licking on no photostim windows between ChR2 and eYFP mice (all other post-hoc comparisons $p>0.10$ ).

(J) We initially photostimulated with a fixed duration, but in a follow-up session photostimulated with varied durations $(0-0.5 \mathrm{sec}$, using different number of pulses at the same frequency). When tested with different durations of photostimulation, the likelihood of licking depended on an interaction of Virus and the number of photostimulation pulses (linear mixed effects model, $F_{3,84}=16.22$, $p=2.1 \times 10-8$ ). ChR2 mice licked significantly more on windows with 1 , 2 , or 10 pulses than windows without photostimulation, and more than eYFP mice at each of those numbers of pulses (post-hoc tests with Sidak correction for multiple comparisons: ${ }^{*} p=0.015,{ }^{* *} p=0.0095,{ }^{* * *} p<0.001$; all other post-hoc comparisons $p>0.10$ ).

(K) When tested with different durations of photostimulation, the latency of the first lick depended on an interaction of Virus and the number of photostimulation pulses (linear mixed effects model, $\left.F_{3,84}=4.53, p=0.005\right)$. ChR2 mice licked significantly sooner on windows with 1,2 , or 10 pulses than windows without photostimulation, and sooner than eYFP mice for 2 and 10 pulses (post-hoc tests with Sidak correction for multiple comparisons: ${ }^{* *} p=0.0047,{ }^{* * *} p<0.001$; all other post-hoc comparisons $p>0.10$ ). 


\section{Figure 2 | BFChAT:ChR2-induced conditioned responding is muscarinic receptor- dependent}

(A) Experimental strategy to test the necessity of cholinergic receptors in conditioned responding. Cholinergic neurons in the basal forebrain were photostimulated while cholinergic muscarinic or nicotinic receptors were blocked using intraperitoneal injection of pharmacologic antagonists.

(B) Modification of Window of Opportunity Task (WoOT) to include additional tone conditioned responses. In order to provide additional within-subject controls for pharmacologic testing, mice could now receive rewards on either of two separate types of reward windows: with tones or with photostimulation (both $2 \mathrm{sec}$ duration). Licks during unsignaled, unrewarded windows were recorded but had no consequence.

(C) Photostim-induced licking was abolished by systemic muscarinic receptor antagonist administration. Linear mixed effects modelling confirmed that licking depended upon an interaction between Virus group, Stimulus type, and Drug session $\left(F_{3,363}=4.61, p=0.0002\right)$. Thin lines represent data from individual mice, pooled data are displayed as mean \pm SEM. Saline: Both ChR2 and eYFP mice responded more during tone reward windows than during unsignaled, unrewarded windows (Unrwd) $\left({ }^{* * *} p<0.001,{ }^{*} p<0.05, \# p=0.10\right.$, Sidak post-hoc multiple comparisons). However, only ChR2 mice responded more during photostimulation reward windows than during unsignaled, unrewarded windows, at a similar likelihood as their responses during tone reward windows. Scopolamine $0.3 \mathrm{mg} / \mathrm{kg}$ : ChR2 mice now responded less during photostimulation than during tones. Scopolamine $1 \mathrm{mg} / \mathrm{kg}$ : ChR2 mice no longer responded more during photostimulation than during unrewarded windows, and no longer responded more during photostimulation than eYFP mice, although they continued to respond more during tones than ITIs. Mecamylamine $1 \mathrm{mg} / \mathrm{kg}$ : Response patterns were similar to Saline sessions. For each session, the likelihood of licking during unrewarded windows was similar between ChR2 and eYFP mice (all $p>0.8$ ). Additionally, within each group, the likelihood of licking during unrewarded windows was similar to Saline sessions for all drug doses (all $p>0.8)$. 


\section{Figure 3 | Cholinergic neurons respond to conditioned stimuli and lick, even in the absence of reward delivery}

(A) Strategy to record fluorescent activity from basal forebrain cholinergic neurons expressing the calcium sensor GCaMP6s, using interleaved signal (470 nm, blue) and reference (405 nm, violet) wavelengths to elicit fluorescence (525 nm, green).

(B) Task windows. We recorded fluorescent activity from mice during a traditional operant cue detection task. If mice licked after the onset of a tone, a fluid reward was delivered after a $0.5 \mathrm{sec}$ delay. Licks during the silent unrewarded windows had no consequence.

(C) Sample GCaMP photometry fluorescence traces from one mouse demonstrating signal increases around the times of tones, licks, and reward deliveries. Increases were apparently present even for licking in the absence of tones and rewards. The blue trace represents data from the signal wavelength $(470 \mathrm{~nm})$ and the violet trace represents interleaved data from the reference wavelength (405 $\mathrm{nm})$.

(D) Changes in fluorescence from basal forebrain cholinergic neurons referenced to time of tone onset. Heat maps represent trial-averaged data from each mouse. Top heat maps are for $470 \mathrm{~nm}$ excited fluorescence (Signal 470), bottom heat maps are for $405 \mathrm{~nm}$ reference (Ref 405). The bottom panel summary data are represented as mean \pm SEM. Mice are sorted in all heat maps (D-F, I-J), in the order of average post-lick activity in panel $E$.

(E) Changes in fluorescence from basal forebrain cholinergic neurons around the time of the first lick after tone onset. Licking triggered reward delivery (first lick at $0 \mathrm{sec}$, reward delivery at dashed line, $0.5 \mathrm{sec}$ ).

(F) Changes in fluorescence from basal forebrain cholinergic neurons around the onset of matched lick bouts that were in the absence of tone cues and did not lead to reward delivery.

(G) Fluorescence levels from basal forebrain cholinergic neurons at baseline (-2 to $-1.5 \mathrm{sec}$ before) and post-event ( 0 to $0.5 \mathrm{sec}$ after) time points in the Cued task. Fluorescence levels depended on an interaction of Wavelength, Time point, and Event type (linear mixed effects model, $\left.F_{2,55}=3.28, p=0.045\right)$. Fluorescence levels increased after events in the $470 \mathrm{~nm}$ wavelength signal channel (blue), but not the 405 reference channel (violet) (Tone: $t_{55}=2.64$, $\# p=0.064$; Lick leading to Reward Delivery (Lick \& Rwd): $t_{55}=7.57,{ }^{* * *} p<0.001$; Licks in absence of Cue \& Reward Delivery (Lick, No Rwd): t55 $=5.29$, ${ }^{* * *} p<0.001$; Sidak correction for six multiple comparisons). Thin lines represent data from all individual mice, pooled data are represented as mean \pm SEM.

(H) Window of Opportunity Task (WoOT). All mice were also recorded from at an earlier stage of WoOT training, before experience with tones or other discrete cues. If a mouse licked during an uncued Reward window, a fluid reward was delivered. A 0.5 sec delay was instituted between lick and reward to account for the slow dynamics of GCaMP6s. Licks during Unrewarded windows were recorded but had no consequence.

(I) Changes in fluorescence from basal forebrain cholinergic neurons around the time of the first lick that triggered reward delivery (first lick at $0 \mathrm{sec}$, reward delivery at dashed line, $0.5 \mathrm{sec}$ ). 
(J) Changes in fluorescence from basal forebrain cholinergic neurons around the onset of matched lick bouts that did not lead to reward delivery.

(K) Fluorescence levels from basal forebrain cholinergic neurons at baseline (-2 to $-1.5 \mathrm{sec}$ before) and post-event ( 0 to $0.5 \mathrm{sec}$ after) time points. Fluorescence levels depended on an interaction of Wavelength and Time point (linear mixed effects model, $F_{1,35}=13.59, p=0.0008$ ), without a third order interaction by Event type $\left(F_{1,35}=0.02, p=0.882\right)$. Fluorescence levels increased after events in the $470 \mathrm{~nm}$ wavelength signal channel (blue), but not the 405 reference channel (violet) (Lick leading to Reward Delivery (Lick \& Rwd): $t_{35}=3.58,{ }^{* *} p=0.004$; Licks in absence of Reward Delivery (Lick, No Rwd): $t_{35}=3.90,{ }^{* *} p<0.002$; Sidak correction for four multiple comparisons). Thin lines represent data from all individual mice, pooled data are represented as mean \pm SEM. 
Figure 4 | Local ACh levels in the BLA, measured using a genetically-encoded sensor, increase during conditioned stimuli and responses

(A) Strategy to record local ACh levels in the BLA. A genetically-encoded, fluorescent ACh sensor (GACh3.0, (B)) was expressed in BLA neurons, and excited with blue light (470 $\mathrm{nm}$ ) to elicit green fluorescence $(525 \mathrm{~nm})$.

(B) The fluorescent ACh sensor, GACh3.0, is a fusion protein between a modified M3 muscarinic receptor and cyclically permuted GFP. GACh3.0 undergoes a conformational change and fluoresces after binding ACh.

(C) Cued task windows. We recorded fluorescent activity from mice during a traditional operant cue detection task. If mice licked after the onset of a tone, a fluid reward was delivered after a $0.1 \mathrm{sec}$ delay. Licks during ITIs had no consequence.

(D) Sample BLA ACh sensor fluorescence traces from one mouse demonstrating apparent increases around the times of tones, licks, and reward deliveries. Increases were apparently present even for licking in the absence of tones and rewards.

(E) Changes in BLA ACh sensor fluorescence around the time of tone onset. Heat maps represent trial-averaged data from each mouse. The bottom panel summary data are represented as mean \pm SEM. Mice are sorted in all heat maps $(E-G, J-K)$, in the order of average post-lick activity in panel $\mathrm{F}$.

(F) Changes in BLA ACh sensor fluorescence around the time of the first lick that triggered reward delivery (first lick at $0 \mathrm{sec}$, reward delivery at dashed line, $0.1 \mathrm{sec}$ ).

(G) Changes in BLA ACh sensor fluorescence around the onset of matched lick bouts that were in the absence of a cue and did not lead to reward delivery.

(H) BLA ACh sensor fluorescence levels at baseline ( -2 to $-1.5 \mathrm{sec}$ before) and post-event ( 0 to $0.5 \mathrm{sec}$ after) time points in the Cued task. Fluorescence levels were higher post-events than at baseline (linear mixed effects model, $F_{1,45}=24.09, p<0.0001$ ), without a second order interaction by Event type $\left(F_{2,45}=1.33, p=0.274\right)$. Post-hoc tests showed changes were clearest for Licks leading to Reward delivery (Tone: $t_{45}=2.13, p=0.112$; Licks leading to Reward Delivery (Lick \& Rwd): $t_{45}=4.17,{ }^{* * *} p<0.001$; Licks in absence of Cue \& Reward Delivery (Lick, No Rwd): $t_{45}=2.21, \# p=0.094$; Sidak correction for three multiple comparisons). Thin lines represent data from all individual mice, pooled data are represented as mean \pm SEM.

(I) Uncued Reward Task. All mice were also recorded from at an earlier stage of training in the Uncued reward task, before experience with tones or other discrete cues. If a mouse licked during an uncued Reward window, a fluid reward was delivered. Licks during Unrewarded ITIs were recorded but had no consequence.

(J) Changes in BLA ACh sensor fluorescence around the time of the first lick that triggered reward delivery (first lick at $0 \mathrm{sec}$, reward delivery at dashed line, $0.1 \mathrm{sec}$ ).

(K) Changes in BLA ACh sensor fluorescence around the onset of matched lick bouts that did not lead to reward delivery. 
(L) BLA ACh sensor fluorescence levels at baseline ( -2 to $-1.5 \mathrm{sec}$ before) and post-event ( 0 to $0.5 \mathrm{sec}$ after) time points in the Uncued Reward task. Fluorescence levels were higher postevents than at baseline (linear mixed effects model, $F_{1,27}=60.97, p<0.0001$ ), without a second order interaction by Event type $\left(F_{1,27}=1.80, p=0.191\right)$. Effects were strong both for Licks leading to Reward Delivery (Lick \& Rwd: $\mathrm{t}_{27}=6.47,{ }^{* * *} \mathrm{p}<0.001$ ), and Licks in absence of Cue \& Reward Delivery (Lick, No Rwd): $t_{27}=4.57,{ }^{* * *} p<0.001$; Sidak correction for two multiple comparisons). Thin lines represent data from all individual mice, pooled data are represented as mean \pm SEM. 


\section{Figure 5 | Cholinergic signaling in the BLA is sufficient to drive conditioning responding} but is independent of reward contingency

(A) Optogenetic strategy to photostimulate cholinergic (ChAT::Cre) basal forebrain terminals in the BLA selectively.

(B) The likelihood of licking did not change with photostimulation in the BLA when delivered during Unrewarded windows (paired t-tests for ChR2 and eYFP mice, $p>0.10$, corrected for 4 multiple comparisons across B\&C using Holm's procedure).

(C) The likelihood of licking increased with photostimulation in the BLA when delivered during Rewarded windows for ChR2 mice, but not eYFP mice (paired t-tests for ChR2 mice: $\mathrm{t}=4.58, \mathrm{df}=9,{ }^{* *} \mathrm{p}=0.005$, corrected for 4 multiple comparisons across $\mathrm{B} \& \mathrm{C}$ using Holm's procedure).

(D) Schematic showing concurrent photostimulation of cholinergic terminals in the BLA while measuring local ACh using a genetically-encoded fluorescent sensor, through the same optic fiber. Mice either expressed ChrimsonR or a control fluorophore (tdTomato) in basal forebrain ChAT neurons.

(E) Sample fluorescent traces from ACh sensor (orange) from a mouse with ChrimsonR, in relationship to reward delivery (red), licks (black), behavioral windows (Reward green/Unrewarded purple), and photostimulation (orange). Photostimulation was either delivered in a Photostim-Unreinforced session (during unrewarded windows, left, purple) or Photostim-Reinforced session (during rewarded windows, right, green).

(F) Sample ACh fluorescent traces from ACh sensor (gray) from a mouse with a control fluorophore, displayed similarly to (E), in relationship to rewards, licks, behavioral windows, and photostimulation, delivered either in a Photostim-Unreinforced (left, purple) or PhotostimReinforced session (right, green).

(G) Heat maps comparing average ACh measurements for each mouse around the time of photostimulation on the Photostim-Unreinforced session. Mice are separated based on whether they expressed ChrimsonR (orange, $n=6$ ) or control fluorophore (gray, $n=4$ ). Summary data in the bottom panel are represented as mean \pm SEM. Mice are sorted in all panels based mean DF/F during laser stimulation.

(H) Heat maps comparing average ACh measurements for each mouse during photostimulation in the Photostim-Reinforced session. Conventions are as in (F), and mice are sorted in the same order as in (F).

(I) Mean ACh measurements evoked by photostimulation on the Unreinforced (left) or Reinforced (right) session. Evoked ACh measurements were higher for ChrimsonR mice than control fluorophore mice, but evoked ACh measurements did not depend upon whether photostimulation was provided on Unreinforced or Reinforced sessions (linear mixed effects model: effect of Virus $F_{1,8}=20.21,{ }^{* *} p=0.002$; effect of Session $F_{1,8}=0.47, p=0.51$; interaction between Virus and Session type $\mathrm{F}_{1,8}=0.86, \mathrm{p}=0.38$ ). 
Figure 6 | Cholinergic modulation of neural activity in vivo depends upon reward context in the amygdala, but not in the prefrontal cortex

(A) Strategy for photostimulation of cholinergic basal forebrain neurons and terminal region electrophysiology in the dorsomedial prefrontal cortex (dmPFC) and basolateral amygdala (BLA). Six ChR2 mice had electrodes implanted in both dmPFC and BLA. Five ChR2 mice had electrodes implanted only in the BLA, yielding a total of $11 \mathrm{ChR} 2$ mice with electrodes in BLA. Photostimulation parameters were the same as in ChR2 behavioral experiments (Fig 1). See also Figure S 4 and Figure S 5.

(B) Activity from all recorded neurons in each target area (dmPFC and BLA, total 963 neurons over two sessions per 11 mice), from sessions in which photostimulation was delivered during ITI windows (Photostim-Unreinforced, purple) or sessions in which photostimulation was delivered during reward windows (Photostim-Reinforced, green). Each row represents activity from a single neuron, normalized to baseline (-2 to 0 sec before photostimulation onset), and smoothed with a $50 \mathrm{~ms}$ Gaussian. Neurons are sorted according to mean activity during photostimulation $(0$ to $+2 \mathrm{sec}$ ). Summary population data in the bottom panels are represented as mean \pm SEM. Black marks underneath the population data represent $10 \mathrm{~ms}$ bins when the population activity differed between Photostim-Unreinforced vs. Photostim-Reinforced sessions (rank-sum test, $p<0.01$ ).

(C) Example neural activity from each target area (dmPFC left, BLA right) around photostimulation of basal forebrain cholinergic neurons (0-2 sec), from Photostim-Unreinforced sessions. Top panels are individual trial rasters and black markers indicate the first lick following Photostim onset. Trials are sorted by lick latency. Summary data in the bottom panels are represented as mean \pm SEM, smoothed with a $50 \mathrm{~ms}$ Gaussian kernel. We observed neurons that were facilitated and suppressed relative to baseline in both regions (signed-rank test of activity in the $1 \mathrm{sec}$ before stimulation vs $0.5 \mathrm{sec}$ after, $\mathrm{p}<0.01$ ).

(D) Example neural activity from each target area (dmPFC left, BLA right) around photostimulation of basal forebrain cholinergic neurons (0-2 sec), from Photostim-Reinforced sessions. We again observed neurons that were facilitated and suppressed relative to baseline in both regions. Conventions are the same as in (C).

(E) Proportions of neurons that were facilitated (solid bars) or suppressed (open bars) in each area during Photostim-Unreinforced sessions (purple) or Photostim-Reinforced sessions (green). Denominator n's refer to neurons recorded across all mice during each session type. A higher percentage of BLA neurons were suppressed on Photostim-Reinforced sessions than Photostim-Unreinforced sessions (2-sample tests for equality of proportions: $X_{2}=6.81, d f=1$, ${ }^{*} p=0.036$, corrected for 4 multiple comparisons using Holm's procedure). There was a trend towards a lower percentage of BLA neurons being facilitated on Photostim-Reinforced sessions than Photostim-Unreinforced sessions $\left(X_{2}=4.52, d f=1, \# p=0.10\right)$.

(F) Proportions of neurons that were facilitated (solid bars) or suppressed (open bars) in each area during Photostim-Unreinforced sessions (left, purple) or Photostim-Reinforced sessions (right, green). Data is replotted from (E) to facilitate comparisons between areas for each session type. A higher percentage of BLA neurons than dmPFC neurons were suppressed 
during both Photostim-Unreinforced and Photostim-Reinforced sessions (2-sample tests for equality of proportions: Photostim-Unreinforced: $X_{2}=13.11, \mathrm{df}=1,{ }^{* *} \mathrm{p}<0.001$; PhotostimReinforced: $X_{2}=35.61, \mathrm{df}=1,{ }^{* * *} p<0.001$; all $p$ values corrected for 4 multiple comparisons using Holm's procedure). A lower percentage of BLA neurons than PFC neurons were facilitated during Photostim-Reinforced sessions $\left(X_{2}=9.21, d f=1,{ }^{* *} p=0.005\right)$. 


\section{Figure 7 | Cholinergic afferents suppress basolateral amygdala output through muscarinic receptors and feed-forward inhibition}

(A) Schematic of injection strategy to express ChR2 in cholinergic neurons of the basal forebrain (B) and eYFP in GABAergic neurons of the BLA (BLAGABA), using conditional viral expression in ChAT::Cre x VGAT::Flpo mice (VGAT=vesicular GABAergic transporter), along with CTB-647 as a retrograde marker of neurons projecting to dmPFC.

(B) Confocal image of the BLA showing whole-cell patch-clamp recording arrangement in the BLA with optical stimulation of ChR2-expressing BF terminals.

(C) High magnification images of neurobiotin-filled recorded BLA neurons expressing CTB647 (BLA-mPFC; upper panels) and eYFP (BLAGABA, lower panels).

(D) Passive membrane properties of BLA-mPFC and BLAGABA neurons. BLA-mPFC neurons had significantly greater capacitance (unpaired t-test: $t_{42}=11.90,{ }^{* *} p<0.001, n=20 B L A-m P F C$, $\mathrm{n}=24$ BLAGABA, from 9 mice), smaller membrane resistance (unpaired t-test: $\mathrm{t}_{42}=6.326$, ${ }^{* * *} \mathrm{p}<0.001, \mathrm{n}=20$ BLA-mPFC, $\mathrm{n}=24$ BLAGABA , from 9 mice), and more negative resting membrane potential (unpaired t-test: $\mathrm{t}_{29}=2.857,{ }^{* *} \mathrm{p}=0.0078, \mathrm{n}=13$ BLA-mPFC, $\mathrm{n}=18$ BLAgABA , from 8 mice) than BLAgaba neurons.

(E) Example trace and frequency histogram showing suppression of firing in BLA-mPFC neurons and facilitation of firing of BLAGABA neurons following optical stimulation of cholinergic terminals (470 nm light, $20 \mathrm{~Hz}$; scale bars $=20 \mathrm{mV}, 5 \mathrm{~s}$ ).

(F) Membrane potential of BLA-mPFC (upper traces) and BLAGABA neurons (lower traces) in response to $1 \mathrm{~s} 470 \mathrm{~nm}$ light delivered at 5,10 , and $20 \mathrm{~Hz}$ in current-clamp.

(G) At each stimulation frequency the amplitude of the fast excitatory postsynaptic potential (EPSP) was greater in BLAGABA neurons (green) compared with BLA-mPFC neurons (magenta; 2-way ANOVA, main effect of cell type: $F_{1,40}=102.7,{ }^{* * *} p<0.001 ; n=7,7,15$ BLA-mPFC neurons at $5,10,20 \mathrm{~Hz}, \mathrm{n}=6,5,6 \mathrm{BLA}$ GABA neurons at $5,10,20 \mathrm{~Hz}$, from 9 mice), while the slower inhibitory postsynaptic current (IPSP) was greater in BLA-mPFC neurons (2-way ANOVA, main effect of cell type: $F_{1,40}=47.79,{ }^{* *} p<0.001 ; n=7,7,15$ BLA-mPFC neurons at 5, 10, $20 \mathrm{~Hz}, n=6$, 5, 6 BLAgaba neurons at 5, 10, $20 \mathrm{~Hz}$, from 9 mice).

(H) Response of BLA-mPFC (upper traces) and BLAGABA neurons (lower traces) to a single 5 $\mathrm{ms}$ pulse of $470 \mathrm{~nm}$ light, with application of TTX/4AP to isolate monosynaptic currents.

(I) Following application of TTX/4AP, the EPSP was maintained in BLAGABA neurons (green; unpaired t-test: $\mathrm{t}_{15}=0.367, \mathrm{p}=0.719, \mathrm{n}=8$ (ACSF) and $\mathrm{n}=9$ (TTX/4AP) BLAGABA cells from 4 mice), while the IPSP was maintained in BLA-mPFC neurons (magenta; unpaired t-test: $t_{16}=0.094$, $p=0.926, n=9$ (ACSF) and $n=9$ (TTX/4AP) BLA-mPFC cells from 3 mice).

(J) Example traces showing inhibition of the IPSP in BLA-mPFC neurons (upper panels) by the muscarinic receptor antagonist scopolamine $(10 \mu \mathrm{M})$ (dark gray), but not nicotinic antagonists (dihydro-ß-erythroidine $10 \mu \mathrm{M}$, methyllycaconitine $0.1 \mu \mathrm{M}$, mecamylamine $10 \mu \mathrm{M}$ ) (light gray), and inhibition of the EPSP in BLAGABA neurons (lower panels) by nicotinic receptor antagonists, but not muscarinic. 
bioRxiv preprint doi: https://doi.org/10.1101/2022.02.04.479188; this version posted February 5, 2022. The copyright holder for this preprint (which was not certified by peer review) is the author/funder. All rights reserved. No reuse allowed without permission.

(K) Proposed circuit model showing BF inhibition of BLA output by ACh acting at nicotinic receptors on BLAGABA neurons and muscarinic receptors on $\mathrm{mPFC}$ projection neurons. 


\section{Figure S 1 Training history was similar for optogenetic experimental ChR2 mice and control eYFP mice}

(A) Histological evaluation of basal forebrain tissue. Blue=DAPI nucleic acid staining, Green=cre-dependent expression of ChR2-eYFP, Red=anti-ChAT immunohistochemical staining. Yellow overlap indicates ChAT+ cells expressing ChR2-eYFP.

(B) Validation of ChR2 expression in ChAT::Cre neurons. $88.9 \%$ of ChR2 expressing cells were also immunoreactive for ChAT (442/497 cells, 18 total sections from 3 mice).

(C) After surgery, mice were trained on the Window of Opportunity Task (WoOT) until they attempted to collect rewards on at least $30 \%$ of uncued Reward windows. The number of training sessions were similar for ChR2 and eYFP mice (ChR2: $n=17$ mice, $7.5 \pm 1.2$ sessions; eYFP: $n=11$ mice, $6.9 \pm 1.6$ sessions; mean \pm SEM; rank-sum $p=0.46)$. Pooled data are represented as mean (horizontal lines) \pm SEM (vertical lines).

(D) Following WoOT training, mean licking rates over a session were similar between both groups (ChR2: $1.18 \pm 0.14$ licks/sec; eYFP: $1.30 \pm 0.25$ licks/sec; mean \pm SEM; rank-sum $\mathrm{p}=0.93)$. Pooled data are represented as mean \pm SEM.

(E) Following WoOT training, the number of rewards earned over a session were similar between both groups (ChR2: $292.5 \pm 29.1$ rewards; eYFP: $270.5 \pm 23.8$ rewards; rank-sum $p=0.74)$. Pooled data are represented as mean \pm SEM.

(F) Mice were similarly likely to lick on WoOT Reward windows as on Unrewarded windows, confirming that mice could not predict reward delivery prior to licking (Figure 1C; linear mixed effects model: effect of Virus $p=0.967$, effect of Reward window type $p=0.550$, interaction between Virus*Window $p=0.473$ ). 


\section{Figure S 2 Photostimulation of basal forebrain cholinergic neurons increases arousal, but does not increase unconditioned movement and is not inherently reinforcing}

(A) Optogenetic strategy for photostimulation of basal forebrain cholinergic (ChAT::Cre) neurons. The same photostimulation parameters $(473 \mathrm{~nm}, 4 \mathrm{~mW}, 5 \mathrm{~ms}$ pulses at $20 \mathrm{~Hz}$ ) were used for all ChR2 and eYFP experiments.

(B) Open field test protocol. Mice explored an open chamber for three contiguous windows, during which photostimulation was off for $5 \mathrm{~min}$, then on for $5 \mathrm{~min}$, then off again for the last 5 min. Example tracks are shown for a ChR2 mouse (dark blue, top row) and an eYFP mouse (gray, bottom row).

(C) Basal forebrain cholinergic photostimulation did not increase mouse locomotor movement in an open field (linear mixed effects model: effect of Time $F_{1,15}=19.18,{ }^{* * *} p<0.0001$; effect of Virus $F_{1,7.26}=0.71$, $p=0.43$; effect of Photostim $F_{1,15}=0.20, p=0.66$; interaction between Virus and Photostim $F_{1,15}=0.33, p=0.58$ ).

(D) Photostimulation of cholinergic basal forebrain neurons did not modify innate locomotor preference, as measured by time spent in the center of the open field (linear mixed effects model: effect of Time $F_{1,15}=2.90, p=0.11$; effect of Virus $F_{1,7.39}=0.01, p=0.94$; effect of Photostim $F_{1,15}=1.64, p=0.22$; interaction between Virus and Photostim $F_{1,15}=0.04, p=0.85$ ).

(E) Real-time place preference (RTPP) assay. When mice entered the Laser On zone, photostimulation was activated for the duration of the time spent in the On zone. When mice entered the Laser Off zone, photostimulation was terminated for the duration of time spent in the Off zone.

(F) Neither ChR2 nor eYFP mice preferred the chamber side paired with photostimulation (averaged results of two counterbalanced sessions for each mouse, t-test $\mathrm{ChR} 2 \mathrm{t}_{16}=0.94$, $p=0.36$; eYFP $t_{7}=0.08, p=0.94$ ), suggesting that photostimulation of cholinergic basal forebrain neurons was not inherently reinforcing.

(G) We trained a subset of mice to perform the Window of Opportunity Task (WoOT) while on a treadmill to measure unconditioned, spontaneous locomotion during photostimulation. Heat maps: Mean velocity for each mouse on photostimulation trials in $10 \mathrm{~ms}$ bins. Data are stratified by Virus group and sorted by mean velocity during the Photostim-Unreinforced session. Bottom panels: Pooled data are displayed as mean \pm SEM. There was no significant difference in locomotion around photostimulation between the ChR2 and eYFP groups during either the Photostim-Unreinforced or Photostim-Reinforced sessions (no $10 \mathrm{~ms}$ bins were significantly different between groups on either day, rank-sum $p<0.05$, uncorrected).

(H) Mean velocity on the treadmill during photostimulation (0-2 sec) for PhotostimUnreinforced (left) and Photostim-Reinforced (right) sessions did not differ between groups or by sessions (linear mixed effects model: Virus ${ }^{*}$ Session $F_{1,20}=0.09, p=0.769$; effect of Virus $F_{1,37}=0.02, p=0.887$; effect of Session $F_{1,20}=1.26, p=0.275$ ).

(I) We measured pupil diameter in a subset of mice as an index of arousal. Heat maps: Mean change in pupil diameter across laser trials for each mouse for the PhotostimUnreinforced session (left), and Photostim-Reinforced session (right). Data are normalized to 
baseline pupil diameter -2 to -1 sec before photostimulation, and sorted by mean pupil diameter during the Unreinforced session. Bottom panels: Pooled data are displayed as mean \pm SEM (ChR2: blue, $n=16$; eYFP: gray, $n=10$ ). Black marks underneath pooled data signify frames (33.3 ms bins) during which pupil responses were different between ChR2 and eYFP (rank-sum $p<0.05$, uncorrected).

(J) Mean change in pupil diameter after photostimulation onset (0-4 sec), for PhotostimUnreinforced (left) and Photostim-Reinforced (right) sessions. Mean pupil change depended on Viral Group and Session Type (linear mixed effects model: Virus ${ }^{\star}$ Session $F_{1,24}=4.37$, ${ }^{*} p=0.047$; effect of Virus $F_{1,24}=24.40$, ${ }^{* * *} p<0.001$; effect of Session $F_{1,24}=2.01, p=0.169$ ). ChR2 mice had greater pupil dilation during the Photostim-Reinforced session than during their PhotostimUnreinforced session (post-hoc tests with Sidak correction for multiple comparisons: ${ }^{*} p<0.05$ ). ChR2 mice also had greater pupil dilation than eYFP mice during the Photostim-Reinforced session $\left({ }^{* *} p<0.001\right)$. During the Photostim-Unreinforced session, there was a trend towards a small increase in pupil dilation in ChR2 mice vs eYFP mice $(\# p=0.075)$.

(K) Pupil diameter surrounding reward onset, during Photostim-Unreinforced (left) and Photostim-Reinforced (right) sessions, similar conventions as in (I), sorted in the same order as G. There was no significant difference between ChR2 and eYFP groups for any $10 \mathrm{~ms}$ bin (rank-sum $\mathrm{p}<0.05$, uncorrected).

(L) Mean change in pupil diameter after reward onset (0-4sec), for Photostim-Unreinforced session (left) vs. Photostim-Reinforced sessions (right). Mean pupil change was independent of Viral Group and Session (linear mixed effects model: Virus ${ }^{*}$ Session $F_{1,24}=2.43, p=0.132$; effect of Virus $F_{1,24}=0.01, p=0.942$; effect of Session $F_{1,24}=0.01, p=0.910$ ). Mean pupil change across all mice was greater than 0 (Linear mixed effects model: intercept 2.78\%, t24=7.067, $\left.{ }^{* * *} p<0.001\right)$. 


\section{Figure S 3 Comparison of ACh evoked by reward collection with that evoked by photostimulation}

(A) Schematic showing strategy for concurrent photostimulation of cholinergic terminals in the BLA while measuring local ACh using a genetically-encoded fluorescent sensor, through the same optic fiber. Mice either expressed ChrimsonR or a control fluorophore (tdTomato) in basal forebrain ChAT neurons.

(B) Heat maps comparing average ACh measurements for each mouse around the time of reward delivery (left panel), or with increasing photostimulation. Mice are separated based on whether they expressed ChrimsonR (orange, $n=5$ ) or control fluorophore (gray, $n=4$ ). Summary data in the bottom panel are represented as mean \pm SEM. Mice are sorted in all panels based on the reward related activity in the first panel.

(C) Area Under the Curve (AUC) for \%DF/F elicited by Reward (leftmost point) or increasing pulses of photostimulation $(1,2,10)$, for mice with ChrimsonR (orange) or control fluorophore (gray). Data was analyzed for $0-0.5 \mathrm{sec}$ after the event, consistent with the longest duration of photostimulation. Fluorescence levels depended upon an interaction between photostimulation duration and virus type (linear mixed effects model, $F_{3,21}=10.36, p<0.001$ ). Post-hoc tests compared to rewards showed that fluorescence changes only were greater for 10 pulses $\left(\mathrm{t}_{21}=5.24,{ }^{* *} \mathrm{p}<0.001\right)$, and were most clearly greater in ChrimsonR mice than control fluorophore mice for increasing pulses ( 2 pulses $t_{16.5}=2.98$, $\# p=0.083 ; 10$ pulses $t_{16.5}=5.36$, ${ }^{* * *} p<0.001$; Sidak correction for ten comparisons). Summary data are represented as mean \pm SEM. 


\section{Figure S 4 Effects of laser illumination on neural activity were not seen in control eYFP subjects}

(A) Control strategy for laser illumination of cholinergic basal forebrain neurons expressing non-optogenetic fluorophore (eYFP). Four mice expressing eYFP in basal forebrain cholinergic neurons had electrodes implanted in both dmPFC and BLA. One eYFP mouse had electrodes implanted only in the BLA, yielding a total of five eYFP mice with electrodes in BLA.

(B) Activity from all recorded neurons in each area (total 449 neurons over two sessions per 5 control eYFP mice), from sessions in which laser illumination was delivered during Unrewarded windows (Photostim-Unreinforced, purple) or sessions in which laser illumination was delivered during reward windows (Photostim-Reinforced, green). Each row represents activity from a single neuron, normalized to baseline (-2 to $0 \mathrm{sec}$ before laser illumination onset), and smoothed with a $50 \mathrm{~ms}$ Gaussian. Neurons are sorted according to mean activity during laser illumination $(0$ to $+2 \mathrm{sec})$. Summary population data in the bottom panels are represented as mean \pm SEM. Black marks underneath the population data represent $10 \mathrm{~ms}$ bins when the population activity differed between Photostim-Unreinforced vs. Photostim-Reinforced sessions (rank-sum test, $\mathrm{p}<0.01$ ). Axis and color limits are the same as for ChR2 mice in Figure 4 to enable comparison with experimental mice.

(C) Percents of neurons that were facilitated (solid bars) or suppressed (open bars) in control eYFP mice in each area during Photostim-Unreinforced sessions (purple) or PhotostimReinforced sessions (green). Denominator n's refer to neurons recorded across all mice during each session type. There were no clear differences in percentages of neurons facilitated or suppressed on Rewarded or Unrewarded days (2-sample tests for equality of proportions: $p>0.10$, corrected for 4 multiple comparisons using Holm's procedure). Axis limits are the same as for ChR2 mice in Figure 4 to enable comparison with experimental mice.

(D) Percents of neurons that were facilitated (solid bars) or suppressed (open bars) in control eYFP mice in each area during Photostim-Unreinforced sessions (left, purple) or PhotostimReinforced sessions (right, green). Data is replotted from (C) to facilitate comparisons between areas for each session type. There were no clear differences in percentages of neurons facilitated or suppressed between areas (2-sample tests for equality of proportions: $p>0.10$, corrected for 4 multiple comparisons using Holm's procedure). Axis limits are the same as for ChR2 mice in Figure 4 to enable comparison with experimental mice. 
Figure S 5 Neurons facilitated or suppressed by cholinergic photostimulation may have different baseline firing rates

(A) The baseline firing rates of neurons in ChR2 mice that were either facilitated (solid distributions) or suppressed (open distributions) by photostimulation of cholinergic basal forebrain neurons are plotted by region (dmPFC left, BLA right) and session (PhotostimUnreinforced sessions in purple, Photostim-Reinforced sessions in green). Significant facilitation and suppression were determined based on a sign-rank test comparing activity in the $1 \mathrm{sec}$ before stimulation vs $0-0.5 \mathrm{sec}$ after $(p<0.01)$. Distributions are displayed as kernel density estimates. Given that firing rate distributions were right-skewed, data were log-transformed prior to analysis. Linear models revealed a main effect of Region $\left(F_{1,187}=14.56,{ }^{* * *} p<0.001\right.$; dmPFC neurons had higher baseline firing rates than BLA neurons) and Facilitation vs. Suppression $\left(F_{1,187}=6.11,{ }^{*} p=0.014\right.$; Facilitated neurons had higher baseline firing rates than Suppressed neurons), but no effect of Session or interactions. Exploratory two-sample t-tests revealed that facilitated neurons may have had higher baseline firing rates during the Photostim-Reinforced session in both dmPFC ( $\mathrm{t}_{33}=2.78,{ }^{*} \mathrm{p}=0.036$, corrected for 4 multiple comparisons using Holm's procedure) and the $B L A\left(t_{71}=2.40, \# p=0.057\right.$, corrected). Data from eYFP mice is not shown given how few neurons passed statistical criteria for significant modulation. 


\section{STAR Methods}

\begin{tabular}{|c|c|c|}
\hline REAGENT or RESOURCE & SOURCE & IDENTIFIER \\
\hline \multicolumn{3}{|c|}{ Experimental Models: Organisms/Strains } \\
\hline Mouse: B6N.ChAT-IRES-Cre & Jackson Laboratory & IMSR_JAX_018957 \\
\hline Mouse: C57BL/6NJ & Jackson Laboratory & IMSR_JAX_005304 \\
\hline \multicolumn{3}{|l|}{ Viruses } \\
\hline $\begin{array}{l}\text { AAV5/EF1a-DIO- } \\
\text { hChR2(H134R)-eYFP }\end{array}$ & UNC Vector Core & AV4313X \\
\hline AAV5/EF1a-DIO-eYFP & UNC Vector Core & AV4310G \\
\hline AAVDJ/EF1a-DIO-GCaMP6s & Stanford Vector Core & 2612 \\
\hline $\begin{array}{l}\text { AAV5/Syn-FLEX- } \\
\text { rc[ChrimsonR-tdTomato] }\end{array}$ & Addgene & 62723-AAV5 \\
\hline AAV1/CAG-FLEX-tdTomato & UNC Vector Core & AAV-CAG-FLEX-tdTomato \\
\hline AAV9/hSyn-Ach4.3 (h-A06) & ViGene & h-A06 \\
\hline \multicolumn{3}{|c|}{ Chemicals, Peptides, and Recombinant Proteins } \\
\hline Tetrodotoxin & Tocris & $4368-28-9$ \\
\hline 4-Aminopyridine & Sigma Aldrich & $504-24-5$ \\
\hline Scopolamine & Sigma Aldrich & S0929-1G \\
\hline Mecamylamine hydrochloride & Sigma Aldrich & M9020-5MG \\
\hline Methyllycaconitine citrate salt & Sigma Aldrich & M168-5MG \\
\hline Dihydro-ß-erythroidine & Tocris & 2349 \\
\hline $\begin{array}{l}\text { VECTASHIELD HardSet } \\
\text { Antifade Mounting Medium } \\
\text { with DAPI }\end{array}$ & VectorLabs & $\mathrm{H}-1500$ \\
\hline $\begin{array}{l}\text { Donkey Anti-Goat IgG } \\
\text { Antibody (DyLight 405) }\end{array}$ & $\begin{array}{l}\text { Jackson } \\
\text { ImmunoResearch }\end{array}$ & 705-475-147 \\
\hline $\begin{array}{l}\text { Donkey Anti-Chicken IgY } \\
\text { Antibody (Alexa Fluor 647) }\end{array}$ & $\begin{array}{l}\text { Jackson } \\
\text { ImmunoResearch }\end{array}$ & 703-605-155 \\
\hline
\end{tabular}




\begin{tabular}{|c|c|c|}
\hline $\begin{array}{l}\text { AB144 Anti-Choline } \\
\text { Acetyltransferase Antibody }\end{array}$ & EMD Millipore & AB144P-1ML \\
\hline Buprenorphine hydrochloride & MIT Veterinary Pharmacy & NDC 12496-0757-5 \\
\hline $\begin{array}{l}\text { C\&B Metabond Quick } \\
\text { Adhesive Cement System }\end{array}$ & Parkell & S380 \\
\hline Ortho-Jet BCA Liquid & Lang & B1303 \\
\hline \multicolumn{3}{|l|}{ Software and Algorithms } \\
\hline MATLAB & Mathworks & https://www.mathworks.com/ \\
\hline $\mathrm{R}$ & $\begin{array}{l}\text { R Foundation for } \\
\text { Statistical Computing }\end{array}$ & http://www.R-project.org/ \\
\hline Adobe Illustrator & Adobe & $\begin{array}{l}\text { https://www.adobe.com/products/illustr } \\
\text { ator.html }\end{array}$ \\
\hline Offline Sorter & Plexon & $\begin{array}{l}\text { https://plexon.com/products/offline- } \\
\text { sorter/ }\end{array}$ \\
\hline Ethovision XT & Noldus & https://www.noldus.com/ethovision-xt \\
\hline pClamp 10.4 software & Molecular Devices, & $\begin{array}{l}\text { https://www.moleculardevices.com/pro } \\
\text { ducts/axon-patch-clamp- } \\
\text { system/acquisition-and-analysis- } \\
\text { software/pclamp-software-suite }\end{array}$ \\
\hline \multicolumn{3}{|l|}{ Other } \\
\hline Optic fiber & Thor Labs & TS1843490 \\
\hline Ferrules & Kientec Systems & FSS-LC-330 \\
\hline $\begin{array}{l}\text { Small animal stereotaxic } \\
\text { frame }\end{array}$ & David Kopf Instruments & Model 942 \\
\hline USB cameras & ELP & ELP-USBFHD01M-RL36 \\
\hline $0.10 \mathrm{~mL}$ Microsyringe & $\begin{array}{l}\text { World Precision } \\
\text { Instruments }\end{array}$ & NANOFIL-NF33BL-2 \\
\hline $\begin{array}{l}\text { Microsyringe Pump UMP3 and } \\
\text { Controller Micro4 }\end{array}$ & $\begin{array}{l}\text { World Precision } \\
\text { Instruments }\end{array}$ & UMP3-3 \\
\hline $\begin{array}{l}\text { Peristaltic pump for ex vivo } \\
\text { recordings }\end{array}$ & Minipuls 3 Gilson & F155001 \\
\hline $\begin{array}{l}\text { Miniature Inert Liquid Solenoid } \\
\text { Valve }\end{array}$ & Parker Hannifin & 003-0218-900 \\
\hline
\end{tabular}




\begin{tabular}{|c|c|c|}
\hline ATmega328 Arduino & Digi-Key Electronics & 1050-1001-ND \\
\hline Speaker & Digi-Key Electronics & GF0401M-ND \\
\hline Laser Shutter Heads & $\begin{array}{l}\text { Stanford Research } \\
\text { Systems }\end{array}$ & SR475 \\
\hline Rotary Encoder & US Digital & E2-200-250-NE-D-D-B \\
\hline Multifunction I/O Device & National Instruments & USB-6211 \\
\hline Pulse stimulator & A.M.P.I. & Master-8 \\
\hline 5mm White LED & Digi-Key Electronics & C513A-WSN-CY0Z0341-ND \\
\hline $\begin{array}{l}\text { Electrodes: } 22.9-\mu \mathrm{m} \text { nichrome } \\
\text { wire }\end{array}$ & California Fine Wire & Stablohm 675 \\
\hline Gold Non-Cyanide & Sifco asc & 80535500 \\
\hline Open Ephys Acquisition Board & Open Ephys & C3324 \\
\hline HM430 Microtome & Thermo Fisher Scientific & 910010 \\
\hline $\begin{array}{l}\text { Confocal Laser-Scanning } \\
\text { microscope }\end{array}$ & Olympus & FV1000 \\
\hline Diode Blue 473 nm Laser & OptoEngine LLC & MBL-III-473/ 1 100mW \\
\hline $\begin{array}{l}\text { Horizontal puller for glass } \\
\text { microelectrodes for ex vivo } \\
\text { recordings }\end{array}$ & Sutter & P-1000 \\
\hline $\begin{array}{l}\text { Multiclamp amplifier for ex vivo } \\
\text { recordings }\end{array}$ & Molecular Devices & $700 \mathrm{~B}$ \\
\hline $\begin{array}{l}\text { Microscope for ex vivo } \\
\text { recordings }\end{array}$ & Olympus & $\mathrm{B} \times 51$ \\
\hline
\end{tabular}

\section{Subjects}

Female and male hemizygous ChAT::Cre mice (Chen et al., 2018; Rossi et al., 2011) were group housed by sex until surgery on a reversed 12-hour light-dark cycle in a humidity and temperature controlled vivarium. All behavioral experiments were conducted during the dark phase of the animals' cycle. All experiments involving the use of animals were in accordance with National Institutes of Health guidelines and approved by the Massachusetts Institute of Technology's Committee on Animal Care. 


\section{General Stereotaxic Surgery Methods}

General surgical methods are provided here and specific subject/surgery details for each experiment are detailed in their respective sections below. Surgeries were performed prior to behavioral training and all other experiments. For all mice, surgeries were performed under aseptic conditions and body temperature was maintained with a heating pad. Mice were anesthetized with isoflurane in oxygen ( $4 \%$ for induction, $1-2 \%$ for maintenance, $0.8 \mathrm{~L} / \mathrm{min}$ oxygen flow rate). Following induction, we shaved the scalp and placed the subjects on a digital small animal stereotaxic instrument (David Kopf Instruments). Ophthalmic ointment was applied to the eyes and the incision area was scrubbed three times with alternating betadine and $70 \%$ ethanol. An incision was made along the midline to expose the skull, which was then leveled. All measurements for virus injections and implants were made relative to Bregma using the approximated intersection of skull sutures. A dental drill was used to perform small craniotomies (EXL-M40, Osada).

Viral injections were performed using a beveled 33-gauge microinjection needle connected to a $10 \mu \mathrm{L}$ microsyringe (Nanofil; WPI, Sarasota, FL, USA) at a rate of $100 \mathrm{~nL} / \mathrm{min}$ using a microsyringe pump (UMP3; WPI) and pump controller (Micro4; WPI). After injections were complete, ten minutes were allowed to pass before the needle was slowly withdrawn. Optic fibers and/or electrodes were then implanted. For head-fixation, a $2 \mathrm{~mm} \times 2 \mathrm{~mm} \times 25 \mathrm{~mm}$ aluminum headbar was placed horizontally over Lambda. A layer of adhesive cement (C\&B Metabond; Parkell Inc., NY, USA) was used to secure the implants and headbar to the skull, followed by a black cranioplastic cement (Ortho-Jet; Lang, IL, USA) to prevent light escape. The cement was allowed to dry completely before closure of the incision with 4.0 nylon sutures.

Subjects received a perioperative subcutaneous injection of sustained release buprenorphine (1 $\mathrm{mg} / \mathrm{kg}$ ) for analgesia. During recovery, subjects were also injected subcutaneously with $1 \mathrm{ml}$ of warm Lactated Ringers solution and kept on a heat pad until fully recovered from anesthesia. For all experiments involving viral or tracer injections, animals containing mistargeted injections were excluded after histological verification.

\section{Stereotaxic Surgery for Optogenetic Photostimulation of Basal Forebrain Cholinergic Neurons}

For optogenetic photostimulation of basal forebrain cholinergic neurons, $500 \mathrm{~nL}$ of an adenoassociated virus encoding either channelrhodopsin (AAV5/EF1a-DIO-hChR2(H134R)-eYFP; UNC, $5.5 \times 1012$ ) or a control fluorophore (AAV5/EF1a-DIO-eYFP; UNC, $4.4 \times 1012$ ) were injected bilaterally into basal forebrain of each hemisphere at AP $-0.4, \mathrm{ML} \pm 1.8$, DV -4.7 . For photostimulation of cholinergic neurons at their basal forebrain soma, optic fibers $(300 \mu \mathrm{m}$ diameter) were implanted bilaterally into the basal forebrain at AP $-0.4, M L \pm 1.8, D V-4.3$. For photostimulation of cholinergic neuron axon terminals in the BLA, optic fibers $(300 \mu \mathrm{m}$ diameter) were implanted unilaterally above the BLA at AP -1.4, ML \pm 3.1 , DV -4.6.

\section{Head-fixed Behavioral and Optogenetic Equipment}

Head-fixed boxes were custom built using various optomechanical components (ThorLabs) and 3D printed parts mounted on top of a solid aluminum optical breadboard (SAB0810, Base Optics) housed within a 19 quart drybox (UC19-YHV, Engel Coolers). Mice were head-fixed on either a 3D printed rectangular platform or a custom 3D printed linear-belt treadmill, in front of a blunt 18G needle spout (75165A754, McMaster Carr). For electrophysiology experiments, licks 
were registered using an infra-red beam passing in front of the spout tip (emitter $935 \mathrm{~nm}$, OP165A, TT Electronics/Optek Technology; phototransistor SFH 309 FA-4/5, OSRAM Opto Semiconductors). For other experiments, licks were registered using a capacitive contact circuit (MPR121, Adafruit) that was interpreted by a microcontroller (Arduino Uno SMD R3 ATMEGA328, Arduino). A white LED module (1621, Adafruit) provided a low level of ambient light.

\section{Behavioral System Control}

All behavior for each box was controlled by a microcontroller (Arduino Mega 2560 Rev3, Arduino), which ran customized behavioral code to register licks, deliver fluid, present tones, and trigger photostimulation. Fluid rewards consisted of $4 \mu \mathrm{L}$ of a sweet caloric fluid (Vanilla Ensure Original Shake, Abbott). Fluid delivery was controlled by opening a solenoid valve (0030860-900, Parker, NH, USA) and delivered to the spout by gravity flow via plastic acrylic tubing (McMaster-Carr, IL, USA). All valves were calibrated using timing duration to ensure consistent fluid volumes.

\section{Head-fixed Behavioral Training}

After at least 3 weeks of recovery from surgery, animals were food restricted and maintained on at least $85 \%$ body weight. Animals had free access to water. After stable food restriction, training was initiated. On each day, mice received enough food supplementation using standard lab chow to maintain their body weight between $85-90 \%$ of their free body weight (typically $2.5-$ $5 g)$.

\section{Handling}

Mice were first handled for 5 min a day for 5 days to reduce stress and increase familiarity with the experimenter. During this time they also were given fluid rewards via a hand held plastic pipette.

\section{Uncued Head-fixed Training}

For uncued head-fixed training, mice were head-fixed in the behavioral box and a lickspout was placed close to the mouth. The animal received a few drops of fluid reward, to initiate licking. Once the mouse started licking, the spout was retracted away slightly to a distance still reachable by licking.

Sessions were divided into trials of $3 \mathrm{sec}$ windows with intervening unrewarded intertrial intervals (ITIs). During early training, $90 \%$ of the $3 \mathrm{sec}$ windows were designated as Reward windows. If mice licked during the Reward windows, they received a $4 \mu$ fluid reward after a brief delay $(0.1 \mathrm{sec})$. Since rewarded windows were not cued, mice did not know when they initiated a lick whether it would be rewarded, making the rewards unpredictable. Only the first lick within an window resulted in reward delivery. The ITIs between reward windows were randomly selected from an exponential distribution between 3-6 sec (mean $4 \mathrm{sec}$ ). The remaining $10 \%$ of $3 \mathrm{sec}$ windows were designated as matched unrewarded windows. If mice licked during this time, no reward was delivered, similar to the rest of the unrewarded ITIs.

The first session was 30 min long and subsequent sessions were $1 \mathrm{hr}$ long. Mice were trained daily until they attempted to collect rewards on at least $30 \%$ of uncued reward windows, in order to avoid ceiling and floor effects of subsequent manipulations. The likelihood of licking was 
defined as percent of 3 sec windows, for either Rewarded or Unrewarded windows, in which mice licked at least once. Mice underwent approximately 7 days of uncued head-fixed training to reach criterion. Single measurements were compared between ChR2 and eYFP mice using rank-sum tests in $\mathrm{R}$ ( $\mathrm{R}$ Core Team, 2015). Repeated measurements from the same mice were analyzed using linear mixed effects models fit by restricted maximum likelihood using the Ime4 package (Bates et al., 2015). Fixed effects included virus group (ChR2 vs. eYFP) and window type (Rewarded vs. Unrewarded), as well as their interaction. Random effects were modeled using random intercepts for each subject. $P$ values were obtained using the ImerTest package (Kuznetsova et al., 2017).

\section{Optogenetic Photostimulation of Basal Forebrain Cholinergic Neurons during Head-Fixed Behavior}

Following initial uncued head-fixed training, ChR2 and eYFP mice were tested to examine whether photostimulation of basal forebrain cholinergic neurons affected licking, the conditioned response. For optogenetic photostimulation, a $473 \mathrm{~nm}$ diode laser (MBL-III-473/1 100mW, OptoEngine LLC) was used as a light source. Photostimulation was delivered at $4 \mathrm{~mW}$ (measured at the fiber tip), using $5 \mathrm{~ms}$ pulses delivered at $20 \mathrm{~Hz}$. Lasers were continuously on to minimize power fluctuations, but photostimulation was gated at the source prior to entering a collimator (HPUC-23AF-473-S-11AS-LBH-BL-SP, OZ Optics) through a laser shutter head (SR475, Stanford Research Systems), controlled by a four-channel laser shutter driver (SR474, Stanford Research Systems). Laser light was then routed from the collimator through patch cords (Doric, Québec, Canada) and split for bilateral photostimulation using a rotary joint (1x2 Fiber-optic Rotary Joints - Intensity Division; Doric, Québec, Canada), with a subsequent patch cord terminating on the implanted ferrule. All connections including that to the implanted ferrule were optically shielded to prevent light leakage.

\section{Photostim-Unreinforced Sessions}

To assess innate behavioral responses to photostimulation of basal forebrain cholinergic neurons, mice underwent one session in which they received photostimulation of cholinergic basal forebrain neurons during unrewarded ITIs (Photostim-Unreinforced sessions). On a subset of ITIs, approximately once a minute, photostimulation was delivered for $2 \mathrm{sec}$, and the likelihood and latency of licking was recorded in the $3 \mathrm{sec}$ following photostimulation onset to assess effects on conditioned responding.

During this session, if mice licked during unsignaled reward windows, which did not have photostimulation, they continued to receive rewards. ITIs between reward windows were randomly selected from an exponential distribution between 4.5-10 sec (mean $5 \mathrm{sec}$ ). Licking during ITIs had no consequence, which included photostimulation during these sessions. Photostimulation was delivered at least $3.5 \mathrm{sec}$ away from either the beginning or end of a reward window.

\section{Photostim-Reinforced Sessions}

During Photostim-Reinforced sessions, 2 sec of photostimulation was now delivered starting at the onset of the $3 \mathrm{sec}$ reward windows. Photostimulation was delivered only on a subset of reward windows (15\%). Approximately one photostimulation trial was delivered per minute, thereby making up the minority of total session time and a minority of reward windows. Licking 
during reward windows yielded a fluid reward, whether the mouse received photostimulation or not.

Mice ran on two Photostim-Reinforced sessions, and behavior was analyzed from the second session. We analyzed data using linear mixed effects models, given the repeated measures from mice. Fixed effects included Virus (ChR2 vs. eYFP), Photostimulation trial types (Photostim vs. No photostim), and Reinforcement Session type (Photostim-Reinforced vs. Photostim-Unreinforced), as well as first and second order interactions. Random effects were modeled using random intercepts for each subject. Post-hoc tests for all linear mixed effects models were performed using the emmeans package (Lenth, 2020), with the Kenward-Roger method for degrees-of-freedom, and the Sidak method for $p$ value adjustment for multiple comparisons.

During a subsequent session, we varied photostimulation parameters to assess how little or brief the stimulation needed to be to produce conditioned responding. We randomly delivered photostimulation on reward windows using either 1, 2, or 10 pulses of light at $20 \mathrm{~Hz}$, corresponding to up to $0.5 \mathrm{sec}$ of photostimulation. These continued to be delivered at the onset of $3 \mathrm{sec}$ reward windows. Fixed effects for linear mixed effects model analysis included Virus (ChR2 vs. eYFP), photostimulation pulses $(0,1,2,10)$, and their interaction. Random effects were modeled using random intercepts for each subject. Post-hoc tests corrected for multiple comparisons included comparisons between ChR2 and eYFP at each number of pulses, and comparisons within each virus group for 1,2 , or 10 pulses to 0 pulses.

\section{Treadmill}

To assess the effects of basal forebrain photostimulation on locomotion, we collected locomotion data from a custom-made linear belt treadmill in the head-fix setup. Locomotion data was collected using a rotary encoder (US Digital E2-200-250-NE-D-D-B), digitized using a NIUSB-6211 at $1 \mathrm{kHz}$ and analyzed using MATLAB. There was no behavioral consequence of running. Behavioral event timings, including trial onset, photostimulation, licking, and reward delivery, were synchronized by sending TTLs from the Arduino microcontroller into an R-2R resistor ladder to multiplex the events into a single analog input channel on the NI-USB-6211.

Treadmill locomotion was analyzed around photostimulation, starting 2 sec before photostimulation onset until $4 \mathrm{sec}$ after. Photostimulation duration was $2 \mathrm{sec}$. Data was binned in $0.1 \mathrm{sec}$ bins for peri-event time histograms. Each bin was compared between ChR2 and eYFP mice for each session type (Photostim-Unreinforced or Photostim-Reinforced). Statistical significance of each bin was tested between groups using rank-sum tests, $p<0.01$. To compare photostimulation evoked locomotion between sessions for the same mice and between groups, we used linear mixed effects models to analyze the mean locomotion during photostimulation ( 0 - $2 \mathrm{sec}$ ). Fixed effects included Virus (ChR2 vs. eYFP), Reinforcement Session type (PhotostimReinforced vs. Photostim-Unreinforced), as well as their interaction. Random effects were modeled using random intercepts for each subject.

\section{Pupillometry}

In order to assess changes in arousal, we recorded pupil diameter during behavioral sessions. An infrared USB camera (ELP-USBFHD01M-RL36, ELP) was placed $15 \mathrm{~cm}$ from the mouse's eye. The infrared LED/emitter panel was unscrewed and pointed away from the mouse to 
decrease eye secretions. Ambient light was adjusted to keep the pupil size at an intermediate level, which allowed the pupil to fluctuate over a dynamic range. Recordings were started and stopped at the same time as behavior using Processing 2.2.1 running on a Windows desktop computer (Hewlett-Packard), which also initiated the Arduino microcontroller running behavior. Files were saved at $30 \mathrm{~Hz}$ as $640 \times 480$ pixel ogg vorbis video files. Behavioral event timings were identified for subsequent synchronization using $940 \mathrm{~nm}$ infrared LEDs (IR204, Everlight Electronics, Digi-Key) to signal behavioral events, including trial onset, photostimulation, licking, and reward delivery.

For pupil and body part tracking we used DeepLabCut (version 2.0.8) (Mathis et al., 2018; Nath et al., 2019). We labeled eight points for the right pupil of each mouse, according to cardinal and intercardinal compass directions (North, NorthEast, East, SouthEast, South, SouthWest, West, and NorthWest). Specifically, we labeled 483 frames taken from 25 videos from 21 animals, then $95 \%$ were used for training. We used a ResNet-50 based neural network with default parameters for 1.03 million training iterations (He et al., 2016; Insafutdinov et al., 2016). We validated with a single shuffle and found the test error was: 1.08 pixels, train: 1.93 pixels. We then used a p-cutoff of 0.9 to condition the $X, Y$ coordinates for future analysis. This network was then used to analyze videos from similar experimental settings. Relative pupil diameters were determined by calculating the distance for each major axis (North-South, East-West, NorthWestSouthEast, NorthEast-SouthWest), and then taking the mean of these four measurements.

Pupil diameter was normalized to the diameter prior to photostimulation ( -2 to $-1 \mathrm{sec}$ relative to photostimulation onset), and the pupil diameter from each frame for each trial was expressed as the percent difference from baseline. Relative pupil diameter changes at each frame were compared between ChR2 and eYFP mice using rank-sum testing $(p<0.05)$.

To compare photostimulation evoked pupil diameter changes between sessions for the same mice and between groups, we used linear mixed effects models to analyze the mean pupil diameter following events onsets $(0-4 \mathrm{sec})$, separately for photostimulation and for reward delivery. Fixed effects included Virus (ChR2 vs. eYFP), Reinforcement Session type (PhotostimReinforced vs. Photostim-Unreinforced), as well as their interaction. Random effects were modeled using random intercepts for each subject. Post-hoc tests corrected for multiple comparisons included four comparisons between ChR2 and eYFP for each session, and between sessions for each viral group.

\section{Cued Tone Task}

In a separate set of sessions, mice were trained to respond to $3.5 \mathrm{kHZ}$ or $12 \mathrm{kHz}$ tones (frequencies counter balanced between mice). Tones were generated using the tone function on the Arduino Mega, passed through analog low and high pass filters, and presented using an 8 ohm speaker (GF0401M, CUI Devices) at 55-60 dBA. Tones were presented for 2 sec and mice were rewarded for licking during the $3 \mathrm{sec}$ response window. These $1 \mathrm{hr}$ sessions included only tone trials to signal rewards opportunities-there were no longer any unsignaled reward windows.

\section{Interleaved Tone or Photostim-Reinforced Trials Session}

After three days of training on the cued tone task, mice were tested on a session which included interleaved tone or Photostim-Reinforced windows. $2 \mathrm{sec}$ of either tone or photostimulation were 
presented, and mice could receive a reward if they licked within $3 \mathrm{sec}$ of the onsets. Only $90 \%$ of lick responses on each trial type were rewarded. Tone and photostimulation trials were equally likely, and were separated by ITIs with a mean of $12 \mathrm{sec}$ (range 7-22 sec, exponential distribution). Baseline/ITI licking was assessed by a priori statistically identifying $3 \mathrm{sec}$ windows between tone and photostimulation trials, with similar ITIs.

\section{In vivo Cholinergic Antagonist Pharmacology}

In order to test which class of receptors mediated the effects of photostimulation of cholinergic basal forebrain neurons, mice were injected with cholinergic receptor antagonists prior to an Interleaved Tone or Photostim-Reinforced Trials Session. Using a 27 gauge needle, we injected mice with either the muscarinic receptor antagonist scopolamine $(0.3$ or $1 \mathrm{mg} / \mathrm{kg})$ (Chintoh et al., 2003) or the nicotinic receptor antagonist mecamylamine $(1 \mathrm{mg} / \mathrm{kg}$ ) (Adermark et al., 2014; Zachariou et al., 2001). Injections were made 10 minutes before behavioral sessions. All drugs were dissolved in sterile saline and injected at $10 \mathrm{ml} / \mathrm{kg}$ volumes. Sterile saline alone was used for control injections. Drug injection orders were counterbalanced across animals.

We analyzed data using linear mixed effects models, given the repeated measures from mice. Fixed effects included Virus (ChR2 vs. eYFP), Trial types (Tone, Photostim, or ITI), and Drug session type (Saline, Scopolamine $0.3 \mathrm{mg} / \mathrm{kg}$, Scopolamine $1 \mathrm{mg} / \mathrm{kg}$, Mecamylamine $1 \mathrm{mg} / \mathrm{kg}$ ), as well as first and second order interactions. Random effects were modeled using random intercepts for each subject. Post-hoc tests corrected for multiple comparisons were stratified by sessions, and included comparisons between ChR2 and eYFP for each trial type, and comparisons within each virus group for all three pairs of trials types.

\section{Open Field Test}

To assess whether BF cholinergic stimulation had an effect on locomotion, animals underwent an open field test (Matthews et al., 2016). We attached fiber optic patch cables to the implanted ferrules on mice. Mice were then placed in the center of an open $50 \times 53 \mathrm{~cm}$ arena composed of four transparent Plexiglas walls illuminated by 30 lux ambient light. They were allowed to freely move throughout the arena for $15 \mathrm{~min}$. A video camera was positioned directly above the arena to track the movement of each mouse throughout the session (EthoVision XT, Noldus, Wageningen, Netherlands).

The session was divided into three $5 \mathrm{~min}$ windows with photostimulation occurring throughout the middle $5 \mathrm{~min}$ window ( $473 \mathrm{~nm}$ light, $4 \mathrm{~mW}, 5 \mathrm{~ms}$ pulses at $20 \mathrm{~Hz}$. The same laser and shutter setup described above was used except that a Master-8 pulse stimulator (A.M.P.I., Jerusalem, Israel) interfaced with the EthoVision XT system was used to drive laser pulses. Acetic acid $(0.03 \%)$ was used to wipe and clean the chamber between animals.

We analyzed data using linear mixed effects models. Fixed effects included Virus (ChR2 vs. eYFP), Laser status (On or Off), and Time by $5 \mathrm{~min}$ window, as well as the interaction between virus and laser status. Random effects were modeled using random intercepts for each subject.

\section{Real Time Place Preference}

To assess whether cholinergic stimulation was inherently reinforcing or pleasurable to the animals, mice underwent a Real Time Place Preference test (RTTP) (Matthews et al., 2016). We attached fiber optic patch cables to the implanted ferrules on mice. Mice were then placed in 
the center of a transparent Plexiglas chamber $(50 \times 53 \mathrm{~cm})$ divided into left and right compartments using center dividers, with an open gap in the middle allowing mice to freely access both compartments. The chamber was illuminated with 30 lux ambient light. Mice were allowed to freely move between compartments for 45 minutes during which entry into one of the two sides resulted in continuous photostimulation ( $473 \mathrm{~nm}$ light, $4 \mathrm{~mW}, 5 \mathrm{~ms}$ pulses at $20 \mathrm{~Hz}$ ). The side paired with photostimulation was counterbalanced between animals and activity was averaged across two days. A video camera was placed directly above the arena to track mouse movement (EthoVision XT) and trigger photostimulation. Acetic acid $(0.03 \%)$ was used to wipe and clean the chamber between animals. The percent of time mice spent on the side on which the laser was On was averaged over two days, and compared between ChR2 and eYFP mice using a t-test.

\section{GCaMP Photometry of Basal Forebrain Cholinergic Neurons}

\section{Stereotaxic Surgery for GCaMP Photometry from Basal Forebrain Cholinergic Neurons}

To measure neural activity from basal forebrain cholinergic neurons, we injected $1000 \mathrm{~nL}$ of an adeno-associated virus encoding the genetically-encoded calcium sensor GCaMP (AAVdj/EF1a-DIO-GCaMP6s; Stanford Vector Core) into the basal forebrain of ChAT::Cre mice (AP -0.7; ML \pm 1.75 ; DV -5.1 and -4.3, $500 \mathrm{~nL}$ at each depth). An optic fiber was implanted over the basal forebrain (AP -0.7; ML 1.75; DV -4.5).

\section{GCaMP Photometry Set-Up}

The hardware setup for acquisition of bulk calcium fluorescence from multiple sites was adapted from (Kim et al., 2016). The setup allowed for excitation of the sample at two wavelengths (405 and $470 \mathrm{~nm}$ ) and collection of fluorescence emission at $525 \mathrm{~nm}$. The excitation path consisted of a $405 \mathrm{~nm}$ and a $470 \mathrm{~nm}$ LED (Thorlabs M405FP1 and M470F3) which were collimated (Thorlabs F671SMA-405) and coupled to $400 \mathrm{~nm}$ and $469 \mathrm{~nm}$ excitation filters (Thorlabs FB40010 and MF469-35), respectively. Compared to $470 \mathrm{~nm}$ excitation, $405 \mathrm{~nm}$ excitation of GCaMP is closer to the isobestic wavelength for calcium-dependent and calcium-independent GCaMP fluorescence, and thus was used to assess movement- and autofluorescence-related noise. Light from these two excitations sources were combined into one path via dichroic mirrors, and filled the back aperture of a 20x air objective (Nikon CFI Plan Apo Lambda). A fiber optic patch cord (Doric) containing optic fibers bundled into a single ferrule (400 $\mu \mathrm{M}$ diameter, $0.48 \mathrm{NA}$ for each fiber) was positioned at the working distance of the objective. The end of the patch cable was connected to implanted ferrules on the animals' head. Emission resulting from the 405 or $470 \mathrm{~nm}$ excitation was split by a dichroic mirror, passed through a $525 \mathrm{~nm}$ emission filter (Thorlabs MF525- 39), and focused through a tube lens (Thorlabs AC254-100-A-ML) onto the face of CMOS camera (Hamamatsu ORCA-Flash V2). Frames were captured at $40 \mathrm{~Hz}$ and each LED was modulated at $20 \mathrm{~Hz}$ in an alternating fashion, resulting in a $20 \mathrm{~Hz}$ sample rate in the reference ( $405 \mathrm{~nm}$ excitation) and signal (470 $\mathrm{nm}$ excitation) channels. LED and camera timing as well as recording of timestamps from behavioral equipment was achieved using a data acquisition board (National Instruments NI BNC-2110). The system was controlled through custom MATLAB scripts modified from those made available by (Kim et al., 2016). Prior to the start of each session, the entire system was shielded from outside light using blackout cloth. 


\section{Behavior during GCaMP Photometry}

To investigate whether basal forebrain cholinergic neural activity increased during conditioning responding, mice first underwent uncued head-fixed training. Mice were rewarded for licking during unsignaled $3 \mathrm{sec}$ reward windows. Rewards were delivered after a $0.5 \mathrm{sec}$ delay from the first lick in a reward window to account for the slow dynamics of GCaMP6s. Mice were not punished for licking during the unrewarded ITIs.

Following recordings during the uncued stage of training, mice were then transitioned to the Cued Tone task described above. Mice were now rewarded for licking following the onset of tone cues, and rewards were delivered after a $0.5 \mathrm{sec}$ delay from the first lick within 3 sec of tone onset.

\section{Photometry Analysis}

Photometry fluorescence traces were filtered using a $60 \mathrm{sec}$ median filter to extract an estimate of baseline fluorescence by accounting for bleaching and low frequency fluctuations. The residual trace was filtered with a 3 rd order median filter to eliminate single time point artifacts. DF/F was obtained by taking the difference between the residual trace and the baseline estimate and dividing by the baseline estimate, which was then expressed in percent. Fluorescence levels were compared as the area under the curve in a time window before (-2 to $1.5 \mathrm{sec}$ ) and after ( 0 to $0.5 \mathrm{sec}$ ) events. Fixed effects for linear mixed effects model analysis included Wavelength (470 nm signal vs. $405 \mathrm{~nm}$ reference), Time point (before or after event), and Event type, and first and second order interactions. Random effects were modeled using random intercepts for each subject. Post-hoc tests corrected for multiple comparisons within each session.

\section{ACh Sensor Measurements}

\section{Stereotaxic Surgery for ACh Sensor Measurements}

To measure local levels of ACh, we injected $400 \mathrm{~nL}$ of an adeno-associated virus encoding the genetically-encoded ACh sensor GACh3.0 (AAV9/hSyn-Ach4.3, ViGene) (Jing et al., 2018) into the BLA (AP -1.4; $\mathrm{ML} \pm 3.1$; DV -5.2). In order to photostimulate basal forebrain cholinergic terminals projecting to the BLA, an anterograde virus driving expression of the red-shifted opsin ChrimsonR (AAV5/Syn-FLEX-rc[ChrimsonR-tdTomato]) was injected into the basal forebrain (500 nL, AP -0.4; $\mathrm{ML} \pm 1.8$; DV -4.7). For control mice, a virus encoding just the fluorophore (AAV1/CAG-FLEX-tdTomato), was injected with the same volume at the same coordinates. An optic fiber (400um diameter) was then implanted over the BLA (AP -1.4; ML \pm 3.25 ; DV -4.8), in order to provide optical access to both record GACh3.0 related fluorescence using $470 \mathrm{~nm}$ blue light as well as photostimulate basal cholinergic forebrain cholinergic terminals in the BLA using interleaved $589 \mathrm{~nm}$ yellow light. Data was analyzed similar to the GCaMP photometry experiments, except that there was only fluorescence data from one channel $(470 \mathrm{~nm})$.

\section{Behavior during ACh Sensor Measurements}

To investigate whether local ACh levels changed in the BLA during conditioning responding, mice first underwent uncued head-fixed training. Mice were rewarded for licking during unsignaled $3 \mathrm{sec}$ reward windows. Rewards were delivered after a brief $(0.1 \mathrm{sec})$ delay from the first lick in a reward window. Mice were not punished for licking during the unrewarded ITIs. 
Similar to optogenetic experiments, mice were then tested during a Photostim-Unreinforced session and two Photostim-Reinforced sessions. Results are presented from the second Photostim-Reinforced session. During a subsequent session, we again varied photostimulation parameters by randomly delivering photostimulation on reward windows using either one, two, or ten $5 \mathrm{~ms}$ pulses at $20 \mathrm{~Hz}$, corresponding to up to $0.5 \mathrm{sec}$ of photostimulation. These pulse trains were also delivered at the onset of $3 \mathrm{sec}$ reward windows.

Mice were then trained for three sessions on the Cued Tone task described above. Mice were rewarded for licking following the onset of tone cues, and rewards were delivered after a brief $(0.1 \mathrm{sec})$ delay from the first lick within $3 \mathrm{sec}$ from tone onset.

\section{Concurrent Optogenetic Photostimulation and Measurement of Local ACh Levels using a Genetically-encoded Fluorescent Sensor}

The hardware setup for acquisition of bulk ACh fluorescence from multiple sites was similar to that for GCaMP photometry. For concurrent optogenetic manipulation experiments, the system was modified to allow for $589 \mathrm{~nm}$ yellow light excitation through the same patch cable. An additional dichroic mirror combined the LED light paths with that of a $589 \mathrm{~nm}$ laser. The laser was powered on throughout the experiments to minimize intensity fluctuations, and was modulated by opening/closing a mechanical laser shutter head (SR475, Stanford Research Systems), controlled by a shutter driver (SR474, Stanford Research Systems). $470 \mathrm{~nm}$ LED light was used to excite the ACh sensor, and $525 \mathrm{~nm}$ emitted photons were collected, for $25 \mathrm{~ms}$ at $20 \mathrm{~Hz}$ (every $50 \mathrm{~ms}$ ) using the filters described above. When photostimulation was provided using $589 \mathrm{~nm}$ laser light, it was delivered as $5 \mathrm{~ms}$ pulses at $20 \mathrm{~Hz}(4 \mathrm{~mW})$ in between the 470 $\mathrm{nm}$ light pulses, in order to prevent spectral cross-talk.

Fluorescence levels were analyzed as the area under the curve after photostimulation onset ( 0 to $0.5 \mathrm{sec}$ for reward, 1, 2, or 10 pulses; 0 to $2 \mathrm{sec}$ for $2 \mathrm{sec}$ photostimulation). Fixed effects for linear mixed effects model analysis for sessions with different durations of photostimulation included Virus (ChrimsonR vs. tdTomato control fluorophore), photostimulation pulses (Reward, 1,2 , or 10 pulses), and their interaction. Random effects were modeled using random intercepts for each subject. Post-hoc tests corrected for multiple comparisons included comparisons between ChrimsonR and tdTomato mice at each number of pulses, and comparisons within each virus group for 1, 2, or 10 pulses to Reward. For comparisons of evoked ACh in Photostim-Unreinforced and Photostim-Reinforced sessions, linear mixed effects model fixed effects included Virus (ChrimsonR vs. tdTomato), Session type (unreinforced or reinforced), and their interaction. Random effects were modeled using random intercepts for each subject.

\section{in vivo Electrophysiology}

\section{in vivo Electrophysiology Surgery}

Mice were anesthetized using isoflurane gas (1-4\%), and mounted on a stereotaxic apparatus (Kopf Instruments) to implant optrodes (i.e., combination of electrode and optical fiber). A midline incision was made down the scalp and craniotomies were opened using a dental drill. Optrodes were chronically implanted in either hemisphere in the basolateral amygdala (BLA) and the prelimbic (PL) subregion of the dorsomedial prefrontal cortex (dmPFC). The stereotaxic coordinates to target the BLA were $-1.50 \mathrm{~mm}$ anterior-posterior $(\mathrm{AP}), \pm 3.15 \mathrm{~mm}$ medial-lateral $(\mathrm{ML})$, and $-5.00 \mathrm{~mm}$ dorsal-ventral (DV). The stereotaxic coordinates to target PL were +1.80 
$\mathrm{AP}, \pm 0.35 \mathrm{~mm} \mathrm{ML}$, and $-2.00 \mathrm{~mm} \mathrm{DV}$. In addition to these optrodes, optical fibers were implanted bilaterally in the basal forebrain (BF) to photostimulate ChR2-expressing ChAT neurons while recording neural activity from the BLA and dmPFC. The stereotaxic coordinates for the BF fibers were $-0.40 \mathrm{~mm} \mathrm{AP}, \pm 1.80 \mathrm{~mm} \mathrm{ML}$, and $-4.50 \mathrm{~mm}$ DV. All stereotaxic coordinates were calculated relative to Bregma. Finally, an aluminum bar was horizontally positioned behind lambda to provide anchoring points during head-fixed recordings. All these implants were secured to the skull using stainless steel self-drilling screws (Small Parts), adhesive cement (C\&B Metabond, Parkell) and dental acrylic (Ortho-Jet, Lang Dental). At the end of the surgeries, incisions were sutured and postoperative analgesia and fluids were provided as needed. Mice were allowed to recover from surgery for at least one week.

\section{in vivo Electrophysiology Recordings}

Extracellular recordings were performed using in-house-built multichannel electrodes, each containing a 16-channel Omnetics connector, an optical fiber attached to the connector, and a low-resistance silver wire to provide ground. The microwire used for the electrodes was a 22.9$\mu \mathrm{m}$ HML-insulated nichrome wire (Stablohm 675, California Fine Wire). Microwires were secured to the connector pins using a silver print coating (GC Electronics). All connections were then secured using dental acrylic. Serrated fine scissors were used to cut the tip of the microwires to a length of 500-1000 $\mu \mathrm{m}$ from the tip of the optical fiber. The microwire tips were then gold-plated to reduce impedance and improve signal-to-noise ratio (Ferguson et al., 2009). Gold plating was achieved by submerging the electrode tips in a solution containing equal parts of a non-cyanide gold solution (SIFCO Selective Plating) and a $1 \mathrm{mg} / \mathrm{mL}$ polyethylene glycol solution. A cathodal current of $1 \mu \mathrm{A}$ was applied to individual channels to reduce impedances to a range of $200-300 \mathrm{k} \Omega$.

Multichannel extracellular recording setups (Open Ephys) were used to monitor neural activity while mice performed behavioral tasks. Extracellular signals were recorded at $30 \mathrm{kHz}$ with bandpass filters set at 0.2 and $7,600 \mathrm{~Hz}$. These raw signals were then processed offline to extract single-unit activity.

\section{in vivo Electrophysiology Spike Extraction}

A common reference was calculated for each 16 channel array, by calculating the median trace across all channels. This trace was then subtracted from each channel on that array. Data was then filtered from 300-7000 Hz using a fourth degree Butterworth filter applied using the filtfilt function in Matlab. Spikes were identified by negative deviations greater than 7.4 times the median absolute deviation. Spikes were aligned to their minima and waveforms from $375 \mu \mathrm{s}$ before the trough and $1000 \mu s$ after the trough were extracted for spike sorting. Single-unit waveforms were then sorted using commercial software (Offline Sorter, Plexon Inc), by combining principal component and peak-trough voltage features in three-dimensional space. Neural firing properties were visually inspected, including auto-correlations and crosscorrelations, in order to exclude multi-unit activity or repeated recordings of the same unit across multiple wires in a bundle. Neurons were additionally inspected to ensure they did not represent behaviorally locked artifacts. Only neurons that fired at least $0.01 \mathrm{~Hz}$ across the whole session were included in analyses. 


\section{in vivo Electrophysiology Analysis}

Peri-event time histograms were constructed by extracting spiking activity around photostimulation in $10 \mathrm{~ms}$ bins from $8 \mathrm{sec}$ before to $16 \mathrm{sec}$ after photostimulation onset. Baseline activity was defined as the activity from $4 \mathrm{sec}$ before up to the onset of photostimulation. Activity for each trial was transformed using the mean and standard deviation of baseline activity across trials. Data was smoothed with a 50 ms Gaussian kernel. Activity within each area for each bin was compared using rank-sum tests to compare PhotostimUnreinforced and Photostim-Reinforced sessions, separately for ChR2 and eYFP mice.

Modulation around the time of photostimulation was calculated by comparing firing rates before photostimulation onset $(-1$ to $0 \mathrm{sec}$ ) with firing rates shortly after photostimulation onset ( 0 to 0.5 $\mathrm{sec}$ ). Facilitation was classified as neurons with statistically significant increases in firing rates after photostimulation onset, and suppression was defined as neurons with statistically significant decreases in firing rates after photostimulation onset (sign-rank test, $p<0.01$ ). Proportions were compared using two-sided Chi-square proportion tests, with $p$ values corrected for multiple comparisons using Holm's procedure.

\section{in vivo Electrophysiology Histology}

Mice were anesthetized using isoflurane to mark the position of electrode tips by producing microlesions (anodal current, $25-40 \mu \mathrm{A}$ for at least $20 \mathrm{~s}$ ). Mice were then euthanized with sodium pentobarbital (150 mg/kg), and transcardially perfused with saline solution and $4 \%$ paraformaldehyde (PFA, pH 7.3). Brains were extracted and fixed in 4\%-PFA for at least $24 \mathrm{~h}$ and then equilibrated in a $30 \%$ sucrose solution for $48 \mathrm{~h}$. Coronal sections were cut at $40 \mu \mathrm{m}$ using a microtome (HM430, Thermo Fisher Scientific). Brain sections containing the BLA, dmPFC, and BF were mounted on microscope slides, and stained with DAPI (4',6-diamidino-2phenylindole). Images of the BLA, dmPFC, and BF were acquired using a confocal laserscanning microscope (Olympus FV1000). Expression of eYFP and/or ChR2 was examined from the BF sections, whereas the location of microlesions was examined from the BLA and dmPFC sections to determine the neural recording sites. These were reconstructed onto coronal drawings adapted from a mouse brain atlas (Franklin, 2008).

\section{ex vivo Electrophysiology}

\section{ex vivo Electrophysiology Surgery}

We generated double transgenic mice by crossing homozygous ChAT::Cre mice with hemizygous VGAT::flpo mice. Double hemizygous offspring (ChAT::Cre x VGAT::flpo mice), confirmed by genotyping (Transnetyx) were used for these experiments. In a first surgery, for optogenetic photostimulation of basal forebrain cholinergic neurons, we injected $500 \mathrm{~nL}$ of an adeno-associated virus encoding channelrhodopsin (AAV5/EF1a-DIO-hChR2(H134R)-mCherry; UNC, $3.5 \times 10_{12}$ ) bilaterally into basal forebrain of each hemisphere at AP $-0.4, \mathrm{ML} \pm 1.8$, DV -5 . For fluorescent labeling of BLA GABAergic neurons, we injected $400 \mathrm{~nL}$ of an adeno-associated virus encoding the fluorophore eYFP (AAV5/EF1a-fDIO-eYFP-WPRE; UNC, $3.8 \times 1012$ ) bilaterally into the BLA at AP -1.6, ML \pm 3.3 , DV -5.1. After at least 6 weeks, we performed a second surgery to label BLA neurons projecting to the medial prefrontal cortex (mPFC) through injection of a retrograde tracer (200 nL cholera toxin b subunit fused to Alexa-647, CTB-647) in the mPFC (AP 1.8, ML \pm 0.35 , DV -2). 


\section{ex vivo Electrophysiology Recordings}

One week after the CTB-647 surgery, mice were deeply anaesthetized via I.P. injection of sodium pentobarbital $(200 \mathrm{mg} / \mathrm{kg})$ prior to transcardial perfusion with $20 \mathrm{~mL}$ ice-cold modified artificial cerebrospinal fluid (ACSF; composition in mM: 75 sucrose, $87 \mathrm{NaCl}, 25 \mathrm{NaHCO}_{3}, 2.5$ $\mathrm{KCl}, 1.3 \mathrm{NaH}_{2} \mathrm{PO}_{4}{ }^{*} \mathrm{H}_{2} \mathrm{O}, 7 \mathrm{MgCl}_{2}{ }^{*} 6 \mathrm{H}_{2} \mathrm{O}, 0.5 \mathrm{CaCl}_{2}{ }^{*} 2 \mathrm{H}_{2} \mathrm{O}, 5$ ascorbic acid, in $\mathrm{ddH}_{2} \mathrm{O}$; osmolarity 324-328 mOsm, $\mathrm{pH} 7.3-7.4$ ) saturated with carbogen gas (95\% oxygen, $5 \%$ carbon dioxide). The brain was quickly dissected out of the cranial cavity and a semiautomatic vibrating blade microtome (VT1200; Leica, IL, USA) was then used to prepare $300 \mu \mathrm{m}$ thick coronal slices containing the BLA. Brain slices encompassing the basal forebrain and MPFC were also collected for verification of ChR2-mCherry and CTB-647 expression, respectively. Slices were then transferred to ACSF (composition in mM: $126 \mathrm{NaCl}, 2.5 \mathrm{KCl}, 26 \mathrm{NaHCO}_{3}, 1.25$ $\mathrm{NaH}_{2} \mathrm{PO}_{4}{ }^{*} \mathrm{H}_{2} \mathrm{O}, 1 \mathrm{MgCl}_{2}{ }^{*} 6 \mathrm{H}_{2} \mathrm{O}, 2.4 \mathrm{CaCl}_{2}{ }^{*} 2 \mathrm{H}_{2} \mathrm{O}$, and 10 glucose, in dd $\mathrm{H}_{2} \mathrm{O}$; osmolarity 299-301 mOsm; pH 7.30-7.40) saturated with carbogen gas (95\% oxygen, $5 \%$ carbon dioxide) in a water bath kept at $30-32{ }^{\circ} \mathrm{C}$. They were allowed to recover for at least $1 \mathrm{~h}$ before transfer to the recording chamber for electrophysiological recordings.

In the recording chamber BLA slices were continually perfused with carbogen-saturated ACSF, at a temperature of $31 \pm 1^{\circ} \mathrm{C}$, via a peristaltic pump (Minipuls3; Gilson, WI, USA). BLA neurons were visualized through an upright microscope (Scientifica, UK) using infra-red differential interference contrast (IR-DIC) optics and a Q-imaging Retiga Exi camera (Q Imaging, Canada). Identification of eYFP+ GABAergic neurons and CTB-647-expressing mPFC-projector neurons was achieved through a 40X water-immersion objective using brief fluorescence illumination from a $470 \mathrm{~nm}$ LED light source (pE-100; CoolLED, NY, USA) or a metal halide lamp (Lumen 200, Prior Scientific Inc., MA, USA), respectively, through appropriate excitation/emission filters (Olympus, PA, USA). Thin walled borosilicate glass capillary tubing was shaped into microelectrodes for recording using a horizontal puller (P-97, Sutter Instruments, CA, USA) and had resistance values of 3-6 $\mathrm{M} \Omega$ when filled with internal solution (composition in $\mathrm{mM}: 125$ potassium gluconate, $20 \mathrm{HEPES}, 10 \mathrm{NaCl}, 3 \mathrm{MgATP}$, and $0.1 \%$ neurobiotin ( $\mathrm{pH} 7.30-7.33$; 286$287 \mathrm{mOsm}$ ). Recorded signals were amplified with a Multiclamp 700B amplifier (Molecular Devices, CA, USA), low-pass filtered at $3 \mathrm{kHz}$, digitized at $10 \mathrm{kHz}$ using a Digidata 1550, and recorded using pClamp 10.4 software (Molecular Devices, CA, USA). Series resistance, input resistance, and holding current were monitored throughout experiments via a $5 \mathrm{mV}, 0.1 \mathrm{sec}$ step. Any significant changes were interpreted as signs of cell deterioration and recordings were terminated. To assess the response of BLA neurons to cholinergic input, ChR2-expressing cholinergic terminals were activated by trains of $5 \mathrm{~ms}$ pulses of $470 \mathrm{~nm}$ light ( $p E-100$; CoolLED, NY, USA) delivered through the 40X objective every $30 \mathrm{~s}$, while recording in current-clamp mode. To isolate monosynaptic currents tetrodotoxin (TTX; $1 \mu \mathrm{M}$; Tocris, MN, USA) and 4Aminopyridine (4AP; $1 \mathrm{mM}$, Sigma, MO, USA) were included in the ACSF (Petreanu et al., 2007). Scopolamine (10 $\mu$ M; Sigma, MO, USA) was used to block muscarinic ACh receptors, and a cocktail of nicotinic antagonists (dihydro-ß-erythroidine (10 $\mu \mathrm{M}$, Tocris, MN, USA), methyllycaconitine $(0.1 \mu \mathrm{M}$; Sigma, MO, USA), and mecamylamine (10 $\mu \mathrm{M}$; Sigma, MO, USA)) was used to block nicotinic ACh receptors. Offline analysis of peak current amplitude was performed in Clampfit 10.4 (Molecular Devices, CA, USA). Capacitance and membrane resistance $(\mathrm{Rm})$ were calculated from a $5 \mathrm{mV}, 0.1 \mathrm{sec}$ hyperpolarizing step in voltage-clamp using custom MATLAB software written by Praneeth Namburi based on MATLAB implementation of the Q-method (Novák and Zahradník, 2006). 


\section{ex vivo Electrophysiology Histology}

Following recording, slices were fixed in $4 \%$ PFA overnight at $4{ }^{\circ} \mathrm{C}$ then washed in PBS $(4 \times 10$ $\mathrm{min})$. To reveal neurobiotin-labelled cells, recorded slices were blocked in PBS containing $0.3 \%$ Triton (PBS-T 0.3\%) and 3\% normal donkey serum (NDS; Jackson ImmunoResearch, USA) at room temperature for 60 min before incubation in PBS-T $0.3 \%$ with $3 \%$ NDS and CF405conjugated streptavidin (1:1000; Biotium, CA, USA). After 90 min slices were washed in PBS (4x $10 \mathrm{~min}$ ) then mounted onto glass slides and coverslipped using polyvinyl alcohol mounting medium with DABCO (Sigma, MO, USA). Images of the BLA were captured using a confocal laser scanning microscope (Olympus FV1000), with FluoView software (Olympus, PA, USA). Neurobiotin-filled recorded neurons were imaged at high magnification through a 40X/1.3 NA oil-immersion objective using serial z-stacks with an optical slice thickness of $3 \mu \mathrm{m}$.

\section{Immunohistochemistry}

After behavioral experiments, mice were anaesthetized with pentobarbital sodium (200 mg/kg), and transcardially perfused with ice-cold Ringer's solution followed by ice-cold 4\% PFA in PBS ( $\mathrm{pH} 7.3$ ). Brains were extracted and fixed in 4\% PFA for 24 hours and equilibrated in $30 \%$ sucrose in PBS for 3 days. Coronal sections were cut at $40 \mu \mathrm{m}$ using a sliding microtome (HM430; Thermo Fisher Scientific) and kept in PBS at $4^{\circ} \mathrm{C}$ until antibody staining.

Sections from the PFC, BF, and BLA were taken for immunohistochemistry. Sections were washed six times for five minutes each in 1x PBS, and then blocked for 2 hours at room temperature in $3 \%$ normal donkey serum in $0.3 \%$ PBS-Triton. Sections were then incubated overnight at room temperature in blocking solution with primary antibody goat-anti-ChAT (1:200 / 1:100) or chicken-anti-GFP (1:500). The next day, sections were washed six times for five minutes in 1x PBS. Sections were then incubated in secondary antibody donkey-anti-goat 488 or 555 (1:500) or donkey-anti-chicken 488 (1:1000) in blocking solution at room temperature for 2 hours. Finally, sections were washed six times for five minutes in 1x PBS and mounted on microscope slides using a Vectashield mounting medium with DAPI. Slides were sealed with clear nail polish to preserve sections. All washing and staining steps were done covered on a shaker.

Confocal Microscopy Fluorescent images were captured using a confocal laser scanning microscope (Olympus FV1000), with FluoView software (Olympus, PA, USA), under a 10X / 0.40 NA dry objective or a 40X/1.30 NA oil immersion objective. Images were subsequently processed in Adobe Illustrator (Adobe Systems Incorporated, CA, USA). Similar to prior work, we also observed some ectopic expression of ChAT (Hedrick et al., 2016), particularly in later litters of breeding pairs, and excluded these mice based on postmortem histological examination. 


\section{References}

Adelsberger, H., Garaschuk, O., and Konnerth, A. (2005). Cortical calcium waves in resting newborn mice. Nat. Neurosci. 8, 988-990.

Adermark, L., Söderpalm, B., and Burkhardt, J.M. (2014). Brain region specific modulation of ethanolinduced depression of GABAergic neurons in the brain reward system by the nicotine receptor antagonist mecamylamine. Alcohol Fayettev. N 48, 455-461.

Aitta-Aho, T., Hay, Y.A., Phillips, B.U., Saksida, L.M., Bussey, T.J., Paulsen, O., and Apergis-Schoute, J. (2018). Basal Forebrain and Brainstem Cholinergic Neurons Differentially Impact Amygdala Circuits and Learning-Related Behavior. Curr. Biol. CB 28, 2557-2569.e4.

American Psychiatric Association (2013). Diagnostic and Statistical Manual of Mental Disorders, 5th Edition: DSM-5 (Washington, D.C: American Psychiatric Publishing).

Bakin, J.S., and Weinberger, N.M. (1996). Induction of a physiological memory in the cerebral cortex by stimulation of the nucleus basalis. Proc. Natl. Acad. Sci. U. S. A. 93, 11219-11224.

Ballinger, E.C., Ananth, M., Talmage, D.A., and Role, L.W. (2016). Basal Forebrain Cholinergic Circuits and Signaling in Cognition and Cognitive Decline. Neuron 91, 1199-1218.

Bates, D., Mächler, M., Bolker, B., and Walker, S. (2015). Fitting Linear Mixed-Effects Models Using Ime4. J. Stat. Softw. 67, 1-48.

Baxter, M.G., and Chiba, A.A. (1999). Cognitive functions of the basal forebrain. Curr. Opin. Neurobiol. 9, 178-183.

Biederman, J., Mick, E., Faraone, S., Hammerness, P., Surman, C., Harpold, T., Dougherty, M., Aleardi, M., and Spencer, T. (2006). A double-blind comparison of galantamine hydrogen bromide and placebo in adults with attention-deficit/hyperactivity disorder: a pilot study. J. Clin. Psychopharmacol. 26, 163-166.

Brown, D.A. (2019). Acetylcholine and cholinergic receptors. Brain Neurosci. Adv. 3, 2398212818820506.

Burgos-Robles, A., Kimchi, E.Y., Izadmehr, E.M., Porzenheim, M.J., Ramos-Guasp, W.A., Nieh, E.H., FelixOrtiz, A.C., Namburi, P., Leppla, C.A., Presbrey, K.N., et al. (2017). Amygdala inputs to prefrontal cortex guide behavior amid conflicting cues of reward and punishment. Nat. Neurosci. 20, 824-835.

Cardinal, R.N., Parkinson, J.A., Hall, J., and Everitt, B.J. (2002). Emotion and motivation: the role of the amygdala, ventral striatum, and prefrontal cortex. Neurosci. Biobehav. Rev. 26, 321-352.

Chen, E., Lallai, V., Sherafat, Y., Grimes, N.P., Pushkin, A.N., Fowler, J.P., and Fowler, C.D. (2018). Altered Baseline and Nicotine-Mediated Behavioral and Cholinergic Profiles in ChAT-Cre Mouse Lines. J.

Neurosci. 1433-17.

Chen, T.-W., Wardill, T.J., Sun, Y., Pulver, S.R., Renninger, S.L., Baohan, A., Schreiter, E.R., Kerr, R.A., Orger, M.B., Jayaraman, V., et al. (2013). Ultrasensitive fluorescent proteins for imaging neuronal activity. Nature 499, 295-300. 
Chintoh, A., Fulton, J., Koziel, N., Aziz, M., Sud, M., and Yeomans, J.S. (2003). Role of cholinergic receptors in locomotion induced by scopolamine and oxotremorine-M. Pharmacol. Biochem. Behav. 76, 53-61.

Chubykin, A.A., Roach, E.B., Bear, M.F., and Shuler, M.G.H. (2013). A cholinergic mechanism for reward timing within primary visual cortex. Neuron $77,723-735$.

Crouse, R.B., Kim, K., Batchelor, H.M., Kamaletdinova, R., Chan, J., Rajebhosale, P., Pittenger, S.T., Role, L.W., Talmage, D.A., Jing, M., et al. (2020). Acetylcholine is released in the basolateral amygdala in response to predictors of reward and enhances learning of cue-reward contingency. BioRxiv 2020.04.14.041152.

Cubo, E., Fernández Jaén, A., Moreno, C., Anaya, B., González, M., and Kompoliti, K. (2008). Donepezil use in children and adolescents with tics and attention-deficit/hyperactivity disorder: an 18-week, single-center, dose-escalating, prospective, open-label study. Clin. Ther. 30, 182-189.

Cui, G., Jun, S.B., Jin, X., Pham, M.D., Vogel, S.S., Lovinger, D.M., and Costa, R.M. (2013). Concurrent activation of striatal direct and indirect pathways during action initiation. Nature 494, 238-242.

Dasgupta, R., Seibt, F., and Beierlein, M. (2018). Synaptic Release of Acetylcholine Rapidly Suppresses Cortical Activity by Recruiting Muscarinic Receptors in Layer 4. J. Neurosci. Off. J. Soc. Neurosci. 38, 5338-5350.

Ferguson, J.E., Boldt, C., and Redish, A.D. (2009). Creating low-impedance tetrodes by electroplating with additives. Sens. Actuators Phys. 156, 388-393.

Ferster, C.B., and Skinner, B.F. (1957). Variable Interval. In Schedules of Reinforcement, (New York: Appleton-Century-Crofts), pp. 355-364.

Franklin, K.B.J. (2008). The mouse brain in stereotaxic coordinates (Amsterdam; Boston :

Elsevier/Academic Press).

Gielow, M.R., and Zaborszky, L. (2017). The Input-Output Relationship of the Cholinergic Basal Forebrain. Cell Rep. 18, 1817-1830.

Gritton, H.J., Howe, W.M., Mallory, C.S., Hetrick, V.L., Berke, J.D., and Sarter, M. (2016). Cortical cholinergic signaling controls the detection of cues. Proc. Natl. Acad. Sci. U. S. A. 113, E1089-1097.

Gunaydin, L.A., Grosenick, L., Finkelstein, J.C., Kauvar, I.V., Fenno, L.E., Adhikari, A., Lammel, S., Mirzabekov, J.J., Airan, R.D., Zalocusky, K.A., et al. (2014). Natural neural projection dynamics underlying social behavior. Cell 157, 1535-1551.

Guo, W., Robert, B., and Polley, D.B. (2019). The Cholinergic Basal Forebrain Links Auditory Stimuli with Delayed Reinforcement to Support Learning. Neuron 103, 1164-1177.e6.

Hangya, B., Ranade, S.P., Lorenc, M., and Kepecs, A. (2015). Central Cholinergic Neurons Are Rapidly Recruited by Reinforcement Feedback. Cell 162, 1155-1168. 
Harrison, T.C., Pinto, L., Brock, J.R., and Dan, Y. (2016). Calcium Imaging of Basal Forebrain Activity during Innate and Learned Behaviors. Front. Neural Circuits 10, 36.

He, K., Zhang, X., Ren, S., and Sun, J. (2016). Deep Residual Learning for Image Recognition. In 2016 IEEE Conference on Computer Vision and Pattern Recognition (CVPR), pp. 770-778.

Hedrick, T., Danskin, B., Larsen, R.S., Ollerenshaw, D., Groblewski, P., Valley, M., Olsen, S., and Waters, J. (2016). Characterization of Channelrhodopsin and Archaerhodopsin in Cholinergic Neurons of Cre-Lox Transgenic Mice. PloS One 11, e0156596.

Herman, A.M., Ortiz-Guzman, J., Kochukov, M., Herman, I., Quast, K.B., Patel, J.M., Tepe, B., Carlson, J.C., Ung, K., Selever, J., et al. (2016). A cholinergic basal forebrain feeding circuit modulates appetite suppression. Nature 538, 253-256.

Higley, M.J., and Picciotto, M.R. (2014). Neuromodulation by Acetylcholine: Examples from Schizophrenia and Depression. Curr. Opin. Neurobiol. 0, 88-95.

Hshieh, T.T., Fong, T.G., Marcantonio, E.R., and Inouye, S.K. (2008). Cholinergic deficiency hypothesis in delirium: a synthesis of current evidence. J. Gerontol. A. Biol. Sci. Med. Sci. 63, 764-772.

Insafutdinov, E., Pishchulin, L., Andres, B., Andriluka, M., and Schiele, B. (2016). DeeperCut: A Deeper, Stronger, and Faster Multi-person Pose Estimation Model. In Computer Vision - ECCV 2016, B. Leibe, J. Matas, N. Sebe, and M. Welling, eds. (Cham: Springer International Publishing), pp. 34-50.

Irmak, S.O., and de Lecea, L. (2014). Basal forebrain cholinergic modulation of sleep transitions. Sleep 37, 1941-1951.

Jiang, L., Kundu, S., Lederman, J.D., López-Hernández, G.Y., Ballinger, E.C., Wang, S., Talmage, D.A., and Role, L.W. (2016). Cholinergic Signaling Controls Conditioned Fear Behaviors and Enhances Plasticity of Cortical-Amygdala Circuits. Neuron 90, 1057-1070.

Jing, M., Zhang, P., Wang, G., Feng, J., Mesik, L., Zeng, J., Jiang, H., Wang, S., Looby, J.C., Guagliardo, N.A., et al. (2018). A genetically encoded fluorescent acetylcholine indicator for in vitro and in vivo studies. Nat. Biotechnol. 36, 726-737.

Kim, C.K., Yang, S.J., Pichamoorthy, N., Young, N.P., Kauvar, I., Jennings, J.H., Lerner, T.N., Berndt, A., Lee, S.Y., Ramakrishnan, C., et al. (2016). Simultaneous fast measurement of circuit dynamics at multiple sites across the mammalian brain. Nat. Methods 13, 325-328.

Kitt, C.A., Höhmann, C., Coyle, J.T., and Price, D.L. (1994). Cholinergic innervation of mouse forebrain structures. J. Comp. Neurol. 341, 117-129.

Kruk, M., Tendera, K., and Biała, G. (2011). Memory-related effects of cholinergic receptor ligands in mice as measured by the elevated plus maze test. Pharmacol. Rep. PR 63, 1372-1382.

Kruk-Słomka, M., Michalak, A., Budzyńska, B., and Biała, G. (2014). A comparison of mecamylamine and bupropion effects on memory-related responses induced by nicotine and scopolamine in the novel object recognition test in mice. Pharmacol. Rep. PR 66, 638-646. 
Kuznetsova, A., Brockhoff, P.B., and Christensen, R.H.B. (2017). ImerTest Package: Tests in Linear Mixed Effects Models. J. Stat. Softw. 82, 1-26.

Laszlovszky, T., Schlingloff, D., Hegedüs, P., Freund, T.F., Gulyás, A., Kepecs, A., and Hangya, B. (2020). Distinct synchronization, cortical coupling and behavioral function of two basal forebrain cholinergic neuron types. Nat. Neurosci.

Lee, S., and Kim, J.-H. (2019). Basal Forebrain Cholinergic-induced Activation of Cholecystokinin Inhibitory Neurons in the Basolateral Amygdala. Exp. Neurobiol. 28, 320-328.

Lenth, R.V. (2020). emmeans.

Letzkus, J.J., Wolff, S.B.E., Meyer, E.M.M., Tovote, P., Courtin, J., Herry, C., and Lüthi, A. (2011). A disinhibitory microcircuit for associative fear learning in the auditory cortex. Nature 480, 331-335.

Li, X., Yu, B., Sun, Q., Zhang, Y., Ren, M., Zhang, X., Li, A., Yuan, J., Madisen, L., Luo, Q., et al. (2018). Generation of a whole-brain atlas for the cholinergic system and mesoscopic projectome analysis of basal forebrain cholinergic neurons. Proc. Natl. Acad. Sci. U. S. A. 115, 415-420.

Likhtik, E., and Johansen, J.P. (2019). Neuromodulation in circuits of aversive emotional learning. Nat. Neurosci. 22, 1586-1597.

Likhtik, E., Pelletier, J.G., Paz, R., and Paré, D. (2005). Prefrontal control of the amygdala. J. Neurosci. Off. J. Soc. Neurosci. 25, 7429-7437.

Likhtik, E., Stujenske, J.M., Topiwala, M.A., Harris, A.Z., and Gordon, J.A. (2014). Prefrontal entrainment of amygdala activity signals safety in learned fear and innate anxiety. Nat. Neurosci. 17, 106-113.

Liu, C.-H., Coleman, J.E., Davoudi, H., Zhang, K., and Hussain Shuler, M.G. (2015). Selective activation of a putative reinforcement signal conditions cued interval timing in primary visual cortex. Curr. Biol. CB 25, 1551-1561.

Lutas, A., Kucukdereli, H., Alturkistani, O., Carty, C., Sugden, A.U., Fernando, K., Diaz, V., FloresMaldonado, V., and Andermann, M.L. (2019). State-specific gating of salient cues by midbrain dopaminergic input to basal amygdala. Nat. Neurosci. 22, 1820-1833.

Lütcke, H., Murayama, M., Hahn, T., Margolis, D.J., Astori, S., Zum Alten Borgloh, S.M., Göbel, W., Yang, Y., Tang, W., Kügler, S., et al. (2010). Optical recording of neuronal activity with a genetically-encoded calcium indicator in anesthetized and freely moving mice. Front. Neural Circuits 4, 9.

Mathis, A., Mamidanna, P., Cury, K.M., Abe, T., Murthy, V.N., Mathis, M.W., and Bethge, M. (2018). DeepLabCut: markerless pose estimation of user-defined body parts with deep learning. Nat. Neurosci. $21,1281-1289$.

Matthews, G.A., Nieh, E.H., Vander Weele, C.M., Halbert, S.A., Pradhan, R.V., Yosafat, A.S., Glober, G.F., Izadmehr, E.M., Thomas, R.E., Lacy, G.D., et al. (2016). Dorsal Raphe Dopamine Neurons Represent the Experience of Social Isolation. Cell 164, 617-631. 
McDonald, A.J., and Mascagni, F. (2010). Neuronal localization of m1 muscarinic receptor immunoreactivity in the rat basolateral amygdala. Brain Struct. Funct. 215, 37-48.

McDonald, A.J., and Mascagni, F. (2011). Neuronal localization of M2 muscarinic receptor immunoreactivity in the rat amygdala. Neuroscience 196, 49-65.

McDonald, A.J., Muller, J.F., and Mascagni, F. (2011). Postsynaptic targets of GABAergic basal forebrain projections to the basolateral amygdala. Neuroscience 183, 144-159.

McGaughy, J., Dalley, J.W., Morrison, C.H., Everitt, B.J., and Robbins, T.W. (2002). Selective behavioral and neurochemical effects of cholinergic lesions produced by intrabasalis infusions of 192 IgG-saporin on attentional performance in a five-choice serial reaction time task. J. Neurosci. Off. J. Soc. Neurosci. 22, 1905-1913.

Mineur, Y.S., Fote, G.M., Blakeman, S., Cahuzac, E.L.M., Newbold, S.A., and Picciotto, M.R. (2016). Multiple Nicotinic Acetylcholine Receptor Subtypes in the Mouse Amygdala Regulate Affective Behaviors and Response to Social Stress. Neuropsychopharmacol. Off. Publ. Am. Coll. Neuropsychopharmacol. 41, 1579-1587.

Morandi, A., Lucchi, E., Turco, R., Morghen, S., Guerini, F., Santi, R., Gentile, S., Meagher, D., Voyer, P., Fick, D., et al. (2015a). Delirium superimposed on dementia: A quantitative and qualitative evaluation of patient experience. J. Psychosom. Res. 79, 281-287.

Morandi, A., Lucchi, E., Turco, R., Morghen, S., Guerini, F., Santi, R., Gentile, S., Meagher, D., Voyer, P., Fick, D.M., et al. (2015b). Delirium superimposed on dementia: A quantitative and qualitative evaluation of informal caregivers and health care staff experience. J. Psychosom. Res. 79, 272-280.

Mu, P., and Huang, Y.H. (2019). Cholinergic system in sleep regulation of emotion and motivation. Pharmacol. Res. 143, 113-118.

Muller, J.F., Mascagni, F., Zaric, V., Mott, D.D., and McDonald, A.J. (2016). Localization of the M2 muscarinic cholinergic receptor in dendrites, cholinergic terminals, and noncholinergic terminals in the rat basolateral amygdala: An ultrastructural analysis. J. Comp. Neurol. 524, 2400-2417.

Nath, T., Mathis, A., Chen, A.C., Patel, A., Bethge, M., and Mathis, M.W. (2019). Using DeepLabCut for 3D markerless pose estimation across species and behaviors. Nat. Protoc. 14, 2152-2176.

Nelson, A., and Mooney, R. (2016). The Basal Forebrain and Motor Cortex Provide Convergent yet Distinct Movement-Related Inputs to the Auditory Cortex. Neuron 90, 635-648.

Newman, E.L., Gupta, K., Climer, J.R., Monaghan, C.K., and Hasselmo, M.E. (2012). Cholinergic modulation of cognitive processing: insights drawn from computational models. Front. Behav. Neurosci. $6,24$.

Nieh, E.H., Matthews, G.A., Allsop, S.A., Presbrey, K.N., Leppla, C.A., Wichmann, R., Neve, R., Wildes, C.P., and Tye, K.M. (2015). Decoding Neural Circuits that Control Compulsive Sucrose Seeking. Cell 160, 528-541. 
Nieh, E.H., Vander Weele, C.M., Matthews, G.A., Presbrey, K.N., Wichmann, R., Leppla, C.A., Izadmehr, E.M., and Tye, K.M. (2016). Inhibitory Input from the Lateral Hypothalamus to the Ventral Tegmental Area Disinhibits Dopamine Neurons and Promotes Behavioral Activation. Neuron 90, 1286-1298.

Novák, P., and Zahradník, I. (2006). Q-method for high-resolution, whole-cell patch-clamp impedance measurements using square wave stimulation. Ann. Biomed. Eng. 34, 1201-1212.

O'Malley, G., Leonard, M., Meagher, D., and O'Keeffe, S.T. (2008). The delirium experience: A review. J. Psychosom. Res. 65, 223-228.

Parikh, V., Kozak, R., Martinez, V., and Sarter, M. (2007). Prefrontal acetylcholine release controls cue detection on multiple timescales. Neuron 56, 141-154.

Petreanu, L., Huber, D., Sobczyk, A., and Svoboda, K. (2007). Channelrhodopsin-2-assisted circuit mapping of long-range callosal projections. Nat. Neurosci. 10, 663-668.

Pidoplichko, V.I., Prager, E.M., Aroniadou-Anderjaska, V., and Braga, M.F.M. (2013). $\alpha 7$-Containing nicotinic acetylcholine receptors on interneurons of the basolateral amygdala and their role in the regulation of the network excitability. J. Neurophysiol. 110, 2358-2369.

Pinto, L., Goard, M.J., Estandian, D., Xu, M., Kwan, A.C., Lee, S.-H., Harrison, T.C., Feng, G., and Dan, Y. (2013). Fast modulation of visual perception by basal forebrain cholinergic neurons. Nat. Neurosci. 16, 1857-1863.

Potter, A.S., Schaubhut, G., and Shipman, M. (2014). Targeting the nicotinic cholinergic system to treat attention-deficit/hyperactivity disorder: rationale and progress to date. CNS Drugs $28,1103-1113$.

Prado, M.A.M., Reis, R.A.M., Prado, V.F., de Mello, M.C., Gomez, M.V., and de Mello, F.G. (2002). Regulation of acetylcholine synthesis and storage. Neurochem. Int. 41, 291-299.

R Core Team (2015). R: A Language and Environment for Statistical Computing (R Foundation for Statistical Computing).

Rossi, J., Balthasar, N., Olson, D., Scott, M., Berglund, E., Lee, C.E., Choi, M.J., Lauzon, D., Lowell, B.B., and Elmquist, J.K. (2011). Melanocortin-4 receptors expressed by cholinergic neurons regulate energy balance and glucose homeostasis. Cell Metab. 13, 195-204.

Równiak, M., Kolenkiewicz, M., and Kozłowska, A. (2017). Parvalbumin, but not calretinin, neurons express high levels of $\alpha 1$-containing GABAA receptors, $\alpha 7$-containing nicotinic acetylcholine receptors and D2-dopamine receptors in the basolateral amygdala of the rat. J. Chem. Neuroanat. 86, 41-51.

Rye, D.B., Wainer, B.H., Mesulam, M.M., Mufson, E.J., and Saper, C.B. (1984). Cortical projections arising from the basal forebrain: a study of cholinergic and noncholinergic components employing combined retrograde tracing and immunohistochemical localization of choline acetyltransferase. Neuroscience 13, 627-643. 
Siddiqi, N., Harrison, J.K., Clegg, A., Teale, E.A., Young, J., Taylor, J., and Simpkins, S.A. (2016). Interventions for preventing delirium in hospitalised non-ICU patients. Cochrane Database Syst. Rev. 3, CD005563.

Singh, J., Kour, K., and Jayaram, M.B. (2012). Acetylcholinesterase inhibitors for schizophrenia. Cochrane Database Syst. Rev. 1, CD007967.

Sturgill, J.F., Hegedus, P., Li, S.J., Chevy, Q., Siebels, A., Jing, M., Li, Y., Hangya, B., and Kepecs, A. (2020). Basal forebrain-derived acetylcholine encodes valence-free reinforcement prediction error. BioRxiv 2020.02.17.953141.

Thany, S.H., and Tricoire-Leignel, H. (2011). Emerging Pharmacological Properties of Cholinergic Synaptic Transmission: Comparison between Mammalian and Insect Synaptic and Extrasynaptic Nicotinic Receptors. Curr. Neuropharmacol. 9, 706-714.

Tye, K.M., Tye, L.D., Cone, J.J., Hekkelman, E.F., Janak, P.H., and Bonci, A. (2010). Methylphenidate facilitates learning-induced amygdala plasticity. Nat. Neurosci. 13, 475-481.

Unal, C.T., Pare, D., and Zaborszky, L. (2015). Impact of basal forebrain cholinergic inputs on basolateral amygdala neurons. J. Neurosci. Off. J. Soc. Neurosci. 35, 853-863.

Vander Weele, C.M., Siciliano, C.A., Matthews, G.A., Namburi, P., Izadmehr, E.M., Espinel, I.C., Nieh, E.H., Schut, E.H.S., Padilla-Coreano, N., Burgos-Robles, A., et al. (2018). Dopamine enhances signal-tonoise ratio in cortical-brainstem encoding of aversive stimuli. Nature 563, 397-401.

Washburn, M.S., and Moises, H.C. (1992). Muscarinic responses of rat basolateral amygdaloid neurons recorded in vitro. J. Physiol. 449, 121-154.

Woolf, N.J., Eckenstein, F., and Butcher, L.L. (1984). Cholinergic systems in the rat brain: I. projections to the limbic telencephalon. Brain Res. Bull. 13, 751-784.

Zaborszky, L., Pol, A.N. van den, and Gyengesi, E. (2012). The Basal Forebrain Cholinergic Projection System in Mice. Mouse Nerv. Syst. 684-718.

Zachariou, V., Caldarone, B.J., Weathers-Lowin, A., George, T.P., Elsworth, J.D., Roth, R.H., Changeux, J.P., and Picciotto, M.R. (2001). Nicotine receptor inactivation decreases sensitivity to cocaine.

Neuropsychopharmacol. Off. Publ. Am. Coll. Neuropsychopharmacol. 24, 576-589.

Zhu, P.J., Stewart, R.R., McIntosh, J.M., and Weight, F.F. (2005). Activation of nicotinic acetylcholine receptors increases the frequency of spontaneous GABAergic IPSCs in rat basolateral amygdala neurons. J. Neurophysiol. 94, 3081-3091. 
bioRxiv preprint doi: https://doi.org/10.1101/2022.02.04.479188; this version posted February 5, 2022. The copyright holder for this preprint (which was not certified by peer review) is the author/funder. All rights reserved. No reuse allowed without permission.

Figure 1 Basal Forebrain (BF)
A

ChAT::Cre mouse $\mathrm{AAV}_{5}$-EF1a-DIO-ChR2-eYFP or $\mathrm{AAV}_{5}-\mathrm{EF} 1 \mathrm{a}-\mathrm{DIO}-\mathrm{eYFP}$

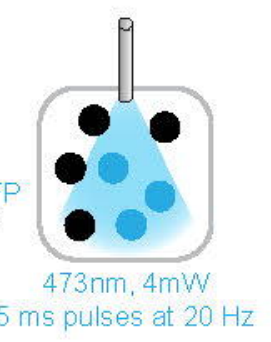

C Window of Opportunity Task (WoOT)

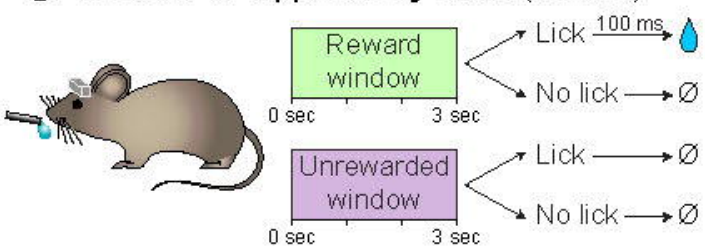

B
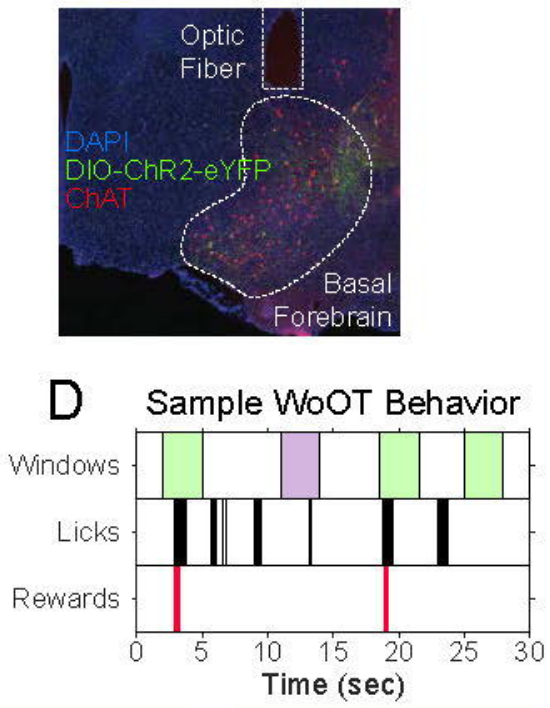
E WoOT training $\begin{aligned} & \text { Photostim-Unreinforced } \\ & \text { No photostim } \rightarrow \text { Fixed Duration }(2 \mathrm{sec}) \rightarrow \text { Fixed Duration }(2 \mathrm{sec}) \rightarrow \text {. } \rightarrow \text { Var Durations }(0-0.5 \text { sec }\end{aligned}$ $\sim 7$ sessions
1 session
2 sessions
1 session

F Photostim-Unreinforced Session

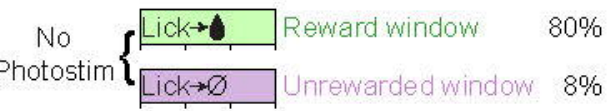

G Photostim-Reinforced Session

No $\quad$ Lick $\rightarrow$ Reward window $68 \%$

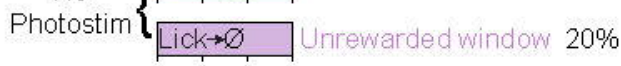

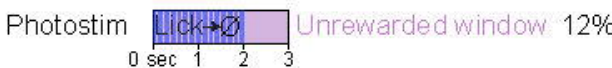

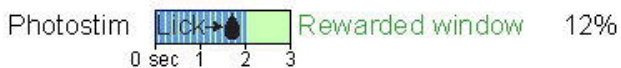

H Photostim-Unreinforced Session

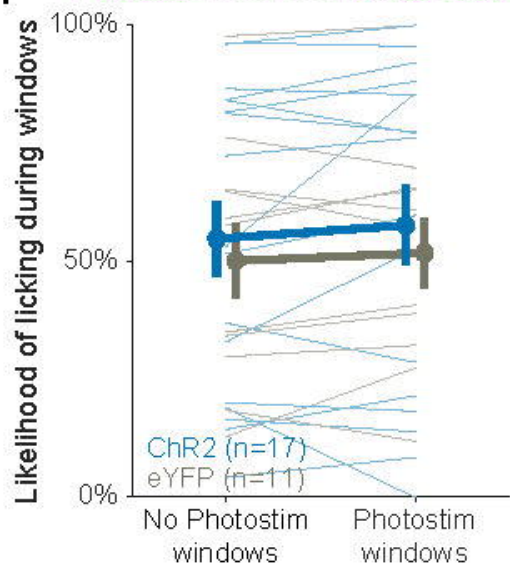

Photostim-Reinforced Session
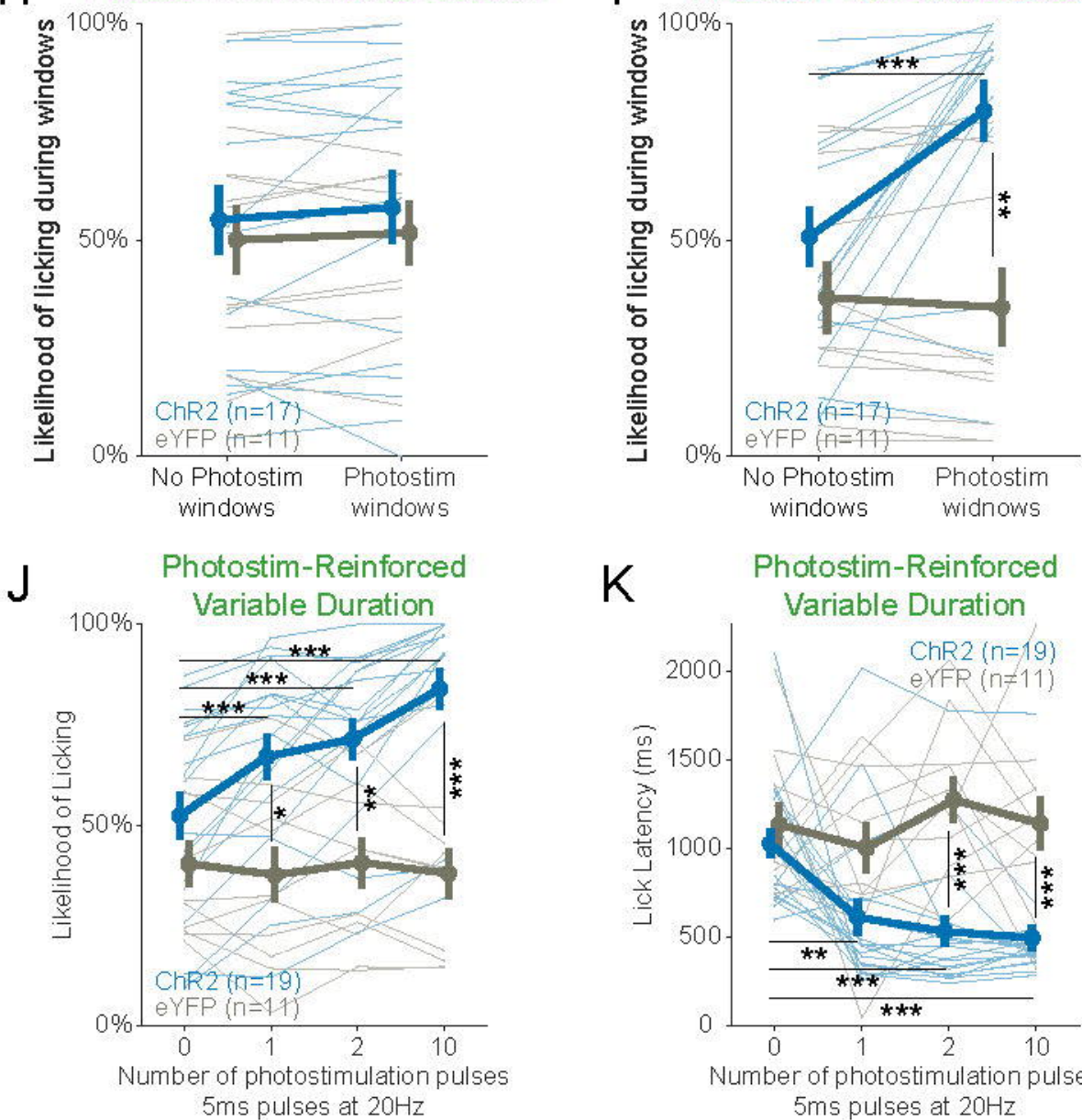

K

Photostim-Reinforced

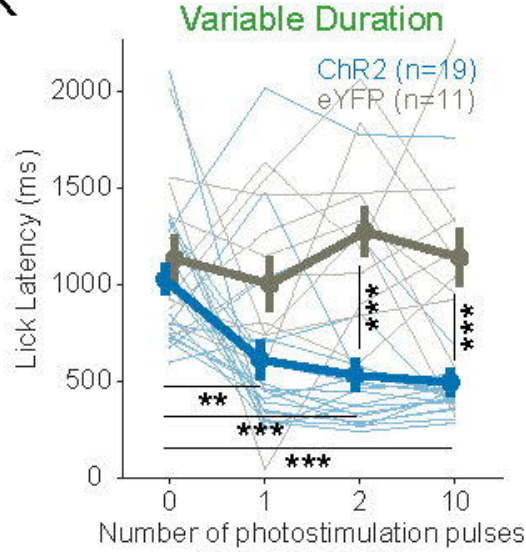

Number of photostimulation pulses

$5 \mathrm{~ms}$ pulses at $2 \mathrm{OHz}$ 
bioRxiv preprint doi: https://doi.org/10.1101/2022.02.04.479188; this version posted February 5, 2022. The copyright holder for this preprint (which was not certified by peer review) is the author/funder. All rights reserved. No reuse allowed without permission.

Figure 2

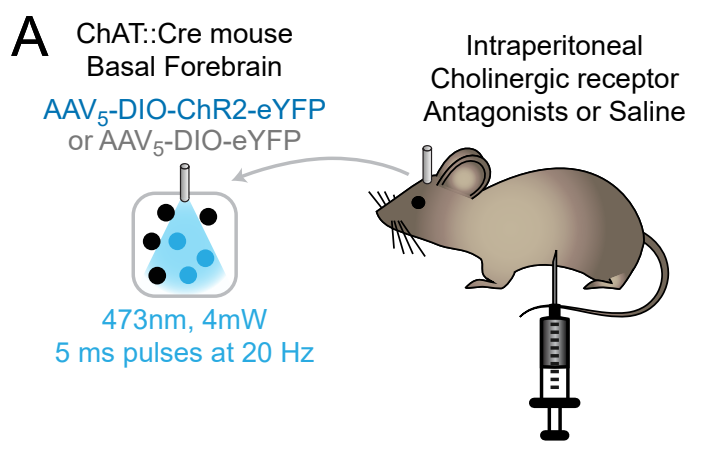

C

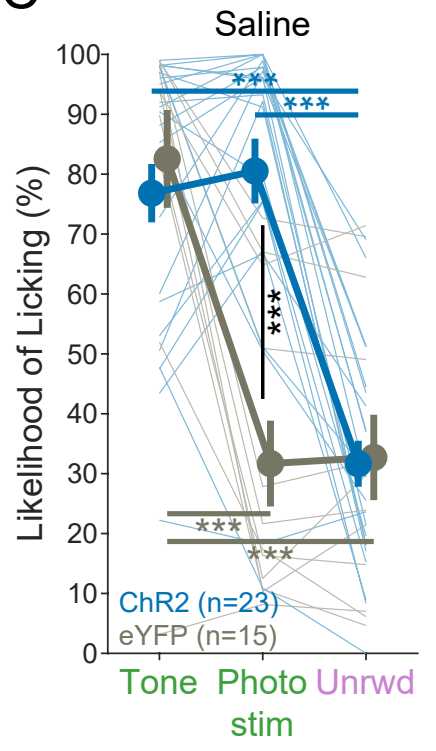

Muscarinic

Receptor Antagonist Scopolamine $0.3 \mathrm{mg} / \mathrm{kg}$

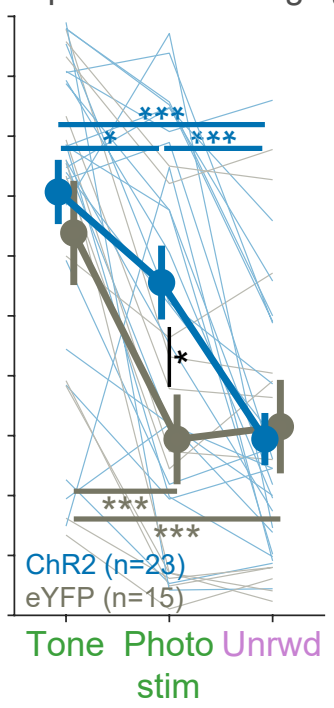

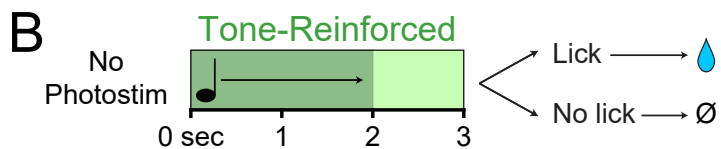

Photostim-Reinforced

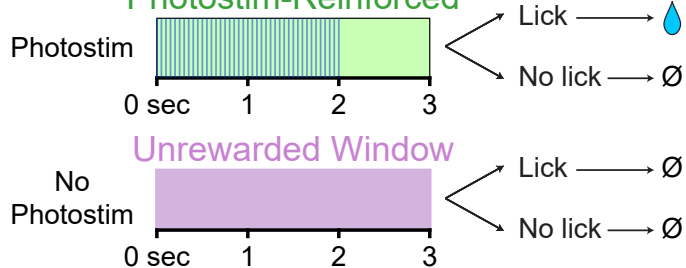

\section{Muscarinic}

Receptor Antagonist

Scopolamine $1 \mathrm{mg} / \mathrm{kg}$

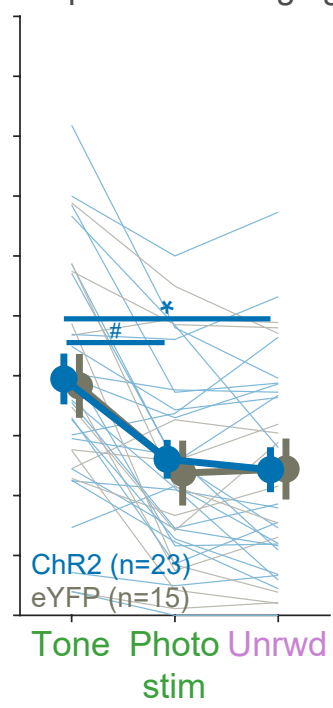

Nicotinic

Receptor Antagonist

Mecamylamine $1 \mathrm{mg} / \mathrm{kg}$

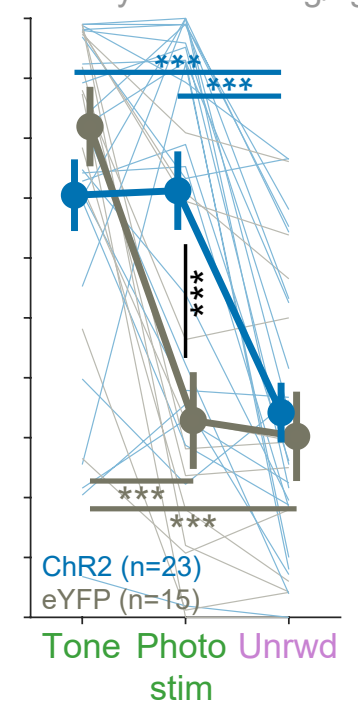




\section{Figure 3}
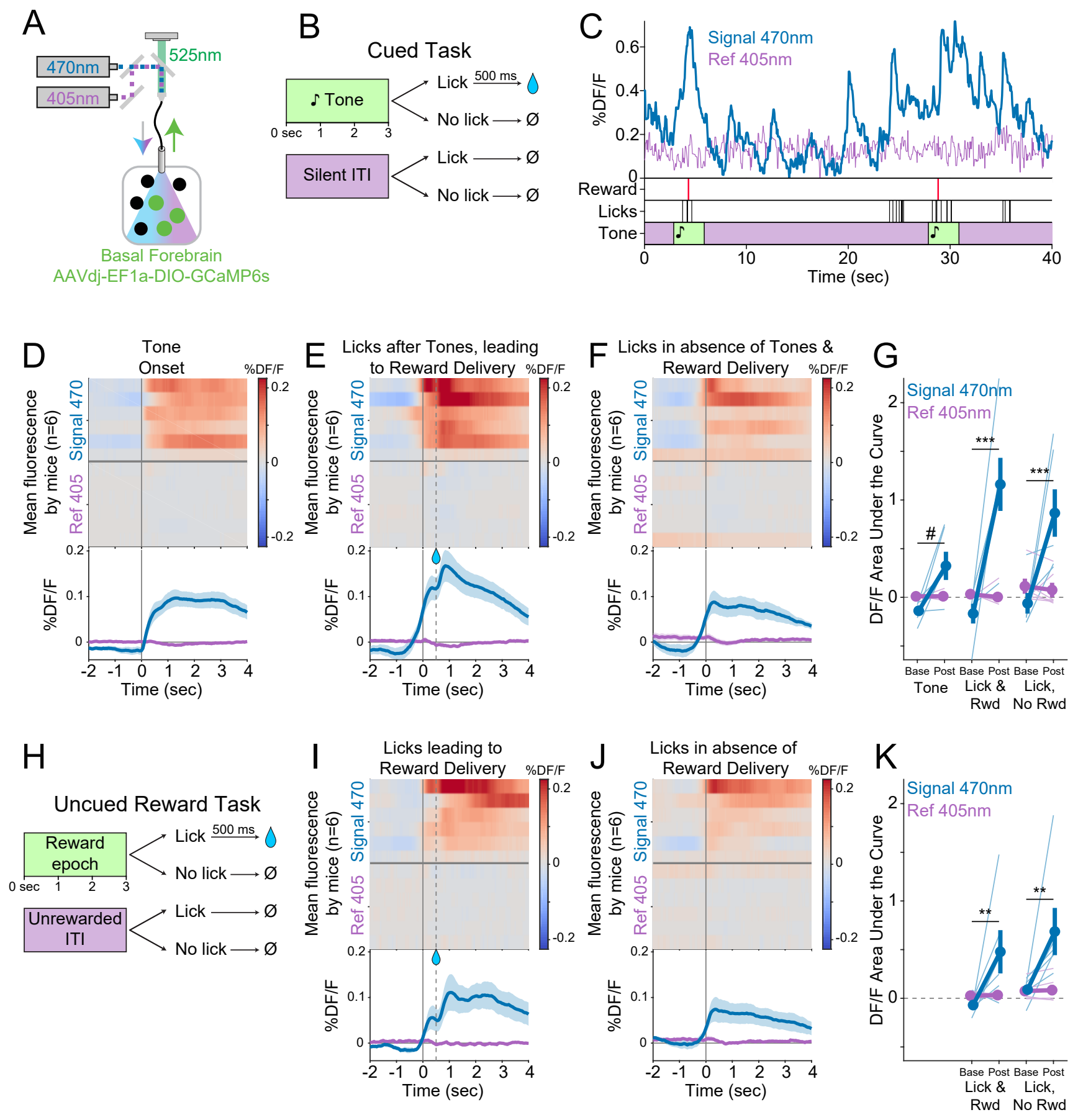


\section{Figure 4}
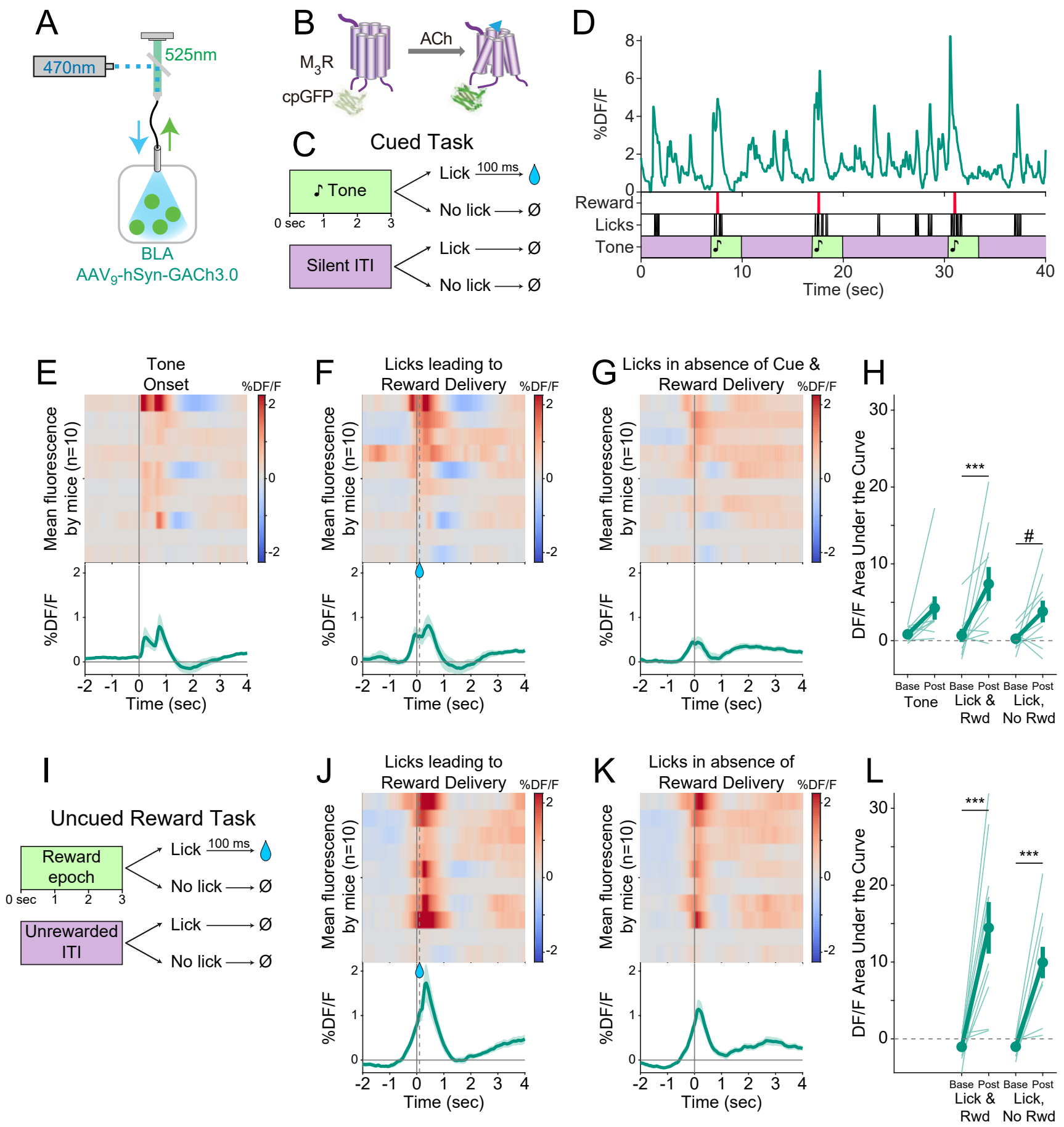
bioRxiv preprint doi: https://doi.org/10.1101/2022.02.04.479188; this version posted February 5, 2022. The copyright holder for this preprint (which was not certified by peer review) is the author/funder. All rights reserved. No reuse allowed without permission.

\section{Figure 5}

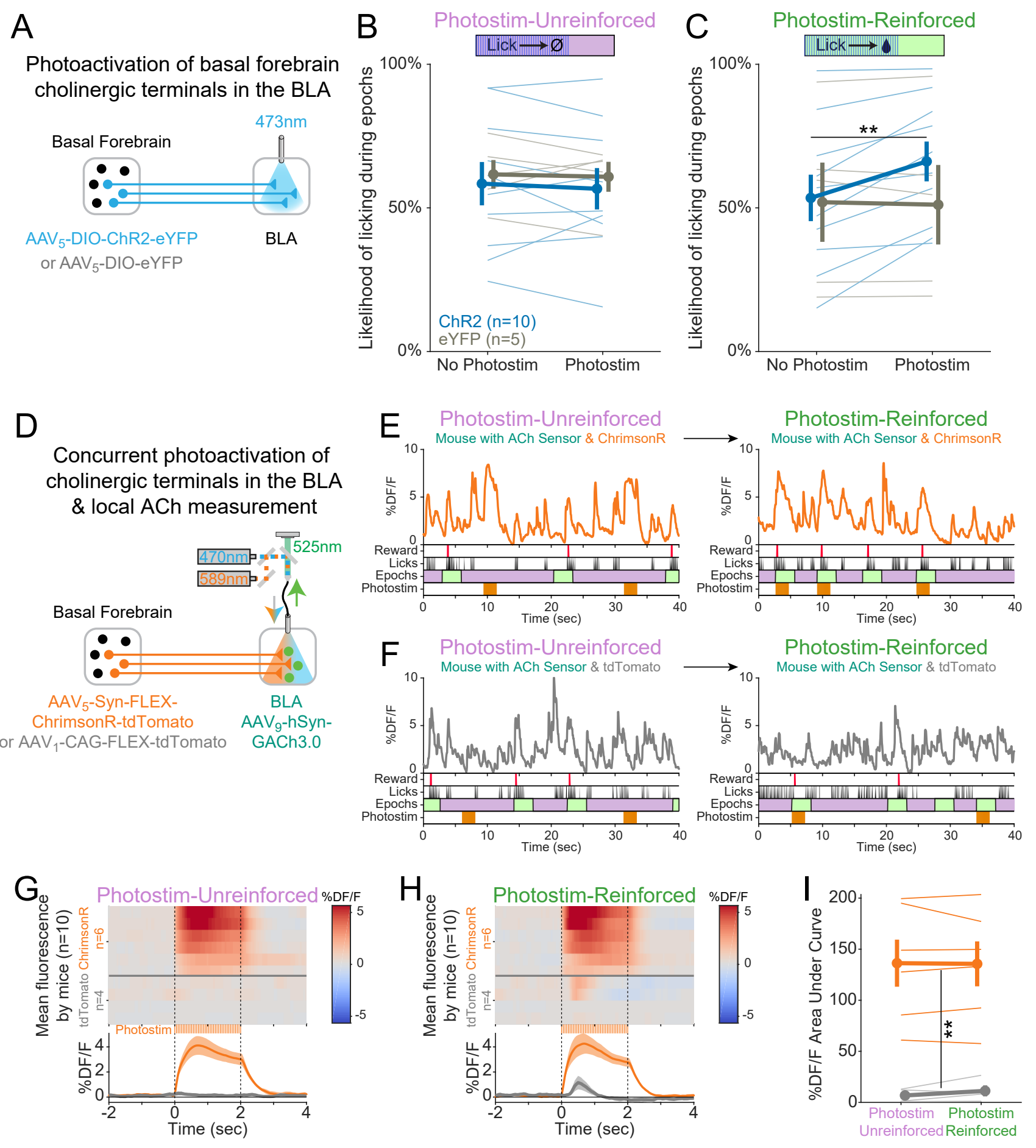


bioRxiv preprint doi: https://doi.org/10.1101/2022.02.04.479188; this version posted February 5, 2022. The copyright holder for this preprint (which was not certified by peer review) is the author/funder. All rights reserved. No reuse allowed without permission.

\section{Figure 6}

A

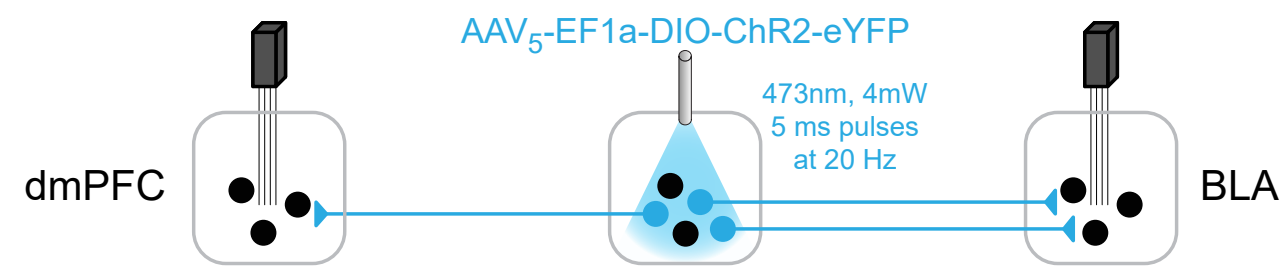

B
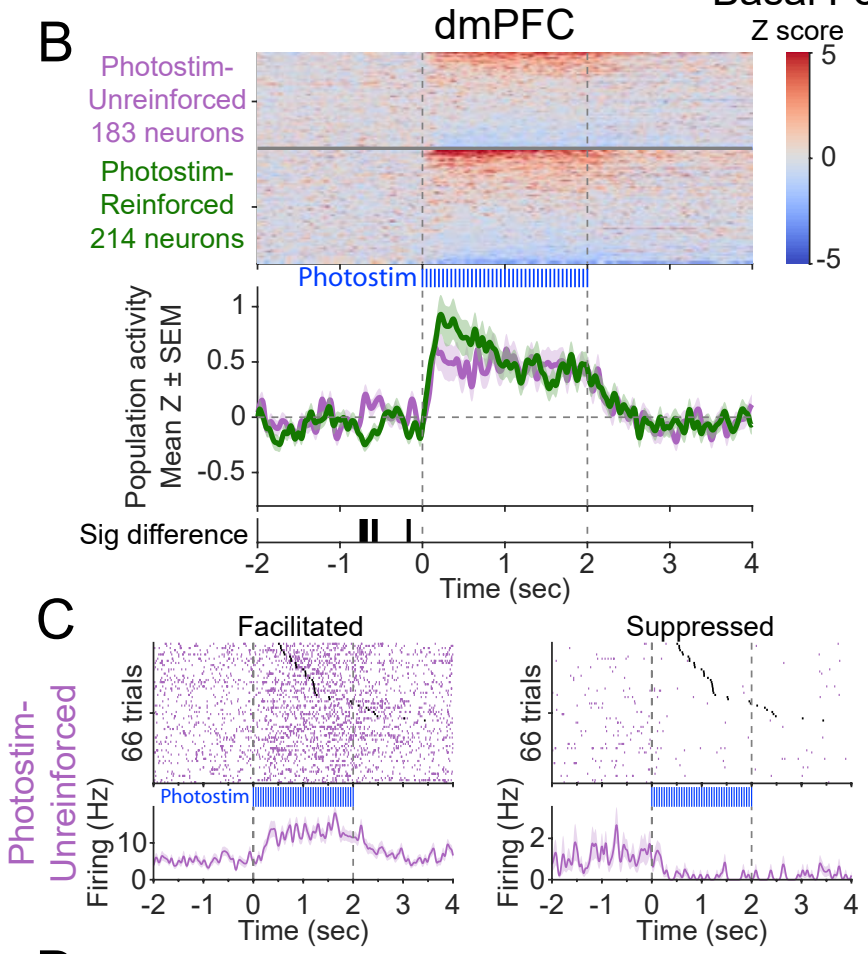

Basal Forebrain

Z score
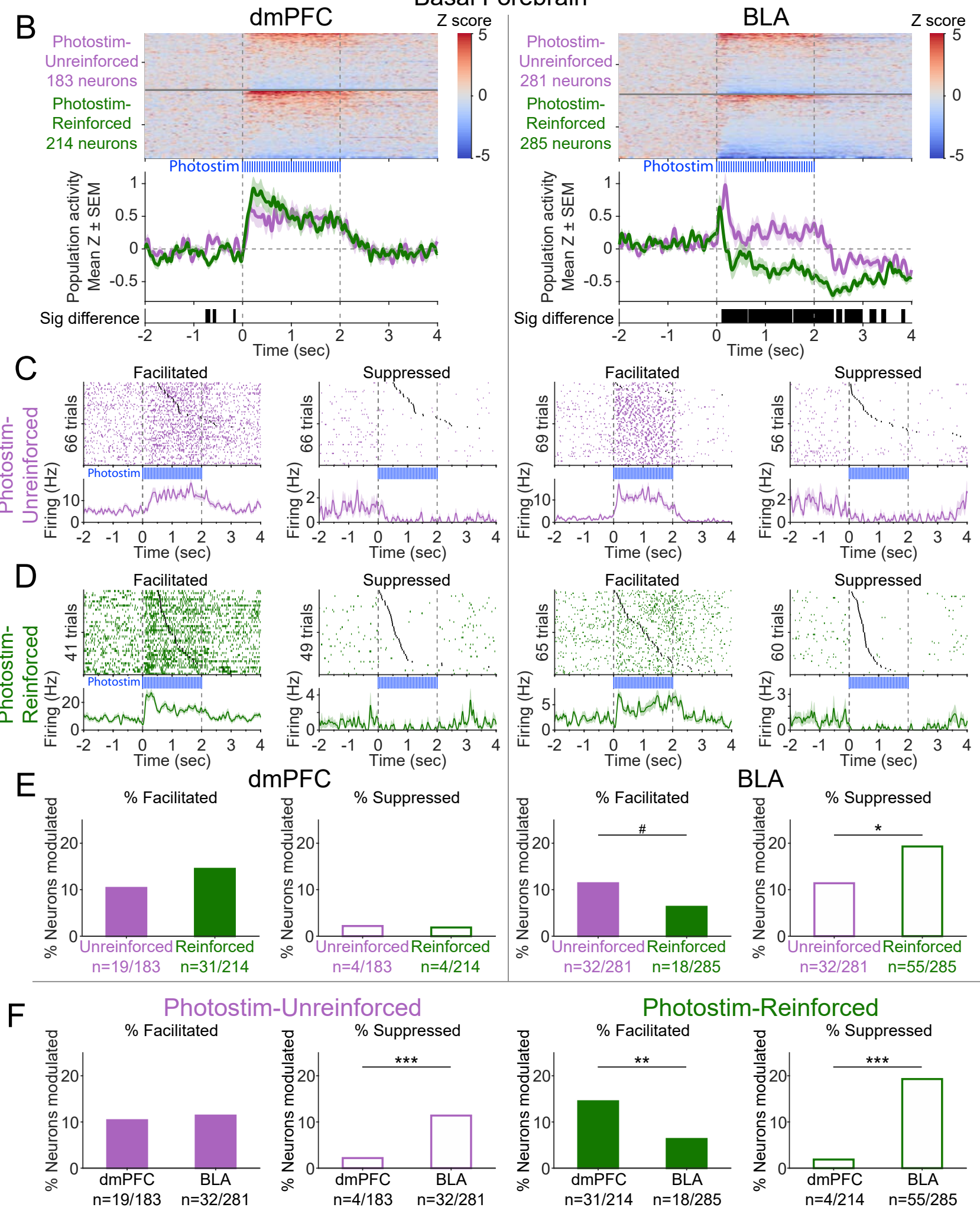


\section{Figure 7}

A

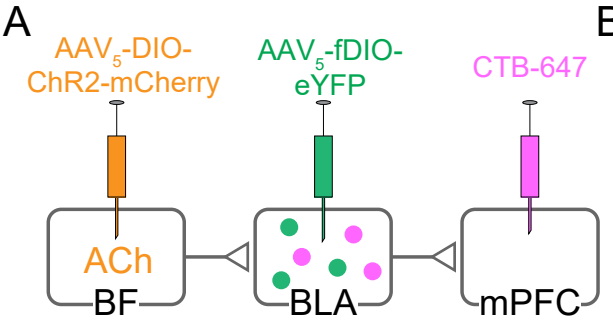

ChAT::Cre x VGAT::Flpo mouse
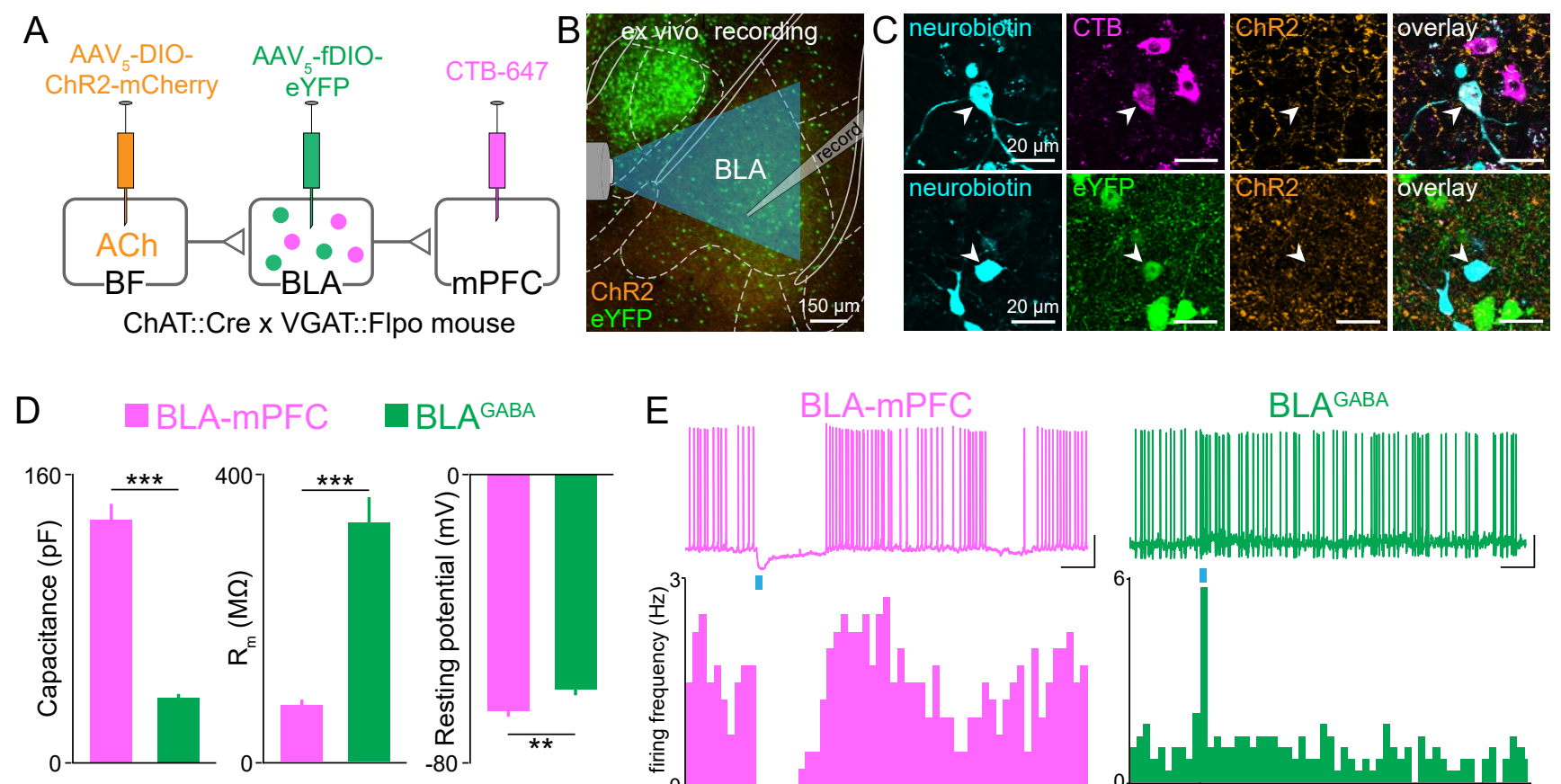

E BLA-mPFC

$\mathrm{F}$
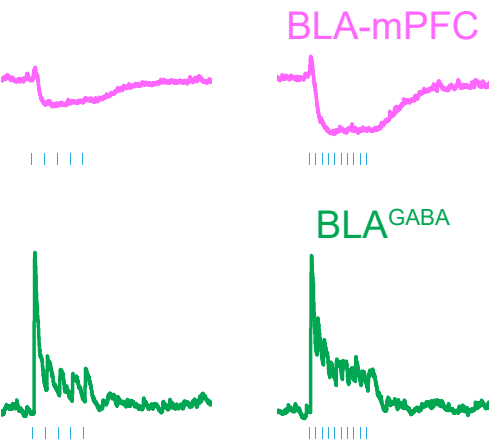

$5 \mathrm{~Hz}$
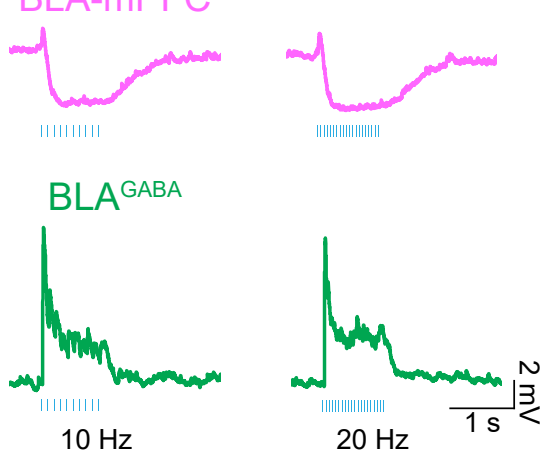

G
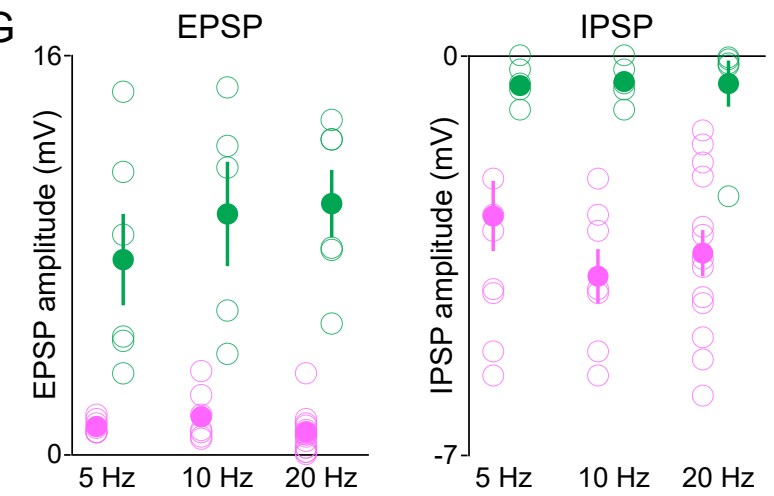
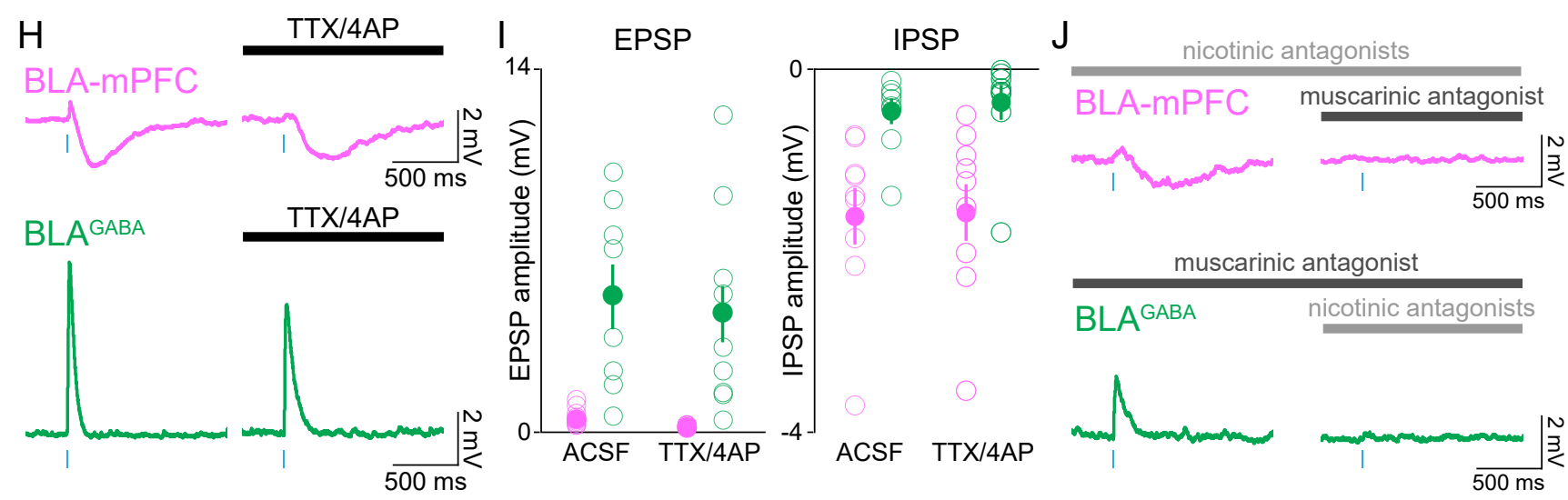

$\mathrm{K}$

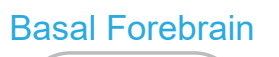

Circuit Model
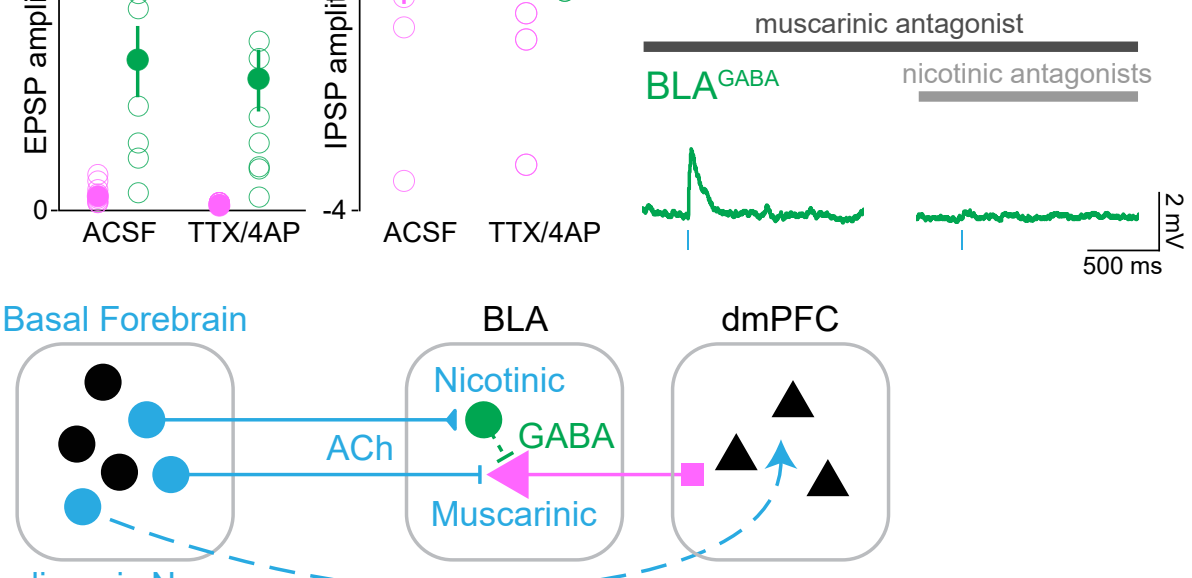
Figure $\mathrm{S} 1$

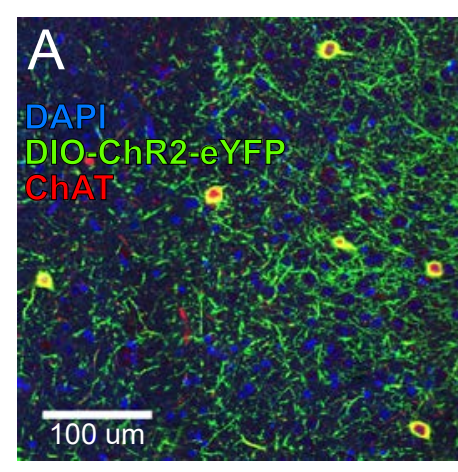

B

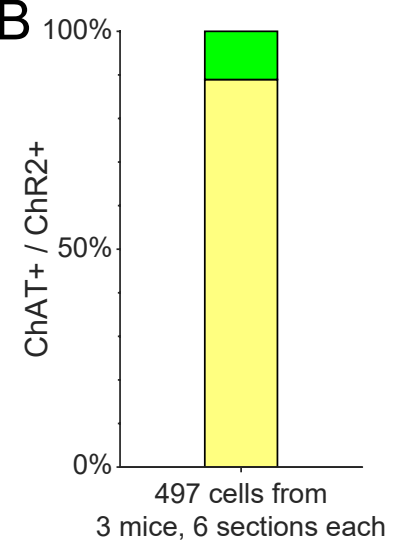

E

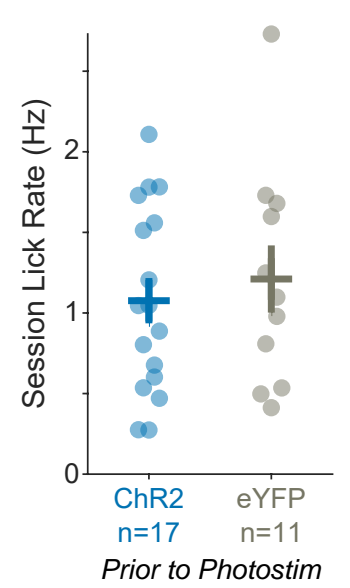

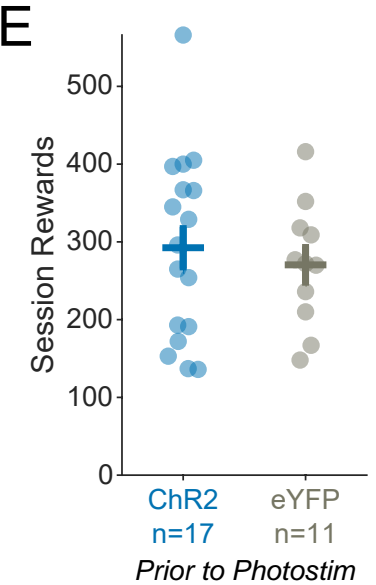

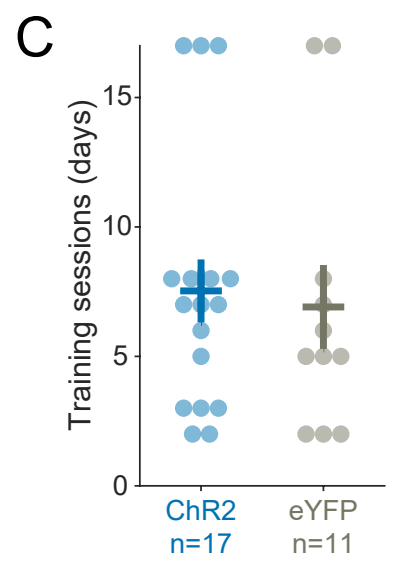

Prior to Photostim

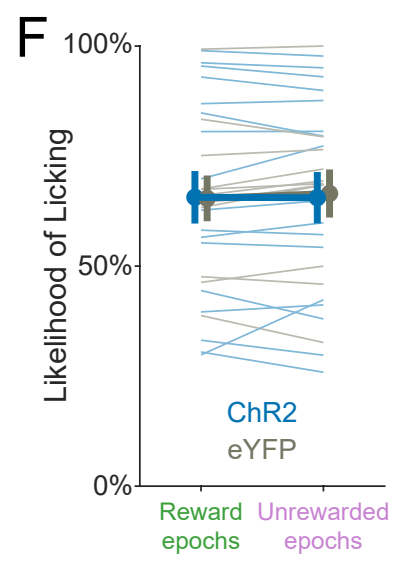

Prior to Photostim 
bioRxiv preprint doi: https://doi.org/10.1101/2022.02.04.479188; this version posted February 5, 2022. The copyright holder for this preprint (which was not certified by peer review) is the author/funder. All rights reserved. No reuse allowed without permission.

\section{Figure S2}

A ChAT::Cre mice AAV 5 -DIO-ChR2-eYFP or $\mathrm{AAV}_{5}$-DIO-eYFP

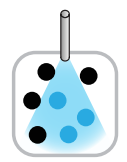

$473 \mathrm{~nm}, 4 \mathrm{~mW}$ $5 \mathrm{~ms}$ pulses at $20 \mathrm{~Hz}$
B

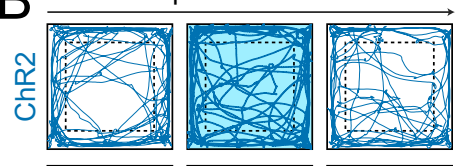

这放

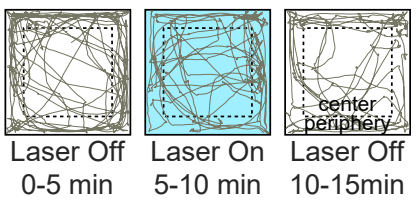

ChR2

E

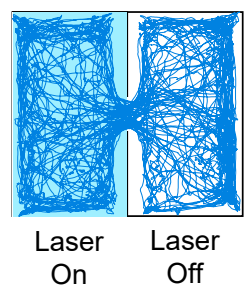

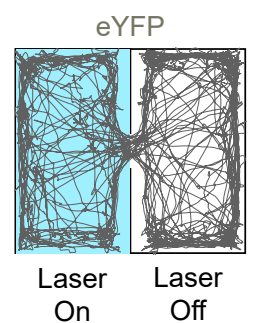
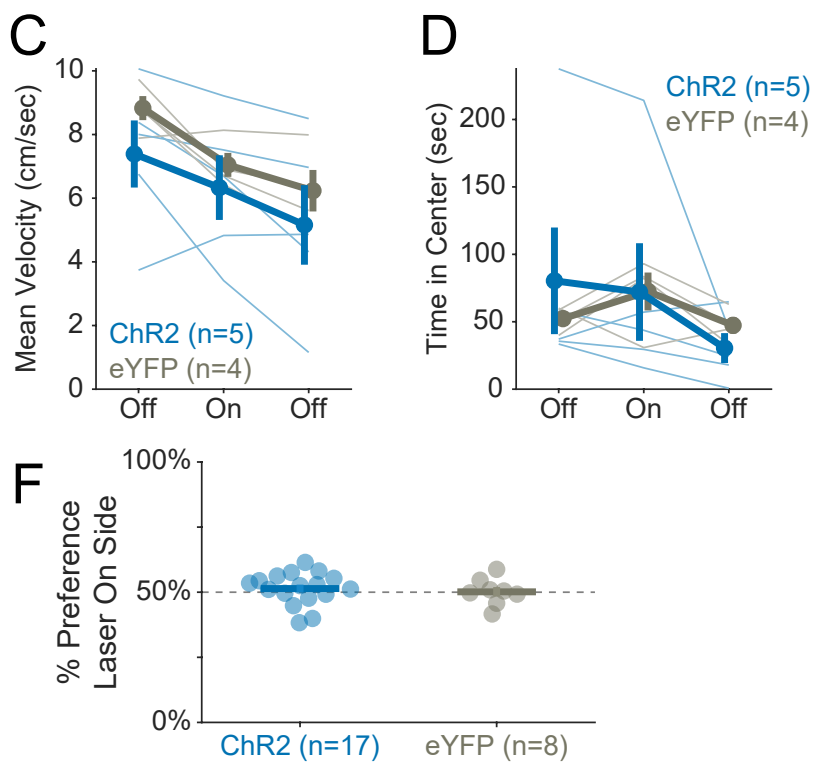

Photostim-Reinforced Session

\section{G}

Photostim-Unreinforced Session

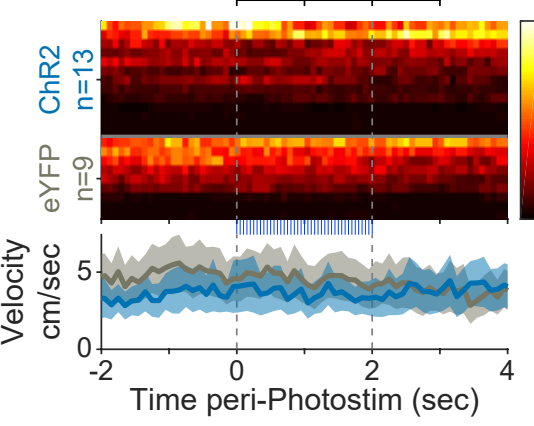

| Photostim-Unreinforced Session

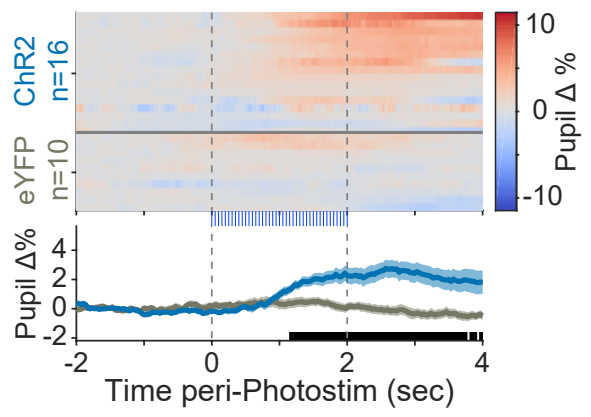

K Photostim-Unreinforced Session
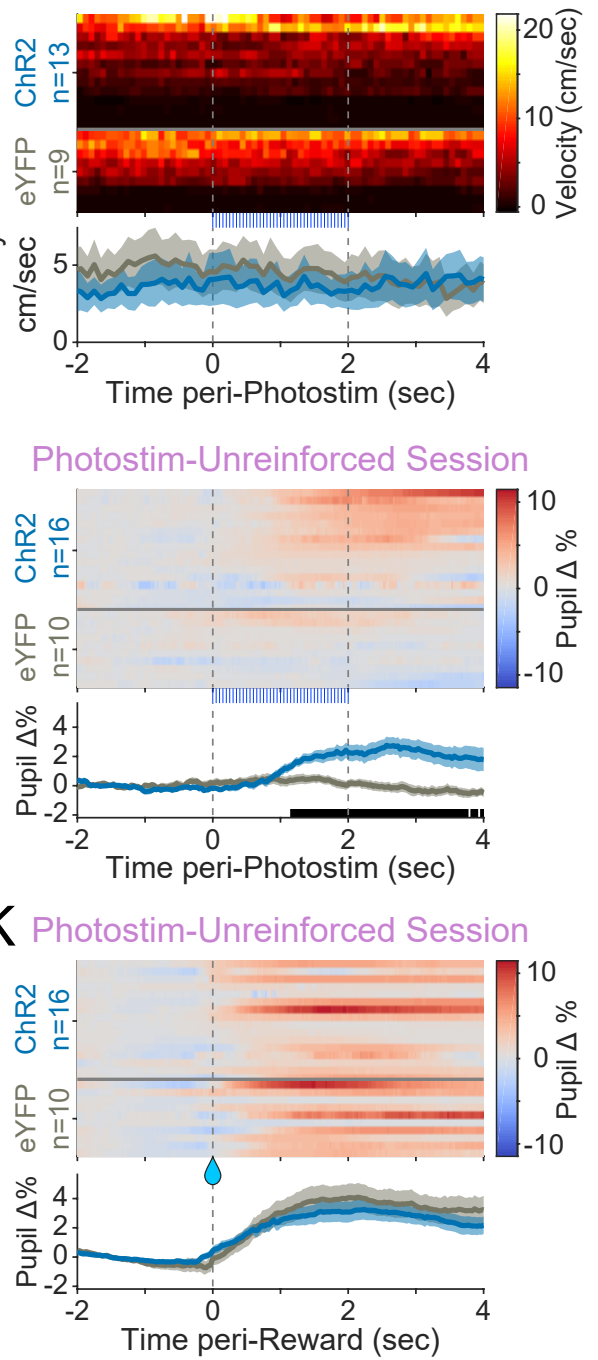

Photostim Lick—_ Reward window
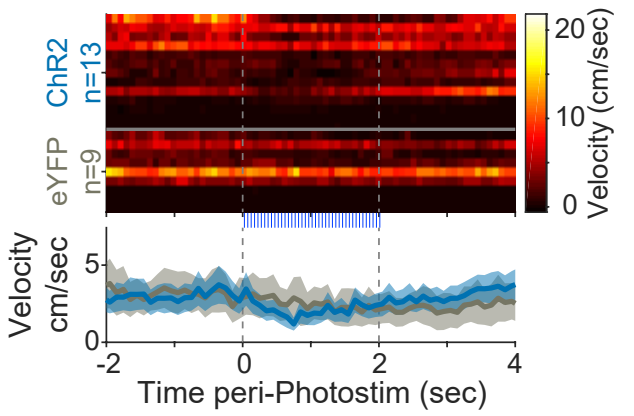

Photostim-Reinforced Session

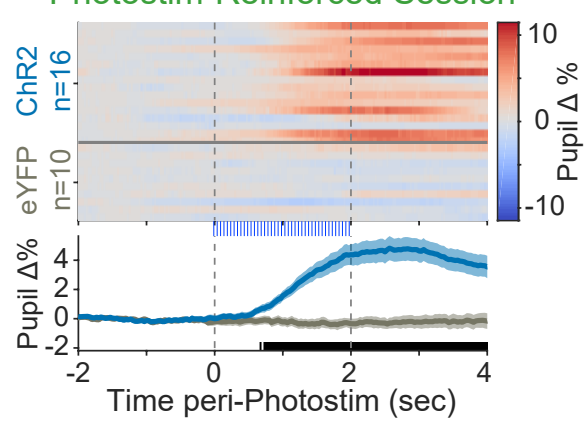

Photostim-Reinforced Session

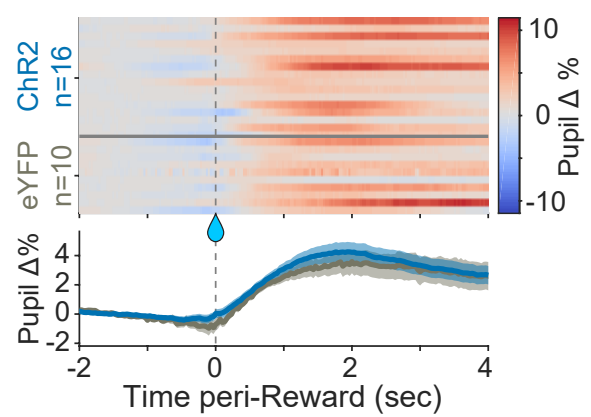

$\mathrm{H}$
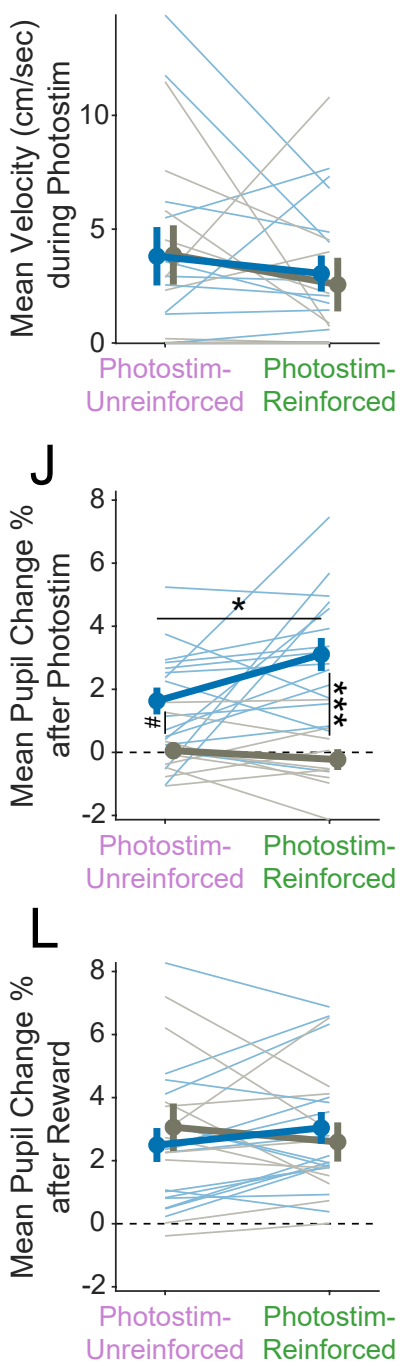
bioRxiv preprint doi: https://doi.org/10.1101/2022.02.04.479188; this version posted February 5, 2022. The copyright holder for this preprint (which was not certified by peer review) is the author/funder. All rights reserved. No reuse allowed without permission.

\section{Figure S3}

A

Concurrent photoactivation of cholinergic terminals in the BLA \& local ACh measurement
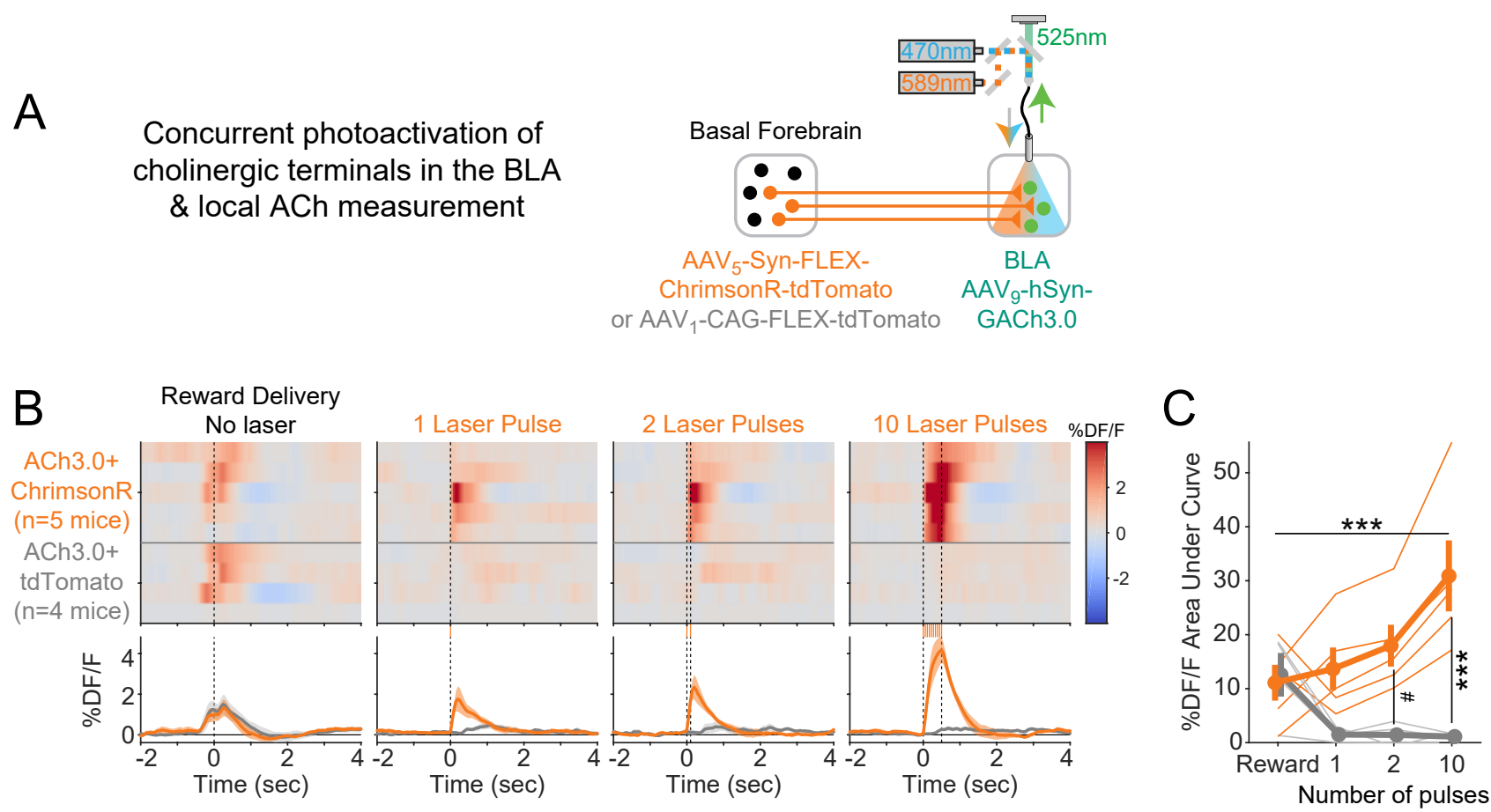
bioRxiv preprint doi: https://doi.org/10.1101/2022.02.04.479188; this version posted February 5, 2022. The copyright holder for this preprint (which was not certified by peer review) is the author/funder. All rights reserved. No reuse allowed without permission.

\section{Figure S4}

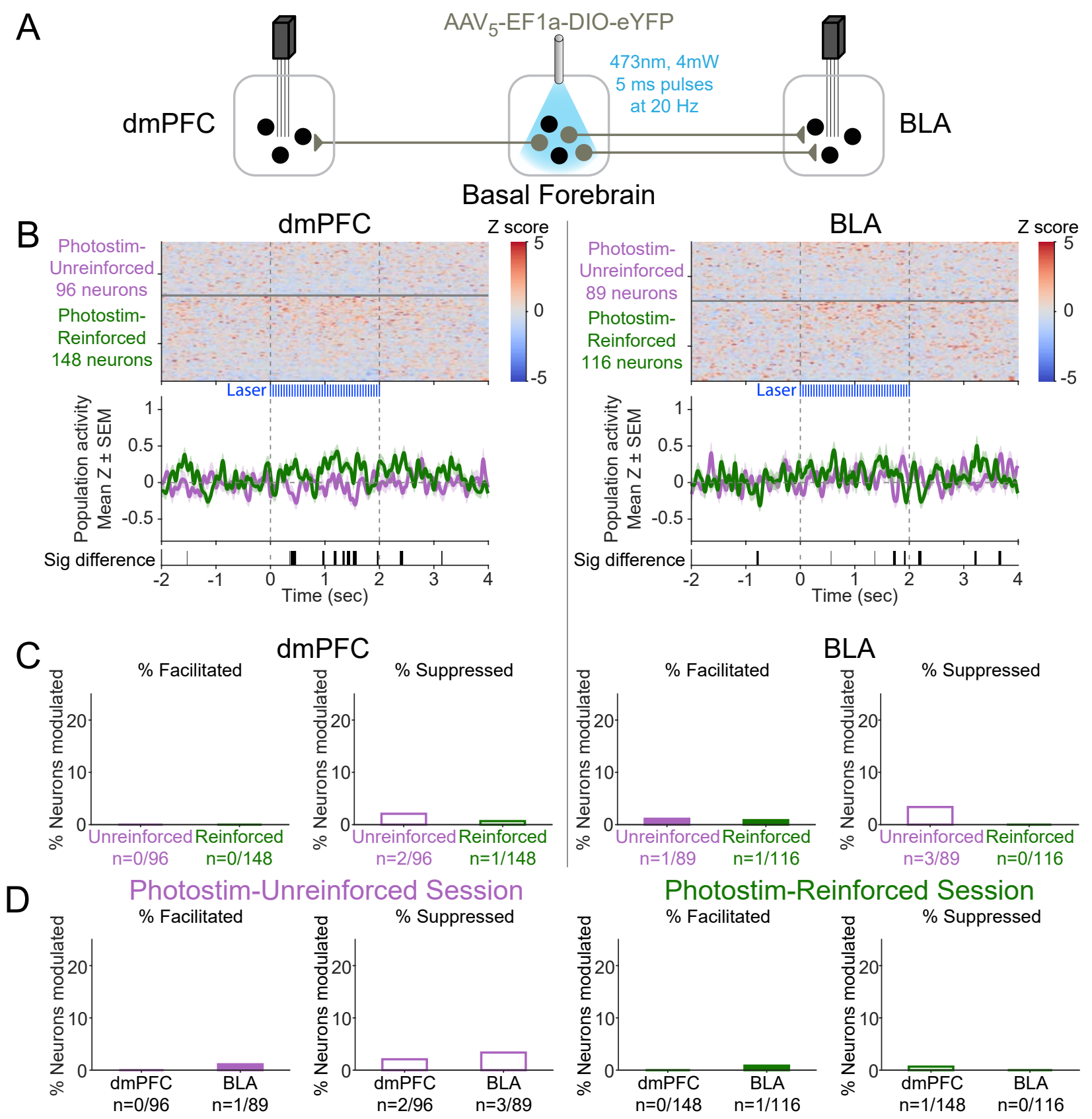


bioRxiv preprint doi: https://doi.org/10.1101/2022.02.04.479188; this version posted February 5, 2022. The copyright holder for this preprint (which was not certified by peer review) is the author/funder. All rights reserved. No reuse allowed without permission.

\section{Figure S5}

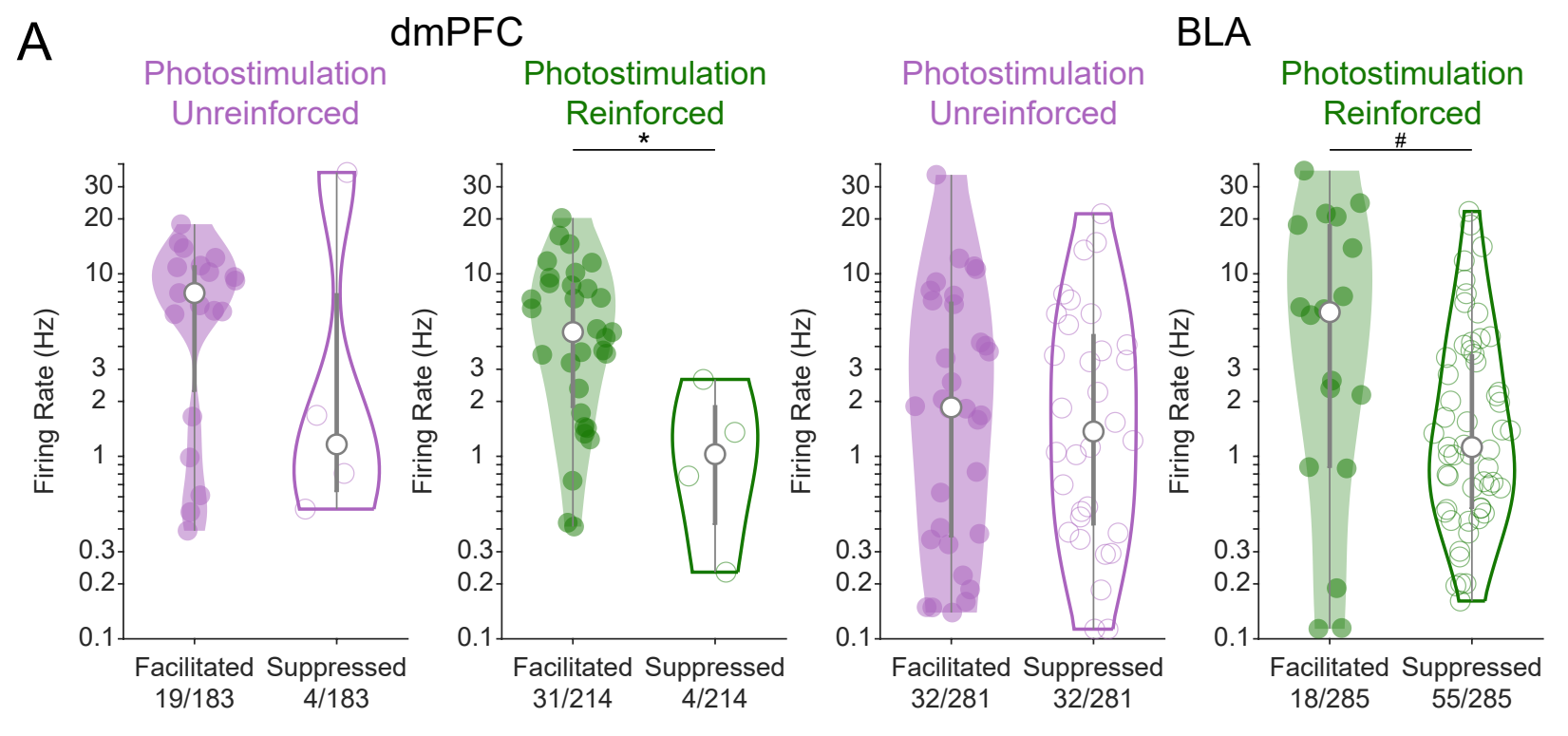

